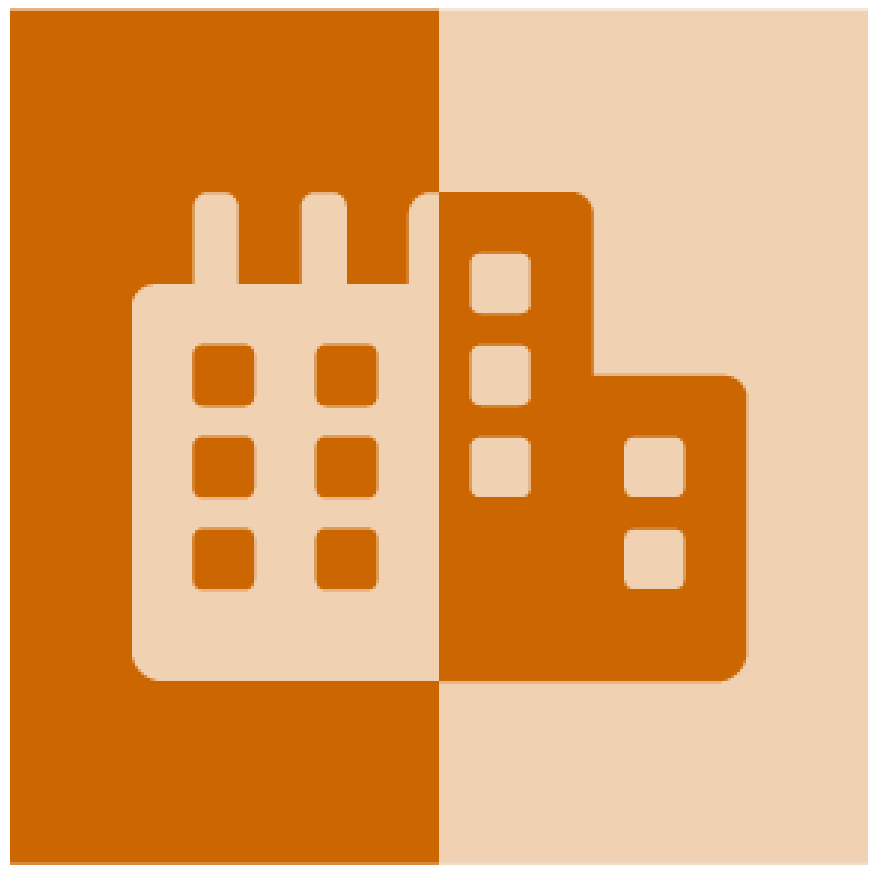

\title{
Building Standards at the University of Michigan
}

A Report Developed for and Supported by the U-M President's Commission on Carbon Neutrality

Revised August 10, 2020

\author{
Creators \\ Lars Junghans, Faculty Co-Lead \\ Jen Maigret, Faculty Co-Lead \\ Hannah Irish \\ McHugh Mac Carroll \\ Mitchell Mead \\ Shuhaib Nawawi \\ Nicole Rusk \\ Kay Wright
}


Copyright (C) 2021 by the Regents of the University of Michigan

Some rights reserved

\section{(c) (i) $(9)$}

This work is licensed under the Creative Commons Attribution-NonCommercial-NoDerivatives 4.0 International License. To view a copy of this license, visit http://creativecommons.org/licenses/by-nc-nd/4.0/ or send a letter to Creative Commons, PO Box 1866, Mountain View, California, 94042, USA.

Published in the United States of America by Michigan Publishing

DOI: http://doi.org/10.3998/mpub.12092354

ISBN 978-1-60785-685-6 (open access)

This publication is a result of work sponsored by the University of Michigan (U-M) President's Commission on Carbon Neutrality (PCCN) to inform the PCCN's final recommendations to U-M President Mark Schlissel. This publication does not reflect Commission-level recommendations, and should not be interpreted as being recommendations of the PCCN nor carrying its endorsement. 


\section{CONTENTS}

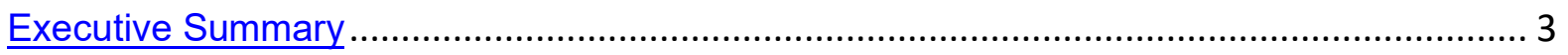

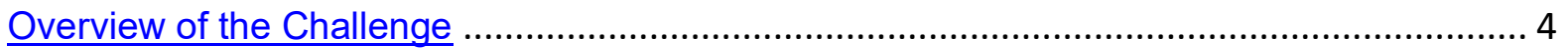

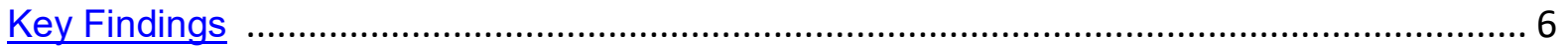

Prioritized Recommendations Summary ......................................................................... 7

Priority \#1 Recommendation ................................................................................. 8

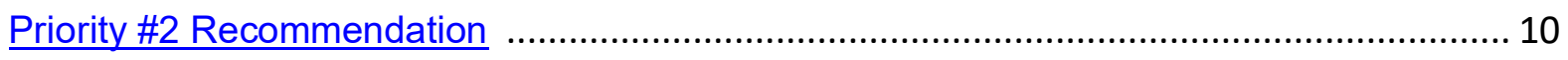

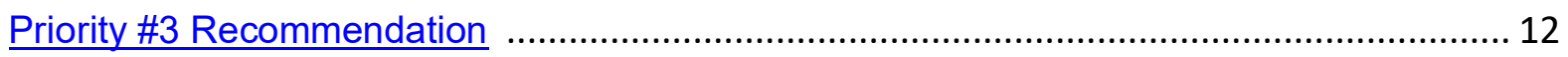

Priority \#4 Recommendation ....................................................................................... 13

Appendices

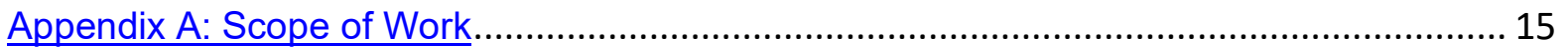

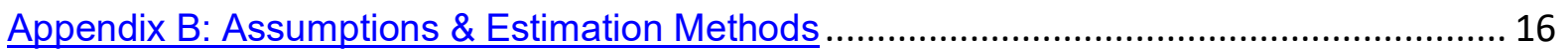

Appendix C: Details of Priority \#1 Recommendation ..................................................... 20

Appendix D: Details of Priority \#2 Recommendation ....................................................... 24

Appendix E: Details of Priority \#3 Recommendation .......................................................... 43

Appendix F: Details of Priority \#4 Recommendation ....................................................... 47

Appendix G: Emerging Zero Codes Benchmarking ............................................................. 49

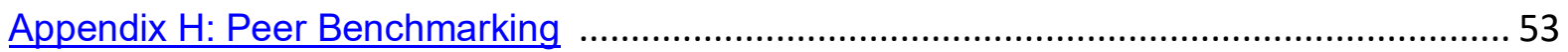

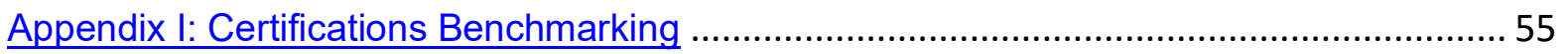

Appendix J: Emerging Building Materials and Technologies ……................................... 59

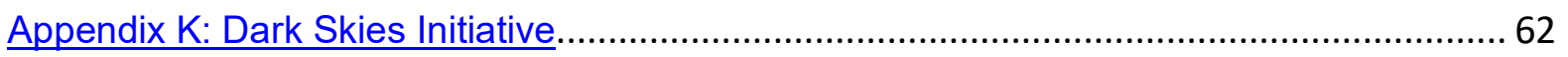

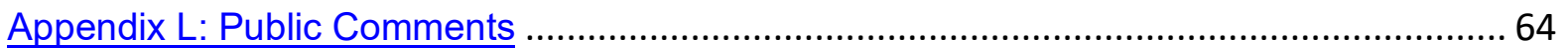

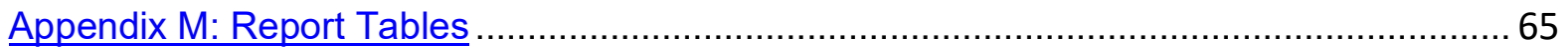

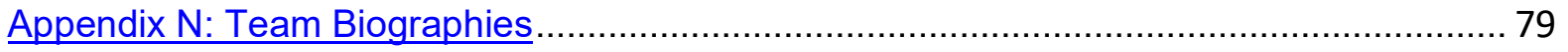

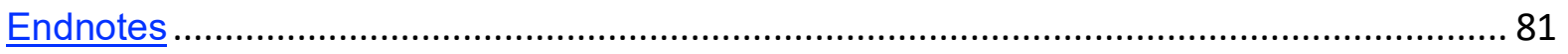




\section{EXECUTIVE SUMMARY}

As of 2019, buildings on the University of Michigan's (U-M) Ann Arbor campus consume 98.5\% of the total measured energy and contribute $97.3 \%$ to measured scopes 1 and $2 \mathrm{CO}_{2} \mathrm{e}$ emissions [1]. In the past 10 years, the Ann Arbor campus has seen approximately 6.5 million gross square feet (sf) of growth in building area. In contrast, the Flint and Dearborn campuses have seen much smaller rates in growth and are also significantly smaller in total building gross area. If growth trends continue, the rate at which new construction contributes to future $\mathrm{CO}_{2} \mathrm{e}$ emissions will also be strongly influenced by the types of buildings constructed. Educational buildings with low percentages of laboratory spaces and residential buildings show the most promise to be constructed to net zero emissions standards, whereas spaces with significant laboratory uses and medical facilities will require investments in significant offsets even with dramatic improvements to new construction building standards.

To achieve a net zero emissions future, major renovation work will also play an essential role. The Building Standards Internal Analysis Team was primarily charged to develop recommendations for performance standards for new construction. Given the significance of the existing built environment's contributions to $\mathrm{CO}_{2} \mathrm{e}$ emissions, we have included additional recommendations for improvements to existing buildings through major renovations. Investments in major renovations that are focused on building envelope and systems improvements offer an opportunity to reduce current $\mathrm{CO}_{2} \mathrm{e}$ emissions by $44 \%$ on average (Appendix M, Table 01 Existing Buildings Potential $\mathrm{MtCO}_{2}$ e Reductions).

To date, most approaches to the design and evaluation of high-performance buildings are based on energy demand calculations, including Energy Use Intensity (EUI). A singular focus on units of energy demand can be misleading because energy demand and consumption have a variable relationship to greenhouse gas (GHG) emissions depending on secondary factors, including energy mix. In contrast, our approach utilized an evaluation process that dynamically searched for solutions that offered the best reductions in carbon dioxide emissions metrics and cost. Furthermore, our approach includes the consideration of initial cost and "embodied" $\mathrm{CO}_{2} \mathrm{e}$ emissions for building materials and system production. Life cycle cost, payback, and return on investment are frequently used calculation methods to estimate the total cost (initial and operation) for a certain time. The decision to base our standards in direct relationship to emissions is more in line with the charge of the President's Commission on Carbon Neutrality to work toward attaining a net zero emissions future.

We propose four recommendations: 1) set maximum $\mathrm{CO}_{2}$ e emissions targets across nine building types for all new construction, 2) optimize strategies for major renovations across nine building types that maximize the relationship between emissions reductions and cost, 3) improve water efficiency standards and site design standards for all new construction, and 4) invest in partnerships bridging commitments to affordable housing with emerging research to attain net zero emissions housing.

These recommendations can be meaningfully addressed by augmenting and strengthening $U$ M's existing building standards to achieve an integrated building framework specific to $\mathrm{CO}_{2} \mathrm{e}$ emissions reduction goals. The framework proposed here contextualizes potential emissions reductions through an economic lens to prioritize options that ensure quality, enduring performance, and fiscal responsibility. 


\section{FINAL REPORT}

\section{Overview of the Challenge}

A transformation of North America's building design and construction industry is underway. Metrics tracking the increase in certified green buildings in both the United States and Canada indicate exponential growth since 2000 [2]. The United States Green Building Council's (USGBC) Leadership in Energy and Environmental Design (LEED) certification program is currently the world's most widely used green building rating system also commonly adopted by universities trying to advance sustainability goals [3]. U-M currently requires all new buildings and additions over $\$ 10$ million construction cost "to determine project-specific LEED certification requirements" [4]. Although LEED is a nationally and internationally sought-after sustainability benchmark for the design, construction, and operation of high-performance buildings, there is not a research-based consensus to validate this popularity [5], and the highest rating level in LEED v4.1 can be achieved with negligible attention given to $\mathrm{CO}_{2} \mathrm{e}$ emissions reductions (for a more detailed overview, see Appendix I).

At a national level, the American Society of Heating, Refrigerating and Air-Conditioning Engineers' (ASHRAE) 90.1 standards have steadily issued revisions to improve energy efficiency standards for both prescriptive and performance pathways yet are still a decade away from issuing net zero energy building standards. Given these limitations of LEED and ASHRAE 90.1, this report examines current building standards and identifies opportunities for revisions with $\mathrm{CO}_{2} \mathrm{e}$ emissions reductions as a primary goal.

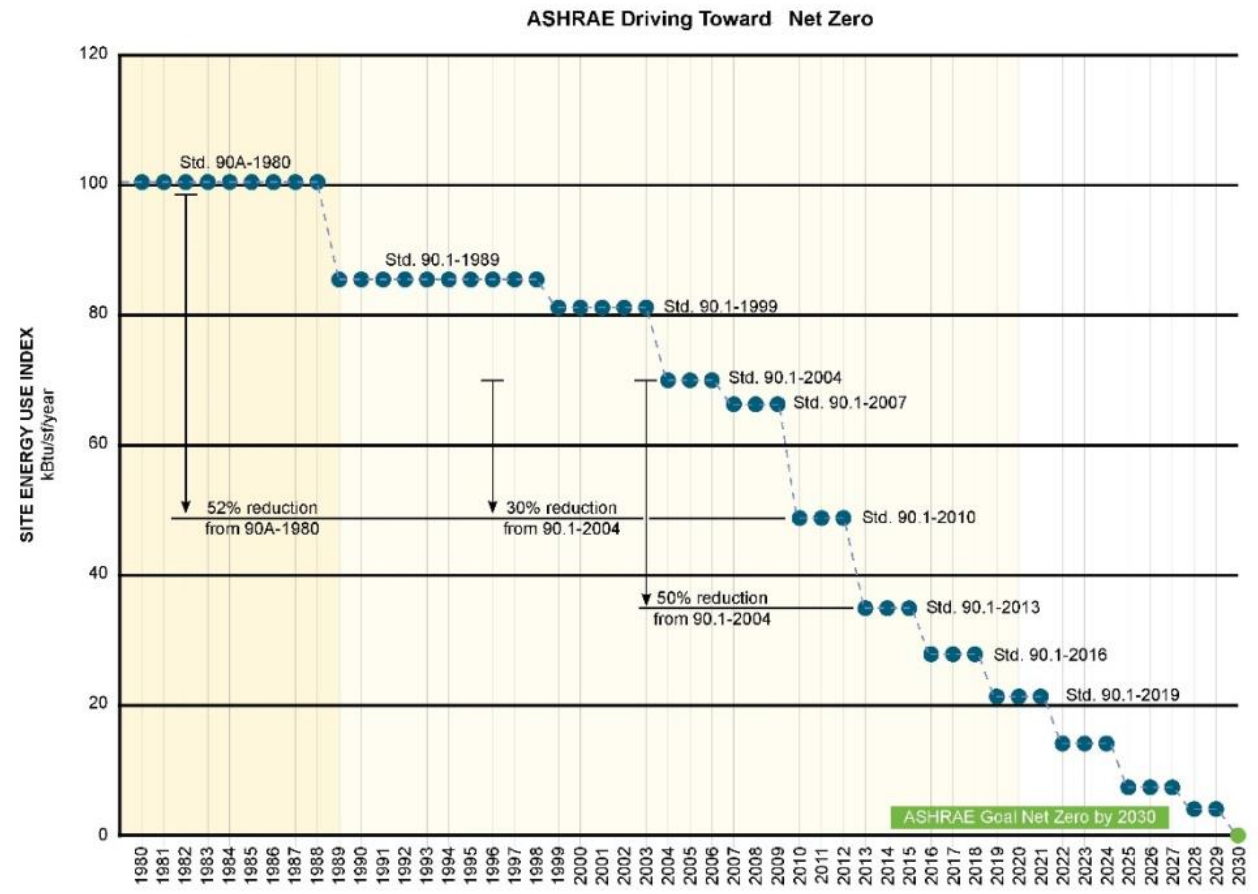

Figure 01_ASHRAE Driving Toward Net Zero 
The challenge of effectively reducing buildings' contributions to $\mathrm{CO}_{2} \mathrm{e}$ emissions across all three of the University of Michigan's campuses requires changes to new construction building standards and significant renovations for most existing buildings. Compounding this challenge is the interplay between the growth in gross constructed floor space and improvements in energy efficiencies. According to the UN Environment Global Status Report 2017, "buildings sector energy intensity (in terms of energy use per $\mathrm{m}^{2}$ ) continues to improve at an annual rate of around 1.5\%" [6]. These improvements are often driven by technological innovations, such as improvements to the energy efficiency of LED lighting. Such improvements are a necessary part of the larger emissions reductions puzzle yet can easily be negated by rates of growth in floor area that exceed $1.5 \%$. The University of Michigan's Ann Arbor campus's building area has seen average growth at a rate of 1\% between FY2004 and FY2019 (if excluding the 2009 acquisition of the North Campus Research Complex) [7]. At this rate, improvements in technology may continue to slightly outpace growth at U-M but not at a rate that will yield meaningful reductions in emissions from buildings.

When considering existing building area, we can see that as of FY2019, building emissions contributed 628,110 $\mathrm{MtCO}_{2} \mathrm{e}$ to UM-Ann Arbor's total emissions $\left(645,485 \mathrm{MtCO}_{2} \mathrm{e}\right)$ [8]. To better understand the dynamics of existing buildings, we examined how much of this was impacted by construction and renovation work over the past five years and found that demolition and replacement were rarely utilized, and additions and renovations each accounted for roughly half of the work completed. To give perspective, just under 740,000 sf of the Ann Arbor campus's 38 million sf underwent renovation, or roughly $1.95 \%$ in a five-year period. Of that total, much of the renovation work undertaken will not directly result in $\mathrm{CO}_{2} \mathrm{e}$ emissions reductions. This leaves a tremendous opportunity to significantly reduce the emissions contributions of buildings by undertaking an ambitious renovation program across the Ann Arbor campus.

The Flint and Dearborn campuses have less specific building data readily available, but both campuses have seen far smaller rates of new construction and rely more heavily on renovation work to make improvements to their campuses. UM-Flint has recently invested in building renovation and construction in line with downtown revitalization efforts $[9,10]$. These new investments are being linked to broader energy management efforts underway to improve energy monitoring and building metering. Continued improvements to building metering empowers the Facilities and Operations staff with better information in support of their laudable efforts to improve daily building efficiencies [11]. UM-Dearborn has one major, new construction project underway (currently at 75\%). The Engineering Laboratory Building will replace a $60-$ year-old building with a new facility. This project has been undertaken in coordination with the U-M Architecture, Engineering and Construction (AEC) office, located on the Ann Arbor campus. Compared to Ann Arbor, the Dearborn campus is young, with its first buildings completed in the fall of 1959, followed by a period of growth in the 1970s to 1980s. Additional major buildings were constructed in the mid-1990s, the last of which was completed in 2001. There have been several major additions to the campus between 2001 and 2006, yet there continue to be opportunities for significant improvements to building performance even if recent projects were built to current code standards. In summary, we see significant opportunities for emissions reductions tied to deep renovation projects across all three campuses.

If establishing new building standards is the first part of the challenge, then the second relates to defining targets that are meaningful and achievable across a wide range of building types. From a code standpoint, buildings are classified into different use and occupancy types that establish the basis for variations in regulations. From an energy consumption and $\mathrm{MtCO}_{2} \mathrm{e}$ emissions perspective, occupancy, equipment, and air exchange rates have a tremendous impact on the building's potential performance. In this regard, U-M faces a particularly 
challenging situation owing to the large number of buildings with high energy and/or air exchange rate demands driven by labs and/or clinical occupancy requirements. Given this unique mix of building types, in partnership with the U-M AEC office, we identified nine representational building types, as a basis for revised standards, that fall into five occupancy categories per code: educational, residential, hospital, athletic, and business (Appendix $\mathrm{M}$, Table 02 Definition of Building Types).

\section{Key Findings}

Overall, investments in building performance improvements provide an opportunity to significantly reduce operation costs and $\mathrm{MtCO}_{2} \mathrm{e}$ emissions. Improvements to technical systems, especially when integrated with the use of local renewable energy systems such as photovoltaics, offer additional opportunities to significantly reduce the emissions contributions of existing buildings. Specifically, we recommend further investigation into the viability of implementing heat pump technologies as a very important step toward a $\mathrm{MtCO}_{2} \mathrm{e}$ emissions neutral campus. The efficiencies (coefficient of performance, or COP) of geothermal and groundwater source heat pump systems are extremely high and are cost competitive in the long term. Additionally, the technical and regulatory feasibility of groundwater well heat pumps needs further examination and geotechnical expertise. For residential buildings, we recommend a combined improvement to building envelopes and intensive use of ductless mini-split units and photovoltaics.

However, a net zero $\mathrm{MtCO}_{2} \mathrm{e}$ emissions campus cannot be achieved by revised building standards and aggressive building renovations alone. While building renovation improvements were found to be very effective, there are limitations to how far $\mathrm{MtCO}_{2} \mathrm{e}$ emissions can be reduced. Emissions offsets are necessary to achieve net zero emissions for existing buildings on all U-M campuses. The investigation into large-scale renewable energy power generation is outside the scope of this analysis but is essential. Investments into research work that focuses on renewables and on optimized local electricity grid systems are needed to attain net zero emissions. With additional research devoted to improvements in building construction and technologies, residential buildings can attain net zero emissions standards. This presents an opportunity for interdisciplinary research efforts that can tackle equity issues associated with affordable housing (and therefore access to education) alongside advances to the technical aspects of high-performance buildings. For this reason, we have included a fourth recommendation specific to net zero emissions affordable housing.

\section{$\mathrm{CO}_{2} \mathrm{e}$ Footprint and Accounting}

Our recommended maximum emissions targets for new construction represent feasible reductions in emissions across all building types when compared with the current emissions rates of similar existing buildings. There is a great degree of variability in the emissions rates of existing buildings, even within similar building types, so estimating an overarching percentage reduction depends upon specific comparisons. To give a high-level view, we can compare the maximum emissions targets for new construction against the average current emissions contribution of existing buildings by funding category (Appendix M, Table 03 New Construction Recommended Emissions Targets, Table 04 Existing Building Emissions by Funding Category). Within the general fund, the average emissions rate of existing buildings is 18 $\mathrm{kgCO}_{2} \mathrm{e} / \mathrm{sf}$ across a range of building types that fall into this category, including educational buildings, libraries, and administrative buildings. Four of our recommended emissions targets fall below the current emissions average, with the one exception being educational buildings with high load laboratories (recommended emissions rate of $21 \mathrm{kgCO}_{2} \mathrm{e} / \mathrm{sf}$ ). Buildings in the 
Athletics, MI Medicine, and Student Life funding categories are comparable to the building types "athletic, clinical and residential." The recommended maximum emissions for the athletic category excludes pool spaces, which have very unusual and specific requirements impacting energy performance. The clinical category represents one of the largest targeted emissions reductions from a current average of $23.3 \mathrm{kgCO}_{2} \mathrm{e} / \mathrm{sf}$ to a recommended target of $15 \mathrm{kgCO}_{2} \mathrm{e} / \mathrm{sf}$. Finally, the recommended target for residential makes a distinction between dormitory buildings and low-rise/single-family housing. Both recommended values indicate targets below the current average emissions rate of $7.1 \mathrm{kgCO}_{2} \mathrm{e} / \mathrm{sf}$.

A range of improvements that can be made to existing buildings was also evaluated from a $\mathrm{CO}_{2} \mathrm{e}$ footprint and cost perspective. Enacting the recommended technological and building envelope improvements across all existing buildings on the Ann Arbor campus would yield an estimated emissions reduction of $324,000 \mathrm{MtCO}_{2}$ e per year, which would reduce the total FY2019 emissions of $583,426 \mathrm{MtCO}_{2} \mathrm{e}$ by $55.5 \%$ (see Appendix D for a detailed description of recommendations). We estimated low and high initial costs per $\mathrm{MtCO}_{2} \mathrm{e}$ to implement campuswide improvements to existing buildings (Appendix M, Table 05 Estimated Cost per $\mathrm{MtCO}_{2} \underline{\mathrm{e}}$ Emissions Reductions). The cost ( $\$ / \mathrm{MtCO}_{2} \mathrm{e}$ reduction) of this level of investment is also projected across a payback timeframe ranging from 5 to 50 years, assuming all of the renovations would occur at once (which does not match an actual timeline that will need to be determined) and assuming an ongoing 1\% rate of growth across the Ann Arbor campus. Our cost estimate does not include hazardous material abatement and excludes escalation associated with construction in future years.

Projected improvements are based on best available data, which can be limited by differences in building metering. Improvements to the uniformity and granularity of metering capabilities are necessary to better understand opportunities for improvements to building performance (this is discussed in more detail in Priority Recommendations 1 and 2). Our $\mathrm{CO}_{2} \mathrm{e}$ accounting also requires assumptions about changes to the current energy mix over time. Additionally, uncertainties in establishing accurate price calculations include fluctuations driven by local and temporal market demands and labor availability compounded by uncertainties predicting cost of emerging and future technologies. We attempted to adjust for these uncertainties and worked closely with more specific pricing information available through the external analysis completed by SmithGroup and through meetings and feedback given by the U-M AEC team, but costing data fluctuates greatly, and all price estimates should be understood as broad guidelines that require additional study on a building-by-building basis for more specific estimating.

\section{Prioritized Recommendations Summary}

We propose four recommendations, ordered by potential to reduce $\mathrm{CO}_{2}$ e emissions: 1) set maximum $\mathrm{CO}_{2}$ e emissions targets across nine building types for all new construction, 2) optimize strategies for major renovations across nine building types that maximize the relationship between emissions reductions and cost, 3) improve water efficiency standards and site design standards for all new construction, and 4) invest in partnerships bridging commitments to affordable housing with emerging research to attain net zero emissions housing (Appendix M, Table 00 Summary Matrix).

Specific recommendation targets were set with cost in mind to prioritize efforts that have the potential for the greatest emissions reductions at the least cost. In turn, the inclusion of economics as part of the dynamic simulation modeling analyses undertaken recognizes that affordability is at the heart of the question of equity. In this regard, U-M could also be a significant model and leader for ongoing research and efforts focused on advancing high- 
performance building standards with the economics of equity in mind. Furthermore, if U-M adopts the recommended maximum emissions targets for new construction, it will be the first university in the United States to adopt emissions-based building performance standards, an achievement made even more significant given U-M's size and the inclusion of hospital facilities.

\section{Priority \#1 Recommendation}

\section{Description of recommendation}

For all new construction, we recommend adopting maximum emissions targets across nine categories of building types (Appendix M, Table 03 New Construction Recommended Emissions Targets). This shift would evaluate buildings by their $\mathrm{CO}_{2} \mathrm{e}$ emissions-a change from the current practice of evaluating buildings by their energy performance. This aligns with the infrastructure scale work undertaken by Integral Group, which holds the potential to transform energy generation and significantly reduce the $\mathrm{CO}_{2} \mathrm{e}$ emissions associated with it. Prioritizing $\mathrm{CO}_{2} \mathrm{e}$ emissions in new construction building standards inherently requires the consideration of the building's individual performance as well as the impact of its energy source on total emissions.

\section{Carbon dioxide emissions reduction potential}

The carbon dioxide emissions reduction potential is assessed relative to the difference between the recommended new maximum emissions by building type and the average emissions rates of the same building type with a building standard that meets the current building code (ASHRAE 90.12013 , benchmark). These benchmark buildings are equipped with heat recovery ventilation and condensing boilers. Adopting the recommended emissions targets for new construction would result in emissions reductions ranging from $20 \%$ to $78 \%$ as compared with buildings meeting the current building code. The largest reductions are seen in the small residence building type category ( $78 \%$ reduction), with the remaining building types seeing reductions of $20 \%-34 \%$. In all building categories, the implementation of a geothermal heat pump and photovoltaic systems have been found to be most effective to reduce the overall $\mathrm{CO}_{2} \mathrm{e}$ emissions.

\section{Financial costs, savings, and considerations}

Financial costs would include increased initial costs (for improved technologies and building systems/materials) as well as increased design and engineering fees associated with additional design and engineering scope to achieve and document maximum emissions targets for a new construction project. Specific costs will vary case by case given that characteristics including a building's orientation, volumetric massing, and window-to-wall ratio significantly influence energy performance and thereby affect the amount of technological "offsets" and cost necessary to attain maximum emissions standards. For example, we estimated the costs associated with achieving a net zero emissions educational building. This estimate compares three possible HVAC alternates to a baseline (condensing boiler and new compression chiller) and demonstrates that investing in heating and cooling systems that have higher initial costs than the benchmark is rewarded by a reduced overall cost given the significant reduction in needed Photovoltaic to offset emissions and the associated reduction in cost (Appendix M, Table 06 Estimated Costs to Achieve Net Zero in an Educational Building). A second estimation of cost is provided in Appendix M, Table 07 Itemized Estimated Costs for $\mathrm{CO}_{2}$ e Emissions Reductions. This calculation assesses eight different potential improvements that can be implemented to help attain reduced $\mathrm{CO}_{2} \mathrm{e}$ emissions in new construction. The table gives a relative understanding of cost per technology per $\mathrm{MtCO}_{2} \mathrm{e}$ emissions reduction and extends the initial cost of implementing each strategy across a payback period ranging from one to 50 years. This cost is based on a static calculation that does not take inflation and other future changes 
into account. There will be additional architect/engineer $(A / E)$ cost and schedule impacts with the implementation of "dynamic thermal simulation tools" as recommended by this report. These costs have not been accounted for in the cost estimates provided. Additionally, this estimate does not account for changes in construction costs, interest, inflation, etc.

\section{Metrics and tracking}

The metrics and tracking of this recommendation require a twofold approach. First, dynamic modeling is required to meaningfully predict emissions during design. Models should include dynamic efficiency values of HVAC systems and locally specific values for the impact of energy mix on $\mathrm{CO}_{2} \mathrm{e}$ emissions. Second, design targets need to be verified with actual performance over time, which necessitates required and ubiquitous metering per building across all energy input and output types. We recommend that all new construction require devices that provide data at least daily and measure at least hourly consumption of electricity, natural gas, steam, water in, and water out.

\section{Organizational structure considerations}

The U-M AEC office currently oversees all building renovation and new construction projects over \$3 million, as described in The User's Guide to Capital Projects (July 1, 2020), and has developed and implemented extensive design standards that meet or exceed building standards implemented at the state level. They operate as a division of Facilities and Operations under the Executive Vice President and Chief Financial Officer. They have the expertise and organizational capacity to participate in the adoption and implementation of new building standards. They will continue to play a pivotal role in the successful implementation of new building standards and should be involved in the additional, necessary, and more detailed work that will be required for each new building to be designed and constructed.

\section{Campus culture and individual accountability considerations}

Individual preferences and broader cultural expectations of thermal comfort can significantly influence building performance and energy consumption. See Appendix $D$ for a more in-depth discussion on the potential impacts of occupant behavior on building performance.

\section{Equity and justice considerations}

The current budget model of U-M places most of the economic responsibility for major renovations at the level of its 19 schools and colleges. The finances of the various schools and colleges differ significantly and would limit or prevent many from voluntarily implementing progressive building systems in support of achieving emissions neutrality. To ensure equity across schools and colleges, and by extension their academic communities, measures will need to be taken to overcome these inherent economic discrepancies.

\section{Scalability, transferability, and external engagement}

Scalability functions at the level of a building, and the nine established building types are representative of most of the built environment. Of importance is the advancement in dynamic modeling methods that have been undertaken and have strong promise for transferability. Finally, external engagement related to issues of thermal comfort, the emerging aesthetics of low-emissions buildings, and the visibility of these efforts on all three U-M campuses will be an important part of implementation.

\section{Timeline for implementation}

The timeline for implementation will be largely influenced by the level of University support for these recommendations and by the additional work that will be necessary to more fully develop and integrate new building standards with the existing U-M AEC design guidelines. The 
recommended targets are achievable on a voluntary basis in the current construction environment.

\section{Potential implementation challenges}

Potential implementation challenges are primarily financial and logistical. Existing technologies and building design and construction expertise are available to attain the goals stated.

\section{Unknowns, gaps, and/or additional analysis required}

1) The real cost of proposed systems including groundwater well heat pumps is not known. This is an emerging and very promising system, but because it has not been widely implemented, there are limitations to available data and possible challenges for implementation related to existing building codes.

2) A cost comparison and feasibility study of different renewables (photovoltaics, biomass, geothermal, etc.) are needed. This sector needs additional work and is critical in contributing to necessary offsets to achieve net zero emissions overall.

3) Cooperation with DTE Energy to achieve the goal of a net zero emissions campus will play a critical role. This may signal larger opportunities for cooperative strategies to develop infrastructural-scaled renewable energy systems.

\section{Critical next steps to catalyze work}

Ongoing work is necessary to maintain the momentum of the work that has been initiated. Additional research will play an important role to achieve a net zero emissions campus with buildings being constructed in a cost-effective way given the construction standards and systems in use across the United States. Furthermore, work needs to continue to enable this research to impact the direction of U-M locally and enable the scalability and transferability to other universities and beyond. To expand the potential for groundwater well and geothermal heat pumps, additional testing needs to be done. This requires a level of resources for testing and expert evaluation knowledge that is beyond the scope of our specific team expertise.

Collaborative research work is needed in the field of smart micro grid and control systems. Smart grid systems can decrease elect demand and helps to integrate renewable energy systems (including photovoltaics, wind power, and storage systems) in an efficient way.

\section{Priority \#2 Recommendation}

\section{Description of recommendation}

Establish major renovation targets for all existing buildings currently performing in the "low" or "medium" categories, with the potential to see additional gains with renovations to buildings performing in the "high" category (see Quality of the Building Envelope, Appendix D: Details of Priority \#2 Recommendation).

\section{Carbon dioxide emissions reduction potential}

The estimated percentage reduction of $\mathrm{CO}_{2} \mathrm{e}$ emissions for existing buildings if updated to the proposed strategies is shown per building type by building envelope quality in Appendix $M$, Table 01 Existing Buildings Potential $\mathrm{MtCO}_{2} \mathrm{e}$ Reductions. We made assumptions based on existing information, building age, envelope type, and other visual cues (we did not physically evaluate all buildings) to classify a building envelope performance category for all UM-Ann Arbor campus existing buildings. If all existing buildings on the Ann Arbor campus are updated to recommended standards, the total estimated reduction of annual $\mathrm{CO}_{2} \mathrm{e}$ emissions will equal $324,000 \mathrm{MtCO}_{2} \mathrm{e}$, an overall annual reduction of $55.5 \%$ when compared with FY2019 building emissions. 
Financial costs, savings, and considerations

A range of renovation costs by project type is shown in Appendix $M$, Table 08 Renovation Cost Ranges (this data was provided by U-M AEC based on recent projects completed on the Ann Arbor campus). A second estimation of cost is provided in Appendix M, Table 07 Itemized Estimated Costs for $\mathrm{CO}_{2}$ e Emissions Reductions. This calculation assesses eight different potential improvements that can be implemented to help attain reduced $\mathrm{CO}_{2} \mathrm{e}$ emissions in new construction. The table gives a relative understanding of cost per technology per $\mathrm{MtCO}_{2} \mathrm{e}$ emissions reduction and extends the initial cost of implementing each strategy across a payback period ranging from one to 50 years. There will be additional $A / E$ cost and schedule impacts with the implementation of "dynamic thermal simulation tools" as recommended by this report. These costs have not been accounted for in the cost estimates provided. Additionally, this estimate does not account for changes in construction costs, interest, inflation, etc.

\section{Metrics and tracking}

Upgrading to and/or installing new advanced metering is necessary for ongoing assessment of building energy and water consumption in comparison with design targets. All major renovation work (should require) devices that provide data at least daily and measure at least hourly consumption of electricity, natural gas, steam, water in, and water out.

\section{Organizational structure considerations}

The U-M AEC office currently oversees all building renovation and new construction projects over \$3 million, as described in The User's Guide to Capital Projects (July 1, 2020), and has developed and implemented extensive design standards that meet or exceed building standards implemented at the state level. They operate as a division of Facilities and Operations under the Executive Vice President and Chief Financial Officer. They have the expertise and organizational capacity to participate in the adoption and implementation of new building standards. They will continue to play a pivotal role in the successful implementation of new building standards and should be involved in the additional, necessary, and more detailed work that will be required for each new building to be designed and constructed.

\section{Campus culture and individual accountability considerations}

Individual preferences and broader cultural expectations of thermal comfort can significantly influence building performance and energy consumption. See Appendix $D$ for a more in-depth discussion on the potential impacts of occupant behavior on building performance.

\section{Equity and justice considerations}

The current budget model of U-M places most of the economic responsibility for major renovations at the level of its 19 schools and colleges. The finances of the various schools and colleges differ significantly and would limit or prevent many from being able to afford major renovations toward the end goal of emissions neutrality. To ensure equity across schools and colleges, and by extension to their academic communities, measures will need to be taken to overcome these inherent economic discrepancies.

\section{Scalability, transferability, and external engagement}

Scalability has some limitations in this recommendation given the nuances and complexities of individual buildings. We have established representative building types and made estimations of current building envelope performance levels at a very high level. Additional inspections and analyses of each individual building would need to be done to successfully implement recommendations in this category. Of importance is the advancement in dynamic modeling methods that have been undertaken and have strong promise for transferability. Finally, external engagement related to issues of thermal comfort, the emerging aesthetics of low-emissions 
buildings, and the visibility of these efforts on all three U-M campuses will be an important part of implementation.

\section{Timeline for implementation}

The timeline for implementation will be largely influenced by funding availability and scheduling capacity for major renovation improvements. The U-M AEC recommends three to four buildings as an achievable target given current local construction market conditions for trade labor availability and considering the ability for university units to provide swing space for the time needed to vacate the buildings (partially or entirely).

\section{Potential implementation challenges}

Potential implementation challenges are primarily financial and logistical. Existing technologies and building design and construction expertise are available to attain the goals stated. Facilities and Operations recommends, at least at a high level of study, that a detailed analysis is commissioned for each building prior to renovation. The external analysis undertaken by the SmithGroup for the Art and Architecture Building can serve as a model for this. The additional costs incurred by consultant-based analyses are not factored into the costs presented in this report.

\section{Unknowns, gaps, and/or additional analysis required \\ Estimates are based on assumptions that similar building types will yield equivalent improvements in emissions reductions. More accurate estimates will result from additional detailed studies for each individual building such as is being undertaken for the Art and Architecture Building by SmithGroup. We strongly recommend that a similar high-level study is undertaken prior to each renovation project. The calculations provided in this report serve as guides from which to prioritize more detailed analyses.}

\section{Critical next steps to catalyze work}

Coordination between financial support, logistical capabilities, and individualized building assessments are all critical next steps to catalyze the work.

\section{Priority \#3 Recommendation}

\section{Description of recommendation}

Establish improved water efficiency standards and site design standards for all new construction to attain additional emissions reductions.

\section{Carbon dioxide emissions reduction potential}

As of FY2019, U-M's Ann Arbor campus consumed 1,210,297,948 gallons of potable water, which equates to 1,784 $\mathrm{MtCO}_{2} \mathrm{e}$ emissions, and discharged 942,026,790 gallons of wastewater, which equates to 2,380 $\mathrm{MtCO}_{2} \mathrm{e}$ emissions (see Appendix $\mathrm{E}$ for calculation assumptions). Currently, $\mathrm{CO}_{2} \mathrm{e}$ emissions associated with water are not included in U-M's annual calculations of total GHG emissions. Occupant behavior is a large factor in actual water use, so it is difficult to project a direct correlation between fixture efficiency and emissions reductions.

Recommendations for rainwater harvesting and graywater reuse offer potential reductions in wastewater discharge quantities coupled with heat recovery opportunities. Specific water volumes have not been calculated given the unknown nature of the relationship of building footprint to parcel for future construction.

\section{Financial costs, savings, and considerations}


Low-flow, high-efficiency fixtures can have higher initial costs than less efficient alternates; however, this cost is compensated by savings in water bills. Rainwater harvesting and graywater reuse strategies have initial up-front cost driven by the complexity of a building's plumbing infrastructure and the target capture volumes. Water storage tanks have been demonstrated to account for approximately $50 \%$ of additional up-front costs but can also play an important visual role by displaying the systems at play in low-emissions buildings.

\section{Metrics and tracking}

Daily consumption data is currently available through the city's website:

https://www.a2gov.org/services/Water-Billing/Pages/Water-Consumption-.aspx. This data can

be an ongoing tool to assess water consumption in relation to design targets for reduced emissions. A similar level of data verification is desirable for the Flint and Dearborn campuses as well.

\section{Campus culture and individual accountability considerations}

Water is a highly visible natural resource that has a strong and established campus culture that cuts across research, teaching, and campus life. While the metrics of emissions reductions in water conservation efforts are not as significant as those related to building energy operations recommendations, the visibility and cultural impact can be more direct and visible.

\section{Equity and justice considerations}

Affordability and access to water is an issue of environmental equity and social justice in our region. This is playing out as a public health crisis in Flint (with lead contamination) and in Detroit (with increased coronavirus spread rates due to lack of access to water for handwashing). Efforts made to conserve water and rethink distribution and treatment infrastructures have the potential for meaningful equity impacts.

\section{Scalability, transferability, and external engagement}

U-M currently has many researchers invested in issues of water conservation, water quality, and water infrastructure. Work from the research realm could more directly impact the implementation of new approaches to "One Water" on the U-M campuses.

\section{Timeline for implementation}

Expertise and technologies are currently available to implement all recommendations.

\section{Potential implementation challenges}

The primary implementation challenges are likely to be financial if improvements are not required by building design guidelines.

\section{Priority \#4 Recommendation}

\section{Description of recommendation}

For all residential buildings (townhouses, dormitory buildings, and small apartment buildings), we recommend setting an example to achieve net zero emissions within colder climates. The primary goal is to find solutions that are economically feasible and therefore address the growing challenges of affordable housing and climate change.

\section{Carbon dioxide emissions reduction potential}

Preliminary internal studies have shown that a net zero emissions low-rise residential building (zero $\mathrm{CO}_{2} \mathrm{e}$ emissions over the term of the year) can be achieved by having a payback period of 
seven years. This payback period is based upon ongoing, active research led by Lars Junghans at the U-M Taubman College of Architecture and Urban Planning. Further research is needed to enable implementation.

\section{Financial costs, savings, and considerations}

The proposed concept targets a net zero emissions building with a payback period of seven years. The goal is to have $15 \%$ or less additional costs to achieve the standard compared with conventional new construction or renovation project costs. The authors have achieved this goal in a realized building by having additional costs of only $10 \%$. The technical concept includes new proposals for building ventilation, building automation, and building conditioning. Costs for photovoltaic systems will be compensated by these technologies. Please see the information in Appendix F.

\section{Metrics and tracking}

Smart metering systems can be implemented to easily track the $\mathrm{CO}_{2} \mathrm{e}$ balance.

\section{Campus culture and individual accountability considerations}

The cost of living is relatively high for students. The proposed concept will help to reduce operation costs and thus living costs significantly if tools such as lease agreements are leveraged to incentivize cost savings being passed on to tenants.

\section{Equity and justice considerations}

One goal of the new building concept is to make net zero emissions buildings affordable for lowand middle-class families. The short payback time allows for significant future reductions in operation cost (theoretically down to zero).

\section{Scalability, transferability, and external engagement}

The proposed building concept aims to be effective for all climate zones and most building types. The concept's implementation has the potential to be a cutting-edge technology that is easily transferable to projects outside of the U-M campus. Local external engagement to meet Ann Arbor's goal of net zero emissions is welcome.

\section{Timeline for implementation}

The timeline includes research work on the concept for two years, a demonstration project of one to two years, and implementation to other buildings dependent on U-M planning.

\section{Potential implementation challenges}

Practical experience indicates that there can be challenges with new approaches in the building sector. These challenges are often caused by the construction industry when new systems are used.

\section{Unknowns, gaps, and/or additional analysis required}

A case study is needed to demonstrate the feasibility of the proposed concept in a real environment.

\section{Critical next steps to catalyze work}

Research work is required to demonstrate the feasibility of the proposed concept. The research work would need to be done on advanced thermal building simulation tools with the ability to test new building automation systems (circular control) virtually. The estimated time for this research would be two years. 


\section{APPENDIX A Scope of Work}

Our work prioritizes building codes and standards that explicitly define opportunities to reduce the impact of new construction on $\mathrm{CO}_{2} \mathrm{e}$ emissions (toward a goal of net zero emissions). We believe that this approach both responds to the scope of work assigned to our Internal Analysis Team and models a timely and necessary revision of the conceptualization of building codes more generally by including the consideration of greenhouse gas emissions within the realm of the protection of life safety. We also acknowledge that a wealth of research inquiries are already available that can be used to establish a foundation for a recalibrated approach to building standards, prioritizing solutions that optimize economically feasible strategies that can yield net zero $\mathrm{CO}_{2}$ e emissions outcomes.

In addition to defining maximum emissions targets for new construction, our team analyzed opportunities that would be afforded by major renovations (building envelope and building systems improvements).

Toward this end, the following efforts have been undertaken:

1. Analyzing comparable University efforts to define revised, sustainable building standards;

2. Analyzing current LEED v4.1 and Living Building Challenge certification strengths and weaknesses from a "net zero emissions" standpoint;

3. Developing a framework for a multiple objective optimization algorithm and Pareto Optimal Solution that bring the consideration of economics to bear on the decisions regarding the optimal architectural and building systems approaches contributing to minimum emissions outcomes;

4. Understanding existing sustainable building design strategies and standards currently overseen and opportunities not yet in place yet recognized as such by the University's Architecture, Engineering and Construction (AEC) Department;

5. Analyzing a series of potential technological improvements relative to the potential to reduce $\mathrm{CO}_{2} \mathrm{e}$ emissions for the best cost. Note that all technologies considered are evaluated at the scale of an individual building. Systems that can operate at the scale of a plant were beyond the scope of this report;

6. Developing a framework for a multiple objective optimization algorithm and Pareto Optimal Solution that bring the consideration of economics to bear on the decisions regarding major renovations opportunities;

7. Identifying overlooked opportunities related to water conservation and site design that possess the potential to contribute to emissions reductions;

8. Integrating a longer time frame within the scope of building standards than is typically defined to include considerations of embodied energy and emissions from the perspective of life cycle analysis (LCA); and

9. Expanding and redefining the recognized impact of energy conservation measures by recommending a potential avenue to expand an already successful program.

We would like to acknowledge the high level of support and feedback we received during this process. We would like to thank the Office of Campus Sustainability including Andrew Berki, Ken Keeler, and Kevin Morgan, and the Architecture, Engineering and Construction (AEC) office including Michelle Christensen, Thomas Girard, David Karle, Deanna Mabry, Marian Roelofs, and Scott Wood for the deep level of commitment and collaboration that was offered. 


\section{APPENDIX B}

\section{Assumptions \& Estimation Methods}

\section{Basis of Metrics}

To date, most approaches for setting design and evaluation metrics for high performance buildings are based on energy demand calculations, including Energy Use Intensity (EUI). However, a singular focus on units of energy demand can be misleading because energy demand and consumption has a variable relationship to greenhouse gas (GHG) emissions depending on secondary factors including energy mix. Additionally, there is a complex interrelationship between economic investments in the materials and systems deployed to improve energy performance and the savings gained through reduced operations costs that is not typically accounted for in code requirements.

Our approach utilized an evaluation process that dynamically searched for solutions that offered the best reductions in carbon dioxide emissions metrics and cost. Furthermore, our approach includes the consideration of initial cost and "embodied" $\mathrm{CO}_{2} \mathrm{e}$ emissions for building materials and system production. Life cycle cost (LCC), payback, and return on investment (ROI) are frequently used calculation methods to estimate the total cost (initial and operation) for a certain time. Our calculations reflect the use of life cycle analysis (LCA) wherein the reduction of $\mathrm{CO}_{2} \mathrm{e}$ and the reduction of cost per year are used. Furthermore, for cost calculations, a baseline LCC and LCA is calculated and used as a basis of comparison potential improvements.

In summary, given that the charge of the President's Commission on Carbon Neutrality is to work toward a net zero emissions campus, our work has prioritized the metrics of emissions over energy as the basis from which new building standards are recommended.

\section{Estimations of $\mathrm{CO}_{2} \mathrm{e}$ Emissions}

The unit for $\mathrm{GHG}$ emissions in this analysis is given in $\mathrm{kg}$ or $\mathrm{Mt}$ (metric ton) $\mathrm{CO}_{2} \mathrm{e}$ emission. This value refers to the carbon dioxide equivalent emissions and includes GHG emissions in addition to $\mathrm{CO}_{2} \mathrm{e}$. All $\mathrm{CO}_{2} \mathrm{e}$ emissions calculation follows the guidelines given in ANSI/ASHRAE/ICC/IES Standard 189.1-2017. For dynamic calculation processes like the building and climate seasonal coefficient of performance (SCOP) for heat pumps and chiller systems, the equations from the German building code DIN 18599 are used.

- The $\mathrm{CO}_{2} \mathrm{e}$ emissions per kWh electricity is set to $571 \mathrm{~kg} \mathrm{CO} 2 \mathrm{e} / \mathrm{kWh}$ [12]

- The $\mathrm{CO}_{2} \mathrm{e}$ emissions per kWh gas is $464 \mathrm{~kg} \mathrm{CO} 2 \mathrm{e} / \mathrm{kWh}$ [13]

- The DTE electric energy mix for the year 2020 [14] is assumed to be:

$\begin{array}{lll}\text { Fuel } & \text { Percentage } & \mathrm{CO}_{2} \mathrm{e} \text { emission } \\ \text { Coal } & 64.19 \% & 817.42\left[\mathrm{~g} \mathrm{CO}_{2} \mathrm{e} / \mathrm{kWh}\right] \\ \text { Nuclear } & 18.68 \% & 25.20\left[\mathrm{~g} \mathrm{CO}_{2} \mathrm{e} / \mathrm{kWh}\right] \\ \text { Gas } & 8.67 \% & 464.53\left[\mathrm{~g} \mathrm{CO}_{2} \mathrm{e} / \mathrm{kWh}\right] \\ \text { Hydroelectric } & 0.95 \% & 108.03\left[\mathrm{~g} \mathrm{CO}_{2} \mathrm{e} / \mathrm{kWh}\right] \\ \text { Renewable Biomass } & 1.06 \% & 72.02\left[\mathrm{~g} \mathrm{CO}_{2} \mathrm{e} / \mathrm{kWh}\right] \\ \text { Renewable Wind } & 6.28 \% & 18.00\left[\mathrm{~g} \mathrm{CO}_{2} \mathrm{e} / \mathrm{kWh}\right]\end{array}$

It is worth noting that the electric energy mix changes annually. Currently, DTE is working to reduce the $\mathrm{CO}_{2} \mathrm{e}$ emissions per $\mathrm{kWh}$ with a stated goal to provide an electricity grid without 
$\mathrm{CO}_{2} \mathrm{e}$ emissions by the year 2050. Calculations for the predicted reduction of $\mathrm{CO}_{2} \mathrm{e}$ emissions account for these goals by integrating an estimated annual reduction of the $\mathrm{CO}_{2} \mathrm{e}$ emissions per $\mathrm{kWh}$. There is variability across UM-Ann Arbor campus buildings relative to their sources of electricity and heat supply. Many of the buildings on central campus receive electricity and heat supply from a centralized heat and power co-generation plant. The reduced $\mathrm{CO}_{2} \mathrm{e}$ emissions of this plant have been included in our calculations. The specific $\mathrm{CO}_{2} \mathrm{e}$ emission values have been defined by [15] and [16].

\section{Basis of Thermal Comfort Levels}

An important aspect of building design and construction is to provide for the thermal comfort of occupants and to guarantee high quality indoor air. The technologies and design strategies included as options throughout this report are selected for their potential contributions toward the goal of reducing emissions and for their ability to deliver a high level of thermal comfort and air quality. Three categories of human comfort in buildings are considered, including 1) thermal comfort levels, 2) visual comfort levels, and 3) acoustic comfort levels. The internationally accepted building code ASHRAE 55 [17] is used to define thermal comfort and includes specific requirements for air temperature, radiant temperature, relative humidity, and air velocity. All thermal comfort requirements of ASHRAE 55 will be fulfilled by the recommended solutions.

\section{Estimations of Initial Cost}

Unless otherwise noted, the estimations of initial cost are derived from the RS-Means database. In consultation with the AEC office, cost estimations for Boston/MA provided base values that are best matched to the construction cost climate for construction undertaken at the University of Michigan. These base costs were further adjusted by a factor of $+40 \%$ (contractor bidding) and $+20 \%$ (internal planning work at $U-M$ ).

Additionally, initial cost estimations for heat recovery units were multiplied by a factor of two to account for a high level of uncertainty in estimating the cost associated with adding large pieces of equipment into existing buildings.

The following building operation energy cost values were used:
Electricity:
$\$ 0.086 / \mathrm{kWh}$
Gas Heating:
$\$ 0.4 / \mathrm{CCF}$
Steam Heating:
$\$ 15.64$ /steam

The following initial cost values were used for the following upgrades:

Shading Film \$17/sf

Vertical heat exchanger geothermal heat pump \$40/ft (depth of drilling) 


\section{Calculation of Cost and $\mathrm{CO}_{2} \mathrm{e}$ Emissions for Building Operation}

The cost and $\mathrm{CO}_{2} \mathrm{e}$ emissions for building operations are calculated as follows:

1. Use Energy Demand: The thermal dynamic calculation software calculates the use energy demand for heating and cooling. The use energy is the amount of thermal energy that is needed to provide thermal comfort for the occupants. It includes the energy needed for heating, cooling, humidification, and dehumidification.

2. Site Energy Demand: The site energy demand includes the dynamic calculation of the efficiency and coefficient of performance of the HVAC systems. The building and climate specific values for the efficiency and Coefficient of Performance (COP) is calculated as an integrative process (integrated into the thermal dynamic simulation). The site energy demand includes these values. The result is dependent on the type of fuel (Gas [18], Electricity).

3. Operation Cost: The operation cost is calculated by using the site energy demand. The cost is calculated for electricity and gas consumers separately.

4. $\mathrm{CO}_{2} \mathrm{e}$ emissions operation: The $\mathrm{CO}_{2} \mathrm{e}$ emissions for building operations are calculated by using the fuel specific values provided by the Department of Energy (DOE) [19].

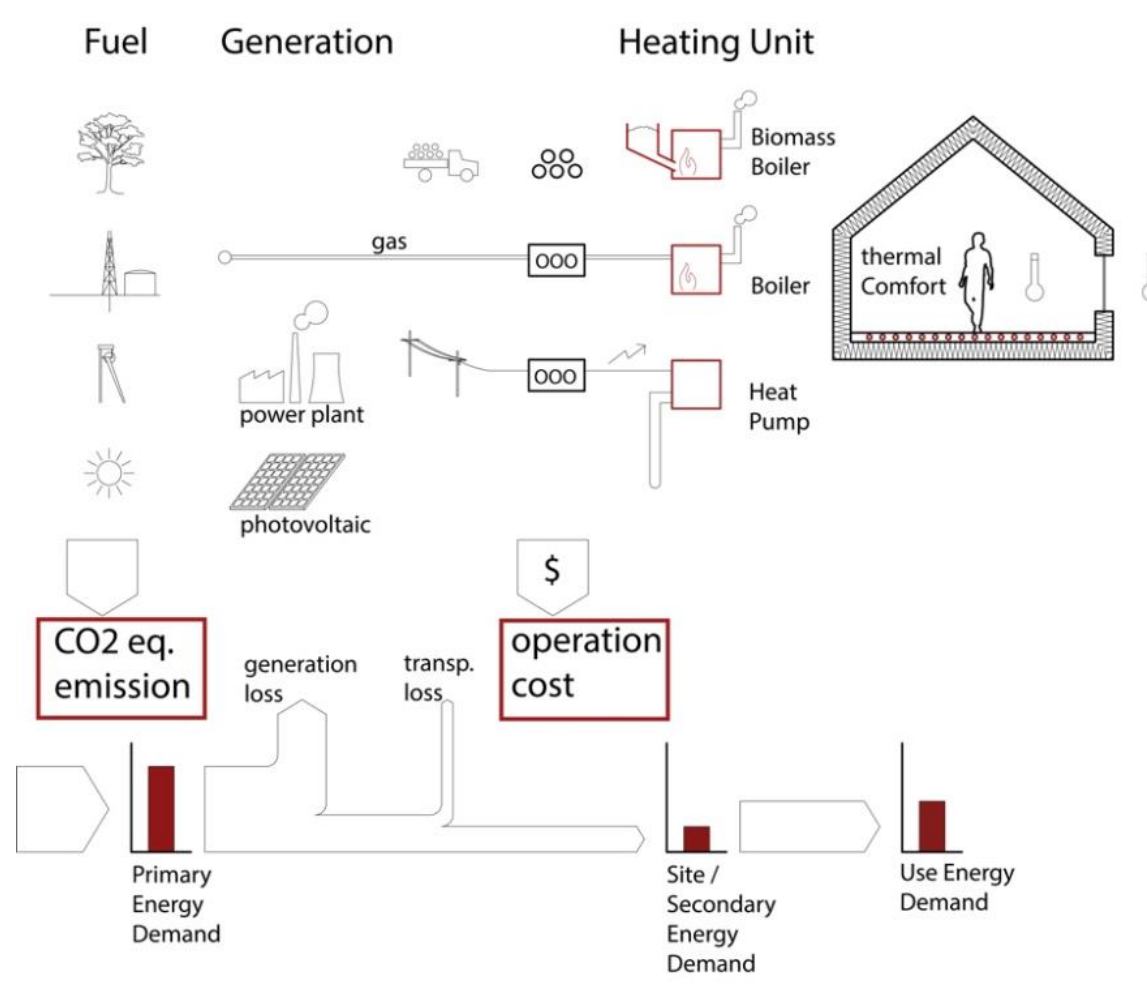

Figure 02_ Energy Flow Diagram 


\section{Limitations of the Calculation Process}

The calculation processes used to estimate the cost and $\mathrm{CO}_{2}$ e emissions of new and existing buildings involve a wide range of uncertainties. Uncertainties include but are not limited to:

Physical calculation of energy demand:

- Design weather data differs from real weather data

- Occupancy schedules in simulation tools differ from real use

- Assumed physical properties like infiltration rate, R-value, and/or internal thermal mass differ from real building attributes

Cost calculation:

- Average initial cost data from data base differs from real cost

- Energy cost data changes over time

- Efficiencies of technical systems in the calculation model differ from reality

$\mathrm{CO}_{2} \mathrm{e}$ emissions:

- Estimations for the embodied energy and $\mathrm{CO}_{2} \mathrm{e}$ emissions for materials and system production derived from the ICE database differ from reality

- Calculations of $\mathrm{CO}_{2} \mathrm{e}$ emissions for building operations differ from reality because of unknowns and variability in the energy conversion process (electricity generation, transportation, etcetera)

- Calculations make static predictions that differ from the dynamic changes in the energy mix for electricity generation over time

\section{Economic factors:}

- Calculations do not accurately predict changes in inflation rates over time

For these reasons, the results presented in this report are estimations with uncertainties. The results can be used as a guideline for initial decision making aimed at identifying the most promising approaches to reduce the $\mathrm{CO}_{2} \mathrm{e}$ emissions of the U-M campuses. 


\title{
APPENDIX C
}

\author{
Detailed Analysis: Priority \#1 Recommendation \\ New Construction, emissions targets
}

Revisions to building standards governing new construction have the potential to achieve near net zero emissions standards because of design opportunities related to passive design strategies including building compactness, window to wall ratio, solar orientation, and daylighting. Additionally, building technologies like demand controlled decentralized ventilation and HVAC systems and façade integrated photovoltaic systems continue to evolve and improve offering significant opportunities for improvements.

The potential to reduce the $\mathrm{CO}_{2} \mathrm{e}$ emissions for new building construction has been analyzed as the basis for recommendations for building standards revisions. The baseline used for all calculations is the current governing building code for the State of Michigan, ASHRAE 90.12013. The results of the analyses for improvements possible with new construction are compared with this baseline. The simulations forming the basis for analysis consider nine building types including: educational buildings with no laboratory space, educational buildings with "low load" laboratory space use, educational buildings with "high load" laboratory space use, library, clinical (in-patient hospital and clinical services), residential (dormitory), residential (low rise, duplex, single family), administrative and athletic.

Several existing buildings served as a base model to establish performance standards per governing building codes and to provide a basis of comparison between improvements that can be achieved with new construction versus major renovation work. In these cases, it is assumed that new construction would replicate the existing dimensions, occupancy, and location of existing buildings. In this regard, the values of improvement are conservative given that adjustments to building massing and orientation could potentially provide additional improvements. The consideration of the additional design strategies available to new construction that would not be feasible in major renovation work requires additional building simulation calculations. These simulations have been done for all building types.

The recommendations given in this section are partly derived from the practical experience of the author, Lars Junghans, on other educational buildings (University of Luxembourg, Bruckner University Linz). The technologies used in these buildings are adjusted to the specific climate conditions of Ann Arbor (colder and longer winter, higher humidity in summer). The following design and technical strategies have been tested in a simulation environment for new buildings:

- Localized occupancy-controlled ventilation systems for rooms at the building perimeter

- Controlled natural ventilation openings at the building envelope

- Use of heavy building material to increase the internal thermal mass

- Holistic integration of high-performance strategies for the building envelope, active systems (HVAC) and renewable energy systems.

As a result of these analyses and simulations, we are proposing a maximum $\mathrm{CO}_{2} \mathrm{e}$ emissions target ( $\left.\mathrm{kg} \mathrm{CO}_{2} \mathrm{e} \mathrm{sf} / \mathrm{yr}\right)$ for new construction in each of the nine building type categories (Appendix M, Table 03 New Construction Recommended Emissions Targets). This specific value allows for comparison between different building sizes and offers the greatest transparency toward achieving net zero emissions goals. 
The recommended emissions targets are an outcome of the consideration of ambitious yet feasible goals. For each building type, lower emissions outcomes are possible if a newly constructed building were to implement the maximum technically achievable reduction including the use of geothermal heat pumps and/or ground source wells without the consideration of the economic impact. In contrast, the Recommended Goal Carbon Dioxide Emission takes into consideration restrictions and limitations in the use of geothermal heat pumps from an economic and feasibility standpoint and models the use of variable refrigerant flow (VRF) systems integrated with all other passive and active strategies mentioned below. The Recommended Goal values also account for the necessary flexibility and variability needed to allow for the wide range of research laboratory spaces integrated in educational buildings.

The recommended emissions targets are also proposed with economics in mind. A more detailed understanding of potential opportunities to achieve a net zero emissions building for a competitive, or even reduced, cost when compared to traditional construction practice can be integrated into early conceptual and schematic design approaches. Cost savings can additionally be leveraged if federal and/or state level incentives are pursued (this level of analysis is beyond the scope of this report). For example, a 2019 USGBC Massachusetts study (done by Integral Group) found that, of the six building types studied, "all can be Zero Energy Ready (ZER) for upfront costs of $0 \%-7 \%$ and when zero energy, all types break even in eight years or less when there are no additional upfront costs" [20]. There is other ongoing work that demonstrates that net zero energy buildings can be cost competitive with traditional buildings. NREL has been working in this realm and have shown in practice that projects can be implemented at no additional cost. One potentially promising approach is to utilize a designbuild approach to construction rather than a traditional strategy of design-bid-build. Further information regarding this approach can be found in section 3.1 of NREL's report [21].

\section{Potential Solutions for Non-Residential Building Types Simulated}

Building Envelope:

- High thermal flow resistance of opaque building envelope (R-45 walls, R60 roof) to reduce heat transmission loss.

- Triple glazing with a U-value of $0.7 \mathrm{~W} / \mathrm{m}^{2} \mathrm{~K}(0.1 \mathrm{IP}$ units $)$ to reduce heat transmission loss. Triple glazing is assumed to have low-e coatings on two layers and yield performance values that cannot be matched by double glazing. The tradeoff between energy performance savings and additional embodied energy can be further analyzed during a detailed building study.

- Building envelope with low air infiltration rate (high air tightness) to reduce heat ventilation loss and humid air infiltration.

- Internal thermal mass in all rooms. The internal mass can be provided by using a brick or concrete construction. Panels with integrated phase change material can be used where a heavy construction is not possible.

- Building envelope and shape that provides sufficient daylight for all building areas to reduce the energy demand for artificial lighting.

- Controlled natural ventilation openings that can provide natural ventilated fresh air supply and night ventilation.

- Use of sustainable building materials to reduce the embodied $\mathrm{CO}_{2} \mathrm{e}$ emissions for building construction, including the use of $\mathrm{CO}_{2} \mathrm{e}$ capturing materials (wood, bamboo, hemp, etcetera) or emerging developments in material science including low $\mathrm{CO}_{2} \mathrm{e}$ concrete (see Appendix J: Emerging Building Materials and Technologies). 
Active Systems:

- High performance heat pump with vertical geothermal heat exchanger loops (closed loop systems). The technology provides the highest coefficient of performance values (efficiency values) so that renewable energy sources can be used most efficiently. The geothermal loops should be used for cooling support (as direct cooling without chiller). The model assumes the following for closed loop geothermal: Density $=1500 \mathrm{~kg} / \mathrm{m}^{3}$, Conductivity $=1.6$ $\mathrm{W} / \mathrm{mK}$, Heat Capacity $=1700 \mathrm{~J} / \mathrm{kg} \mathrm{K}$

- Use of an energy exchanger for heat recovery and humidity recovery in building areas where mechanical ventilation is required (buildings that are not already equipped with heat recovery ventilation).

- Localized ventilation and HVAC systems or DOAS systems with heat recovery ventilation. These systems can be located on the rooftop, at the building perimeter or in a mechanical room inside the building.

- Occupancy demand control of all ventilation systems.

- Integration of radiant heating and cooling systems where it makes sense (thermal active component, radiant heating floor).

Building Automation:

- Model Predictive Control logic that provides predictions for room conditioning for the next day so that renewable energy sources and storage systems can be used more efficiently.

- Comprehensive building automation that increases the use of renewable energy sources, integrates thermal storage technologies, and involves the holistic thermal flow of a building.

Renewable Energy Systems:

- Increase the use of photovoltaic systems on the rooftop.

- Integration of the use of photovoltaic systems on the façade including the possibility of integrating emerging research on the integration of photovoltaics with glazing (see Appendix $\mathrm{J}$ : Emerging Building Materials and Technologies).

- Preparedness for integration with micro smart grid systems that may come into place in the future as U-M evolves its campus-wide infrastructure approach.

\section{Requirements for Architects and Engineers}

To achieve the goal of a zero net emissions campus it is important that architects and engineers have a holistic approach in the design process. This approach must explore the integration of passive design strategies, highly performative HVAC systems, building automation and renewable energy systems. An openness for new technologies is required in this process. Expertise as following is necessary:

1. Use of dynamic thermal simulation tools to calculate the heat flow. The dynamic calculation process should be able to calculate passive design strategies like internal thermal mass, humidity control, dynamic shading systems, $\mathrm{CO}_{2} \mathrm{e}$ concentration and illumination level.

2. Application of dynamic calculation processes for HVAC systems. Calculations of efficiencies and coefficient of performance values of the HVAC systems must be treated dynamically by using weather data for external temperature, dew point and relative humidity. This calculation process provides more information about the building and climate specific seasonal coefficient of performance. Technologies including air cooled VRF and geothermal heat pumps depends heavily on the external local weather, the quality of the building 
envelope and occupant behavior. A simplified estimation of the COP calculations can lead to false outcomes.

3. Knowledge of calculation methods for humidification and dehumidification that include the energy demand for the enthalpy difference between external air and the heating/cooling coil including the bypass factor (latent energy). The latent energy that is needed to achieve dehumidification is not included in conventional building modeling tools, therefore energy demand for dehumidification is underestimated.

4. Knowledge of the dynamic thermal behavior of geothermal and groundwater source heat pump systems.

5. Integration of advanced building automation systems into the dynamic calculation process. Software is needed where the user can define the building control algorithm and is able to test circular control strategies. 


\title{
APPENDIX D
}

\author{
Detailed Analysis: Priority \#2 Recommendation \\ Existing Buildings, potential emissions reductions
}

While new construction will play an important role in moving U-M toward an emission neutral future, existing buildings constitute most of the built space currently and for the foreseeable future. Vast variability exists in the building performance of existing buildings as influenced by factors including age of construction, governing code at time of construction, age of HVAC systems, occupancy and use, orientation, window to wall ratio, etcetera. While establishing recommendations for building standards for new construction was the primary charge of this Internal Analysis Team, we recognize that there are significant positive impacts that can be made through retrofits and renovations. For this reason, we have included analyses considering improvements that would be possible if major renovations were to be undertaken with $\mathrm{CO}_{2} \mathrm{e}$ emissions reductions as a primary goal and following the renovations recommendations of this report.

\section{Approach to Estimating Potential Reductions in $\mathrm{CO}_{2} \mathrm{e}$ Emissions}

Estimations of potential reductions in $\mathrm{CO}_{2} \mathrm{e}$ emissions for existing buildings proceeded as follows:

1. Exemplary existing buildings representative of 9 building types are analyzed for the potential to reduce the energy demand and $\mathrm{CO}_{2} \mathrm{e}$ emissions. The simulations forming the basis for analysis consider nine building types including: educational buildings with no labs, educational buildings with "low load" laboratory space use, educational buildings with "high load" laboratory space use, library, clinical (in-patient hospital and clinical services), residential (dormitory), residential (low rise, duplex, single family), administrative and athletic (excluding natatoria). All existing buildings on the UM-Ann Arbor campus were categorized by building type and building envelope quality and from this sorting, buildings with the best available data were selected to establish a baseline. All buildings were further analyzed and categorized into one of three building envelope performance standards (low, medium, high) to provide a more detailed overview of the emission reduction potentials. This categorization step is based on a broad understanding of existing buildings from data available online and was not field verified nor measured. The intention of the classification was to assess a ballpark range of potential improvements at the campus scale. For a finer grain understanding of potential emissions reductions specific to each building (which is beyond the scope of this report), more detailed analyses including field verifications are required. Selected buildings were modeled, and a dynamic thermal calculation process was used to estimate performance values. A calibration process was used to adjust the simulated model to known data. The outcome of this step is the specific life cycle cost (LCC) and life cycle analysis (LCA). The units are given specific per square foot conditioned floor area to provide comparable data.

2. Selected strategies (parameter settings) to reduce the $\mathrm{CO}_{2} \mathrm{e}$ emissions of the buildings were tested for their efficacy. Strategies were initially tested one by one without changing other parameter settings (Appendix M, Table 06 Existing Buildings Proposed HVAC and Envelope Improvements). Following, potential combinations of parameter settings were calculated. A Multi Objective Optimization Algorithm was used to generate a wide range of possible solution combinations that are then evaluated for their potential to optimize desired 
outcomes. In our case, the optimization objective is the combination of building improvements that yield the largest reduction in $\mathrm{CO}_{2} \mathrm{e}$ emissions for the lowest cost.

3. The results of the optimization process are illustrated in a Pareto Frontier diagram. The Pareto Frontier diagram shows clusters of points representing various solutions to the tradeoff between the two optimization objectives (reduction in $\mathrm{CO}_{2} \mathrm{e}$ emissions and cost). The Pareto Frontier diagram shows 1 ) the maximal potential $\mathrm{CO}_{2} \mathrm{e}$ emissions and 2) most costeffective solutions to reduce the $\mathrm{CO}_{2}$ e emissions. Additionally, the effect of the diminishing return on investment of strategy combinations can be analyzed.

4. The potential to reduce $\mathrm{CO}_{2} \mathrm{e}$ emissions and cost were analyzed for each existing building used as a model for each building type category. The analysis includes the identification of the most effective combinatory strategies (parameter settings) for each building type. The reduction potential for the $\mathrm{CO}_{2} \mathrm{e}$ emissions and cost is expressed as a percent value.

5. The potential improvements identified for each model building was further extrapolated to all existing buildings on the UM-Ann Arbor campus to estimate a "global" potential if all existing buildings were to pursue major renovation improvements.

\section{Details of Calibration Process}

A calibration process is necessary to adjust the thermal characteristic of the computer simulation model to known performance of the real building. In most of the cases, the exact properties of the building envelope, the technical efficiencies of the HVAC systems and the occupant behavior (occupancy schedule, occupancy density) are not known. Therefore, assumptions were made to define the parameter settings of the thermal simulation tool. To do so, two calibration processes have been applied:

1. Parameters were adjusted to known heating and cooling energy demand values of the existing building. An optimization process was employed to adjust the parameter settings in the thermal simulation tool to align the heating and cooling energy model output with known values. Typical values for the occupancy, air volume flow and internal heat gains were used as a starting point to determine realistic parameter settings.

2. In the case of the Art and Architecture Building, the physical properties of the building envelope were measured with a heat flow resistance meter. Typical values for the occupancy, air volume flow and internal heat gains were used as a starting point to determine realistic parameter settings.

\section{Multiple Objective Optimization Algorithm}

The optimization of the performance of buildings are multi-variable problems that include a large number of possible combinations of parameter settings. In the design and planning process for new construction and major renovations, it is often not clear how to assign criteria to parts of the building envelope or to determine which technical system should be targeted to achieve optimal energy, cost or greenhouse gas emissions levels. Recently, thermal simulation programs like EnergyPlus are becoming widely used to perform such parametric studies. These tools have been developed to facilitate an accessible user interface and involve changing one parameter while leaving others constant. As an outcome, studies performed with these tools can miss potentially important interactive effects.

In contrast, building optimization algorithms coupled with simulation programs enable the study of multi-variable, inter-dependent problems to find an optimal solution [22]. Design parameters that have the potential to reduce the energy demand in buildings are typically not linear. The 
term "building optimization" refers to a method that uses an algorithm to find the optimal combination of parameter settings either for building design or for building renovation [23]. For this study, the multi objective genetic algorithm NSGA-II [24] is used to find a near optimal solution for the lowest cost and green-house gas emission.

\section{Pareto Optimal Solution}

A Pareto Optimal Solution describes the optimal trade-off between two objectives. The Pareto diagrams for each building model simulation show the trade-off of different scenarios. Each scenario (combination of design parameter settings) is shown as a dot. Once the Pareto solution set is obtained, a trade-off study can be performed. For each existing building model, we identified an optimal scenario to reduce cost and GHG emission. trade-off between the reduction of cost and the green-house gas emission. The Pareto optimal solution, combined with the multi objective optimization process, offers the advantage of flexibility because it identifies clusters of optimal solutions that can be further studied within the context of additional known constraints or design objectives. For major renovations to existing buildings, having the flexibility to achieve an optimal solution with a variety of combinations greatly increases the feasibility of implementation.

\section{Calculation Methods}

The calculations in this report make use of well-developed and internationally recognized building standards calculation methods. The building standards that were used for analyses include:

- DIN 18599 (German building code for holistic energy demand of buildings) [25]

- EN ISO 13791:2012-Thermal Performance of Buildings-Calculation of Internal Temperatures of a Room in Summer Without Mechanical Cooling-General Criteria and Validation Procedures [26]

- ASHRAE Standard 140 (2001) "Standard Method of Test for Building Energy Simulation Computer Programs" [27]

These standards guided the calculations of:

1. An integrated method for energy distribution (electricity for ventilation), lighting, warm water heating, dynamic efficiency, and COP calculation for HVAC systems specific to the climate demands of southeast Michigan [28]

2. A dynamic thermal simulation process used to calculate the energy demand for heating, cooling, humidification, and dehumidification. Additionally, this calculation process provides the energy demand for energy distribution (ventilation, radiant systems), artificial lighting, warm water heating, and other plug loads. The calculation algorithm for the thermal behavior follows the International Building Code EN ISO 13791:2012. Energy distribution calculations follow DIN 18599. The results of the dynamic calculation processes are used to calculate site energy demand, primary energy demand, operation cost and $\mathrm{CO}_{2} \mathrm{e}$ emissions generated by building operation.

\section{Calculation Process and Its Results}

Following the potential reduction in $\mathrm{CO}_{2} \mathrm{e}$ emissions and cost calculations described above, additional calculation processes were as follows: 
1. The LCC and LCA of each base existing building case was calculated by using the thermal simulation process described above. The base case of each existing building is considered to be the current condition with no improvements to the building envelope or technical systems.

2. The LCC and LCA of each improved building case was calculated. Possible variations in potential improvements parameter scenarios were created by the multiple objective optimization algorithm.

3. The base case and improved case for the LCC and LCA calculations were compared. The values of the base case were subtracted from the improved case and the difference describes the efficacy of the improvement for balance between cost and reductions in $\mathrm{CO}_{2} \mathrm{e}$ emissions. The results were divided by the established time-period for the LCC and LCA (30 years ${ }^{*}$ to yield the annual cost and $\mathrm{CO}_{2} \mathrm{e}$ emissions reductions. The reduction in operations cost is given in $\$ / \mathrm{sf} / \mathrm{yr}$ and the reduction in $\mathrm{CO}_{2} \mathrm{e}$ emissions is given in $\mathrm{kg} \mathrm{CO} 2 \mathrm{e} / \mathrm{sf} / \mathrm{yr}$.

The results of the calculation processes described above illustrate the outcomes of the tradeoffs between the reduction of $\mathrm{CO}_{2} \mathrm{e}$ emissions and minimizing cost. The Pareto diagrams can be read as follows:

- The Upper Right Quadrant represents solutions that optimize reductions in cost and $\mathrm{CO}_{2} \mathrm{e}$ emissions. A solution point that is in the upper right quadrant symbolizes one of the most optimal solutions.

- The Upper Left Quadrant represents solutions that reduce $\mathrm{CO}_{2} \mathrm{e}$ emissions yet have additional annual costs.

- The Lower Right Quadrant represents solutions that reduce cost but do not effectively reduce $\mathrm{CO}_{2}$ e emissions. These solutions should not be considered.

- The Lower Left Quadrant represents solutions that do not reduce $\mathrm{CO}_{2} \mathrm{e}$ emissions or cost. These solutions should not be considered.

Notes:

- The time-period selected for LCC + LCA calculations is 30 years. This was selected on the recommendation and current practice of the U-M AEC office.

- The LCC and LCA calculation considers the expected life span of different materials and technical systems. The life span is taken from the RS Means database and the ICE database.

- The calculation of the LCC and the LCA is done as an economic "static" calculation. Interest rates or inflation rates are not considered. References used for LCC + LCA calculations include $[29,30,31,32,33,34,35,36,37]$.

\section{Quality of the Building Envelope}

To provide a better estimation of potential $\mathrm{CO}_{2} \mathrm{e}$ emissions reductions for existing buildings on the U-M campuses, three potential building performance categories were used. All existing buildings were assessed and classified as currently performing in one of the following three categories:

1. Building with a "poor" envelope: These are buildings that are typically constructed before 1987 and have not had any renovations or improvements to their building envelopes.

- $\quad$ R-value roof $=\mathrm{R} 20$

- $\mathrm{R}$-value wall $=\mathrm{R} 10$ 
- U-value glazing $=4.5 \mathrm{~W} / \mathrm{m}^{2} \mathrm{k}(\mathrm{U}$-value $0.79 \mathrm{BTU} /(\mathrm{h} \mathrm{sf} \mathrm{F})$ )

- Infiltration rate $=0.3[1 / \mathrm{h}]$

- No heat recovery

2. Building with a "medium" envelope: These are buildings that are typically constructed or renovated after the year 1987 and follow the Michigan Building Code.

- $\quad \mathrm{R}$-value roof $=\mathrm{R} 38$

- R-value wall $=\mathrm{R} 20$

- U-value glazing $=2.8 \mathrm{~W} / \mathrm{m}^{2} \mathrm{k}(\mathrm{U}$-value $0.49 \mathrm{BTU} /(\mathrm{h} \mathrm{sf} \mathrm{F}))$

- Infiltration rate $=0.2[1 / \mathrm{h}]$

- No heat recovery

3. Building with a "good" envelope: These are buildings that are typically constructed or renovated after the year 2006 and that are assumed to be $30 \%$ better than the Michigan Building Code. In the year 2006 the University of Michigan adopted building standards that require the building envelope to perform at a level that exceeds MBC by $30 \%$.

- R-value roof $=\mathrm{R} 45$

- R-value wall = R30

- U-value glazing $=1.8 \mathrm{~W} / \mathrm{m}^{2} \mathrm{k}(\mathrm{U}$-value $0.31 \mathrm{BTU} /(\mathrm{h} \mathrm{sf} \mathrm{F})$ )

- Infiltration rate $=0.2[1 / \mathrm{h}]$

- Heat recovery in new buildings (not residential)

\section{Building Improvements Considered in This Analysis}

Building envelope

- R-value roof

- R-value wall

- U-value Glazing

- Air tightness

HVAC system

- Heat recovery system

- Heating system

- Cooling system

Lighting

- LED lighting

- Occupancy control

Renewable energy system

- Photovoltaic

R-value roof: The roof will get additional insulation. The type of insulation used in this study is EPS with an R-value of $\mathrm{R} 5 /$ in. The potential parameter settings are defined as:

- Setting 0: no additional insulation

- Setting 1: additional R-value of R5

- Setting 2: additional R-value of R10

- Setting 3: additional R-value of R15 
- Setting 4: additional R-value of R20

- Setting 5: additional R-value of R25

R- value wall: The wall will get additional insulation. The type of insulation used in this study is EPS with an R-value of R5/in. The potential parameter settings are defined as:

- Setting 0: no additional insulation

- Setting 1: additional R-value of R5

- Setting 2: additional R-value of R10

- Setting 3: additional R-value of R15

- Setting 4: additional R-value of R20

- Setting 5: additional R-value of R25

U-value glazing: The glazing and the window frame will be changed. The potential parameter settings are defined as:

- Setting 0: no additional insulation

- Setting 1: U-value = 1.57, SHGC $0.31(\mathrm{U}$-value $0.27 \mathrm{BTU} /(\mathrm{h}$ sf F))

- Setting 2: U-value $=1.2$, SHGC $0.52(\mathrm{U}$-value $0.21 \mathrm{BTU} /(\mathrm{h}$ sf F $)$ )

- Setting 3: U-value =1.66, SHGC $0.62(\mathrm{U}$-value $0.29 \mathrm{BTU} /(\mathrm{h} \mathrm{sf} \mathrm{F}))$

- Setting 4: U-value $=0.7$, SHGC $0.51(\mathrm{U}$-value $0.12 \mathrm{BTU} /(\mathrm{h} \mathrm{sf} \mathrm{F}))$

- Setting 5: U-value =0.7, SHGC $0.3(\mathrm{U}$-value $0.12 \mathrm{BTU} /(\mathrm{h} \mathrm{sf} \mathrm{F}))$

Air Tightness: The improvement of the air tightness of the building envelope is an important strategy to reduce the heating energy demand and the energy demand for dehumidification [38]. Air infiltrates through cracks in the building envelope and broken or poorly performing window frame seals. Improvement strategies include the installation of air barriers and/or the window frame seal replacements. Entrance doors and windows with air-tight gaskets can also be used to replace poorly performing fenestration. The air change rate $\mathrm{ACH}$ used in this analysis is the estimated average air change for infiltration $(\mathrm{ACH}=$ Volume Flow per hour / Volume of conditioned space). The potential parameter settings are defined as:

- Setting 0: no improvement

- Setting 1: $\mathrm{ACH}$ reduction $40 \%$

- Setting 2: $\mathrm{ACH}$ reduction $60 \%$

Heat recovery system: Because of the relatively high air change rates in educational buildings, the heat recovery system has a large potential to reduce the energy demand for heating and dehumidification. The type of energy exchanger used in this study is a rotating wheel energy exchanger (enthalpy exchanger). It has the advantage to reduce the energy for dehumidification and humidification. The heat recovery rate and the humidity recovery rate are set to $80 \%$.

Heating system (Boiler with higher efficiency): The parameter is set to replace the current heating system with a new boiler. The boiler has an efficiency of $98 \%$. This strategy is tested in larger buildings.

Furnace with higher efficiency: The parameter is set to replace the current old furnace with a new furnace. The new furnace has an efficiency of $92 \%$. This strategy is only applied to smaller residential buildings. 
Geothermal heat pump: The parameter is set to use geothermal heat as a primary heat source for the heat pump. A geothermal heat pump has the advantage that the COP values are very high because of the relatively high temperature level of the ground and because of the relatively constant temperature level. A disadvantage is the relatively high cost because of the cost intensive drilling process. The vertical loops are used as a cooling source for the summer time. The dimension of the vertical loops as thermal heat exchanger to extract the heat from the ground are calculated by using the calculation process by Spitler [39].

Cooling System: The parameter is set to use a new variable speed chiller plant with a higher COP. The coefficient of performance COP is assumed to be rated at $6.5(\mathrm{SI})$. The real COP is calculated in a dynamic calculation process and depends on the external climate and building specific values (building specific cooling season).

Lighting systems: The parameter is set to replace existing fluorescent lighting systems with LED lighting. This is known to be a very efficient strategy to reduce the cost and $\mathrm{CO}_{2} \mathrm{e}$ emissions for building operation (up to $20 \%$ less) [40]. This can be coupled with occupancy controllers which switch off the lighting when the room is not occupied [41]. According to the US Environmental Protection Agency EPA, occupancy sensors have been found to reduce energy demand for lighting up to $40 \%$ in educational buildings. This will contribute a modest overall energy savings for a building. For example, at the Art and Architecture Building, lighting accounts for $4.5 \%$ of the total building energy therefore sensors would reduce overall building energy by $1.1 \%$.

Photovoltaic Systems: The optimization process involves the use of photovoltaic modules on the roof of the building as an on-site renewable energy system. The photovoltaic system produces electricity when the sun is shining (direct radiation). The outcome of electric energy produced by the photovoltaic system is calculated by using a dynamic calculation process. The photovoltaic modules are assumed to be oriented to the south and having a tilt angle of 20 degree. The efficiency of the photovoltaic modules is assumed to be $15 \%$ and the efficiency of the converter is assumed to be $90 \%$. The area of the photovoltaic system defined in the parameter setting:

- Setting 0: no photovoltaic

- Setting 1: $10 \%$ of roof area

- Setting 2: $20 \%$ of roof area

- Setting 3: $30 \%$ of roof area

- Setting 4: $40 \%$ of roof area

- Setting 5: $50 \%$ of roof area

- Setting 6: $60 \%$ of roof area

- Setting 7: $70 \%$ of roof area 


\section{Improvements That Are Not Considered in This Analysis}

\section{Radiant Systems}

In all but one calculation, radiant systems for heating and cooling have not been included in the current version of the analysis. These systems heat and cool the room by providing warm or cold surface temperatures and can be an effective tool for small rooms with small room volume. These systems are typically water-based systems. The advantage of these systems is that they provide comfortable room temperatures by using relatively less electric energy for energy distribution. These systems loose efficiency when room volume gets large (auditoria, studio spaces, etc). This factor influenced why these systems are not included in this study in addition to the fact that university buildings have a relatively high minimum air change rate so that the saving effects for the energy distribution is limited. Additionally, cold surfaces can cause condensation and warm surfaces at the ceiling can cause discomfort.

\section{Ceiling Fans}

The use of ceiling fans instead of active cooling (chillers) would reduce the energy demand for cooling extensively. Ceiling fans (or any other type of fans) increase air velocity and improves thermal comfort at higher temperature and humidity levels. In this scenario, active cooling is needed less frequently. The operation of ceiling fans is up to five times more efficient than centralized chiller systems. The option to use ceiling fans instead of active cooling systems, however, is not included in the current analysis because of the currently limited cultural acceptance of this solution.

\section{Biomass Heat Power Cogeneration/Biomass Boiler}

Biomass Heat Power Cogeneration (Biomass CHP) or the Biomass boiler is an emerging technology that is seen to be a renewable energy source [42]. Both technologies use wood, straw, or other organic materials as a fuel. The Biomass CHP generates heat and electric power at the same time and provides heat for room heating and warm water heating. Both systems can be used in a single building or as a centralized district heating plant. The technology has its advantages in regions where biomass sources, including large forest industries, are available. Despite being classified as "clean" energy and having the potential to reduce transportation distances, it has been demonstrated that biomass energy is a heavily polluting technology. In an analysis of air pollution permits from seven states, the Partnership for Policy Integration found that biomass burners are always more polluting than natural gas and are similar to the pollution levels of coal [43]. Because there are no biomass resources close to the University of Michigan, and because of the high air pollution characteristics, the authors did not include this technology in this study.

\section{Assumptions for Current Building Technologies}

1. U-M Heat Power cogeneration plant: The heat power cogeneration plant on central campus provides thermal heat in form of steam and electricity for most buildings on central campus. The thermal efficiency of this plant is assumed to be $70 \%$.

2. Heating systems values (for buildings that are not connected to the $U-M$ central power plant) are assumed to be:

Furnace (for smaller residential buildings)

- Before 2000: Efficiency 85\%

- After 2000: Efficiency $90 \%$ 
Boiler

- Before 1990: Efficiency 85\%

- Before 2000: Efficiency 90\%

- After 2000: Efficiency 95\% (condensing boiler)

3. Cooling systems: The coefficient of performance COP of the existing chiller systems is estimated according to conventional values of its time. The values are varying according to the time when the building was built of significantly renovated.

- Before 1970: COP 3.5 [SI]

- 1970-1990: COP 4 [SI]

- 1990-2000: COP 5 [SI]

- After 2000: COP 6 [SI]

\section{Estimation of Initial and Embodied Energy Costs}

The calculation process for the embodied energy and the initial cost includes additional material and labor costs associated with the work that would be done as part of a major building renovation. These costs are calculated based on the material and labor necessary for the optimization solution to be implemented and are based on the RS-Means database adjusted by a factor of $+40 \%$ (contractor bidding) and $+20 \%$ (internal planning work at $U-M$ ).

Associated improvements that were estimated include:

- R-value for walls: Cost for additional layers to cover the insulation (drywall and paint)

- R-value for roof: Cost for additional layers to cover the insulation (roofing material, plywood, and timber construction)

- U-value glazing: Cost for framing

- Heat recovery system: Cost AHU changes per room (RS-Means estimations x 2)

\section{Estimation of Cost of $\mathrm{CO}_{2} \mathrm{e}$ Emissions Reduction}

The expected cost per reduced metric ton $\mathrm{CO}_{2} \mathrm{e}$ was estimated. The estimation was done as follows:

1. Each building on the UM-Ann Arbor campus was classified by type of building and construction or renovation year. The quality of the building envelope was estimated according to the year of the construction or renovation. The current $\mathrm{CO}_{2} \mathrm{e}$ emissions and cost for building operations were simulated and then adjusted to known data.

2. The results of the optimization process described above were used to estimate the reductions in operation costs and $\mathrm{CO}_{2} \mathrm{e}$ emissions for each building simulated with renovation improvements.

3. The initial cost of improvements was estimated for each building based on the assumed quality of the building envelope. A range of expected cost was calculated.

4. The total calculated initial cost to improve all existing buildings was divided across a range of observation times in five-year increments up to 50 years. This yielded an estimation of the cost per reduction of $\mathrm{CO}_{2} \mathrm{e}$ emissions (in $\$ / \mathrm{MtCO}_{2} \mathrm{e}$ ). The results of these calculations can be found in Appendix M, Table 05 Estimated Cost per $\mathrm{MtCO}_{2}$ e Emissions Reductions. 
The data for the investment cost that was used for this analysis only includes additional costs required to implement the proposed renovation strategies that optimized reductions in cost and $\mathrm{CO}_{2} \mathrm{e}$ emissions (from the multiple objective optimization algorithm analysis. For example, if the implementation of additional wall insulation resulted from the analysis, cost was calculated by estimating the cost of additional insulation necessary from a baseline. ASHRAE 90.1-2013 is used as an initial benchmark. The cost estimate was reviewed and revised in coordination with the U-M AEC to best reflect numbers in line with pricing associated with known projects completed on the Ann Arbor campus. All costs estimates in this report have been developed to reflect the best available information yet are also operating at a much more abstract level than typical pricing (developed in response to construction documentation intended for bidding) and therefore have a much higher degree of uncertainty than will be possible when a specific renovation project is taken up by an $\mathrm{A} / \mathrm{E}$ team for design and documentation.

\section{Results}

The results of this study show that there are certain building renovation strategies that are especially effective to reduce the $\mathrm{CO}_{2} \mathrm{e}$ emissions and cost of building operation for most building types. These include:

1. The use of a heat recovery unit. This is especially effective in older buildings where it is not included already. The effectiveness of this strategy results from the high air change rate for mechanical ventilation in education buildings.

2. Geothermal heat pumps. This technology is an effective strategy to reduce $\mathrm{CO}_{2} \mathrm{e}$ emissions for building operations. This results from the relatively high geothermal heat input for the heat pump which yields very high coefficient of performance values. Additionally, the use of the geothermal vertical loops as a cooling source contributes to the efficacy. Finally, the 30year period of the LCC and LCA has a positive effect on affordability.

3. Photovoltaics. The installation of photovoltaic systems as a renewable electricity source was found to be effective for all building types. In educational buildings, the electricity can be used directly to reduce the demand of electricity from the grid. In residential buildings, it is recommended to share the additional electricity in time of low demand (daytime) with campus buildings. A local smart grid control for the entire campus is recommended for the most effective use of photovoltaic systems. This strategy helps to reduce the need for cost intensive electric energy storage systems.

4. Improvements to the building envelope. This strategy includes replacing windows and adding insulation in older buildings with a relatively bad building envelope. The implementation of triple glazing reduces the $\mathrm{CO}_{2} \mathrm{e}$ emissions for building operation and increases thermal comfort. The relatively high investment cost of triple glazing pays off against a 30-year period for LCC and LCA. Additional insulation is only recommended when the building needs new insulation or has an envelope with a thermal resistance performing below the minimal requirements of the existing building code.

5. LED lighting. Improvements to reduce the energy demand for artificial lighting is always efficient. The replacement of incandescent or fluorescent lighting with LED integrated with occupancy controllers are recommended. In comparison with other strategies, this yields smaller reductions in $\mathrm{CO}_{2} \mathrm{e}$ emissions and cost because the energy demand of lighting is small relative to other energy consumers including heating and ventilation.

6. Chiller replacement. The replacement of existing chillers to increase the coefficient of performance is recommended in some of the buildings of this study. 


\section{Proposed Technologies}

To achieve the goal of a zero net emissions building, it is recommended to integrate electrically powered heating and cooling systems. This will enable large scale renewable energy systems, like photovoltaic and wind power, to be effectively integrated. Electricity providers like DTE are targeting a goal to provide a net zero emissions grid in the next 30 years. While conventional cooling systems are already powered by electricity, heating systems are typically powered by fossil fuels like natural gas. Currently, heat pumps are the only efficient heating units powered by electricity. For this reason, two heat pump technologies, geothermal heat pumps and air cooled variable refrigerant flow (VRF) heat pumps (external air heat pump), are proposed. Advantages and disadvantages are compared in this section.

Evaluation criteria for these analyses prioritize $\mathrm{CO}_{2} \mathrm{e}$ emissions and the cost for building operations rather than the total energy demand (EUI) of the building. Because differences in the impact that various energy sources (and mixes) have on both $\mathrm{CO}_{2} \mathrm{e}$ emissions and cost, an evaluation using only the energy demand can be misleading. The proposed technologies are selected to best achieve the goal of eliminating the use of fossil fuels including natural gas. Electrification offers the most promise to do so when coupled with increased investments in renewable energy systems like photovoltaic and wind power. Furthermore, the local electric energy provider DTE has the goal to be $\mathrm{CO}_{2} \mathrm{e}$ neutral in three decades.

\section{Geothermal Heat Pump/Groundwater Well Heat Pump for Room Heating}

The geothermal heat pump is a heating technology that uses geothermal heat as a heat source $[44,45]$. Like every heat pump system, it provides higher temperature levels for room heating by using environmental heat derived from vertical heat exchangers (fluid bearing loops). Geothermal heat is extracted by using heat exchangers placed in boreholes. Boreholes are typically drilled to depths of $400 \mathrm{ft}-500 \mathrm{ft}(100 \mathrm{~m}-140 \mathrm{~m})$ with a minimum distance of $30 \mathrm{ft}-40 \mathrm{ft}$ between loops to avoid thermal interaction. For new construction, boreholes can be placed underneath a building and for renovations, boreholes are typically placed beside a building. The number and total length of loops depends on the total heating load of the building [46]. Geothermal testing is required before this technology can be applied.

Geothermal heat pumps utilize electricity for a thermal Carnot compression process. The coefficient of performance (COP) of a heat pump describes the ratio of the thermal energy leaving the system compared to the amount of electric energy that is put into the system. Higher COP values represent a higher efficiency. Heat pumps work more efficiently when the temperature difference between the desired room value and the environmental source is small [47]. For example, when compared to an external air minimum temperature of -10 degrees Fahrenheit, which is an alternative heat source for the heat pump, the average geothermal heat value equals 52 degrees Fahrenheit $(11 \mathrm{C})$. The COP of a well-insulated building was calculated as part of this analysis and found to be very high compared to a heat pump using the external air as a heat source, with values as follows: COP of the geothermal heat pump $=5.3$ and COP of an external air heat pump $=2.4$. For this technology to perform in an efficient manner, it is important for the building envelope to have high performance qualities including a high R-value and low air infiltration. This is important to keep heating loads on the building relatively low. If the building envelope performs well, then geothermal heat pump offers the most effective technology to achieve room heating with the smallest $\mathrm{CO}_{2} \mathrm{e}$ emissions and building operations cost. 
Another advantage is that heat pumps can be used as a very efficient source for cooling. In summer months, the temperature of the ground and groundwater can be used as a direct heat sink. Additionally, conventional compression chillers can be supported to increase the overall efficiency of the building. Heat pumps provide significantly more thermal energy than the amount of electricity needed for operation. This is a tremendous advantage because heat pumps do not depend on fossil fuels. Depending of the way that source electricity is generated, heat pumps can significantly reduce the $\mathrm{CO}_{2} \mathrm{e}$ emissions of a building. In these ways, heat pump technology is seen as a very important part of the net zero emissions building $[48,49,50]$.

\section{Groundwater Well}

The use of a groundwater well is a cost-effective alternative to the geothermal vertical heat exchanger loops [51]. Instead of using cost intensive boreholes, groundwater is used as the environmental heat source. Groundwater is pumped to the surface, used as a heat source, and then pumped back into the ground. Water temperatures decrease about $5 \mathrm{~K}$ in the winter months and increase about $5 \mathrm{~K}$ in the summer months. The temperature differentials are like those of geothermal heat. This technology has the advantage of significantly lower initial costs because groundwater wells do not have to be drilled as deep as geothermal vertical loops. A disadvantage is that this technology requires special planning and approval processes regarding the use of groundwater and requires specialists to be involved $[52,53,54]$.

\section{Variable Refrigerant Flow (VRF) HVAC Systems}

Variable refrigerant flow (VRF) systems can be used for heating and cooling. For heating, VRF systems work as an external air heat pump and uses external air as a primary heat source. It has been shown to work with relative efficiency in heating mode down to external temperatures measuring -5 degrees Fahrenheit. Temperatures this low occur relatively infrequently in southeast Michigan therefore this is a promising option when paired with high performance building envelopes. In comparison with geothermal heat pumps (COP $=5.3)$, VRF systems have a lower heating efficiency $(\mathrm{COP}=2.5)$.

In cooling mode, VRF systems work as a conventional air to air compression air conditioner. VRF systems are comprised of an external unit and several internal units. Internal units can be operated individually, yielding zone control flexibility. Additionally, units are available in a large variety of sizes so the system can be designed for use in residential, educational, or administrative buildings. This technology also affords flexibility for its integration into the building by combining heating and cooling into a single unit. Combined with modern building automation strategies, it reduces the energy demand for heating, cooling and dehumidification and is economically competitive to conventional systems. Indoor units can be combined with decentralized heat recovery systems. For these reasons, VRF systems can be relatively easily implemented for improvements to existing buildings. Recently, this technology is becoming increasingly efficient.

For a summary comparison of these three systems, their initial costs and potential $\mathrm{CO}_{2} \mathrm{e}$ emissions reductions per square foot, see Appendix M, Table 10 Estimated Initial Costs HVAC Renovation + New Construction. This table additionally demonstrates the resulting difference necessary to be balanced by photovoltaics to achieve a net zero emissions standard. The cost of the photovoltaic system is included. The result shows that the geothermal heat pump and groundwater well heat pump are cost competitive compared with the VRF system when the cost 
of the photovoltaics necessary to offset the remaining balance of $\mathrm{CO}_{2}$ e emissions is included in the calculation.

\section{Heat Recovery Ventilation}

Heat recovery ventilation systems are frequently used in new construction. This technology is part of the mechanical ventilation system. It preheats supply air by using the heat of the return air. This process is an effective way to reduce heating energy demand. Using the same process, heat recovery ventilation units can partially dehumidify supply air during humid summer months. This decreases the need for other forms of energy intensive dehumidification. This technology is particularly effective educational buildings because of the relatively high requirements for mechanical ventilation air volume rates. Since heat recovery ventilation is already used in newer buildings on U-M campuses, this technology is proposed as a renovation strategy to improve the energy performance of older buildings. In the case of existing buildings, localized air handling units with heat recovery ventilation are recommend, given that centralized integration is not possible.

\section{Localized Air Handling}

Localized Air Handling units provide fresh air for a limited area such as an office or classroom. This technology has several advantages when compared to centralized systems. One advantage is that the localized air handling equipment is in the room. It has a direct connection to external air through the façade or roof. The unit includes fans, filters, a heating/cooling coil and heat recovery. These units effectively reduce energy demand for heating and dehumidification. They operate with a demand-controlled system which is only operated when the room is occupied. Units utilize an advanced control system that detects the occupancy density of the room and adjusts ventilation rates accordingly. Demand controlled operation greatly reduces energy demand. Furthermore, localized air handling units are easy to integrate in existing buildings where the implementation of a centralized heat recovery unit is difficult. Therefore, these systems are proposed as one of the technologies for building renovation. As an alternative to the above-mentioned system, the air handling unit can be placed on the rooftop. These systems are called Dedicated Outdoor Air Systems (DOAS). DOAS are also localized systems and have the same advantage as localized air handling systems located in a room or building. 

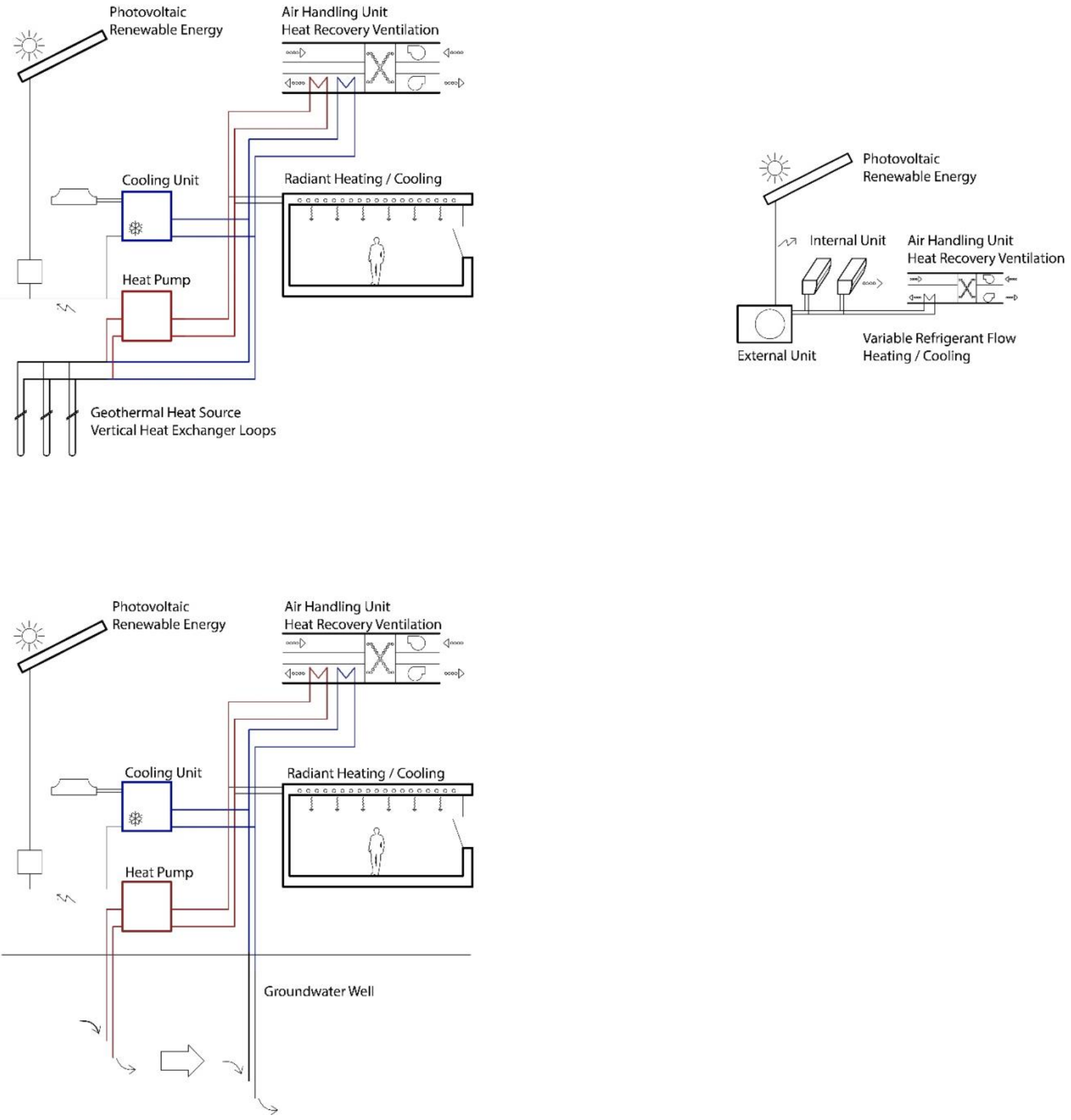

Figure 03_Recommended Active Systems (Geothermal, Groundwater Well, Heat Recovery, VRF, Photovoltaics) 


\section{Limitations of Proposed Technology}

Geothermal heat pump

- Can be cost intensive

- Requirements for boreholes may be too dense for the capacity of the ground

Groundwater well heat pump

- Permission is granted at the state level to protect changes to groundwater temperatures

- Soil conditions may not allow for the installation of a groundwater well

- A relatively new technology that requires additional research

- A relatively rare technology that requires engineering specialization that may not be regionally available

Heat recovery ventilation

- Units are very large and may not fit in existing building's air handling rooms

- Changes to existing buildings to make room for units may impact the building's structure

- Supply and return air must be directed to one location and some buildings may not have existing return air ducts or these ducts may not already go to the air handling unit of the building. Additional cost can be incurred for additional duct systems.

Localized air handling unit

- A known technology in Europe that is new to the North American market

- Best outcomes require additional collaboration with the HVAC industry to design for the special needs of University buildings and introduce new technologies to market

\section{Relative Effectiveness of Proposed Technologies in Relationship to Building Type}

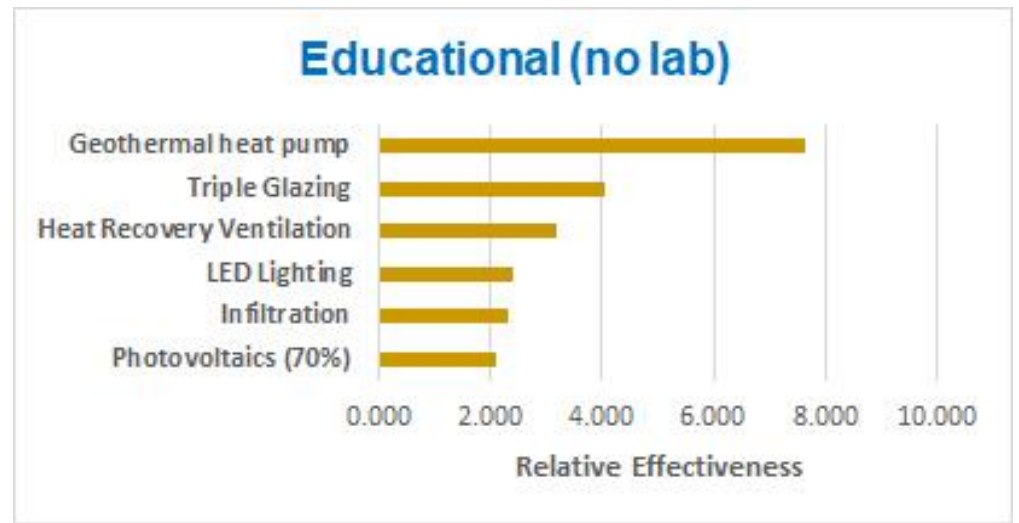

Figure 04_Comparison Proposed Improvements_Education No Lab 


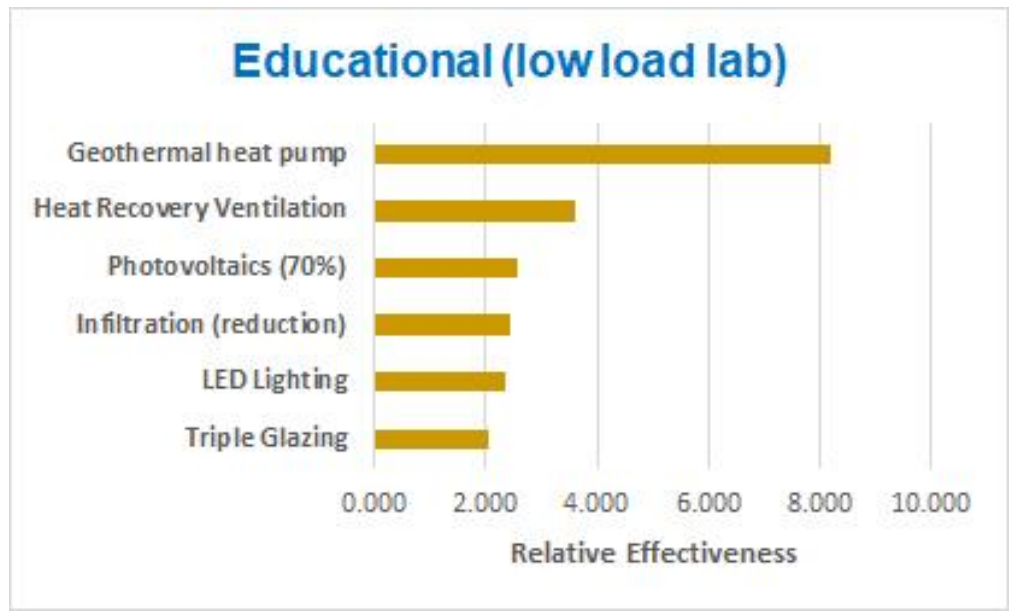

Figure 05_Comparison Proposed Improvements_Education Low Lab

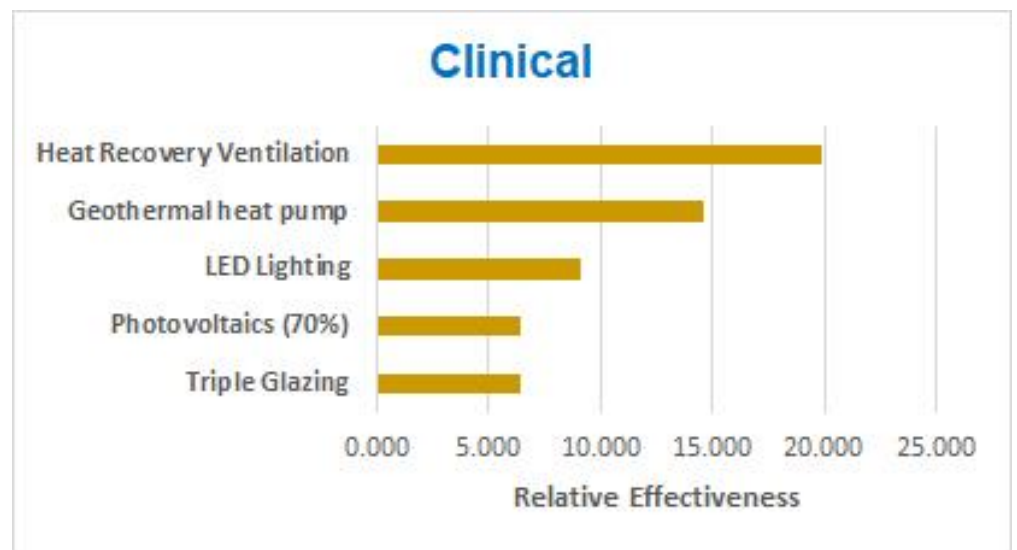

Figure 06_Comparison Proposed Improvements_Clinical

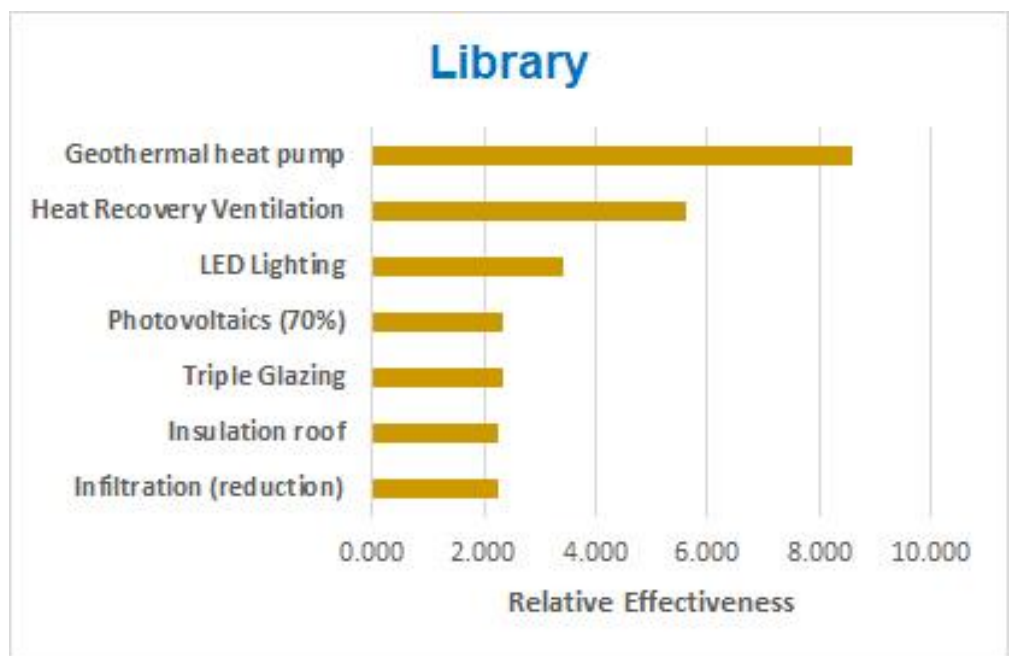

Figure 07_Comparison Proposed Improvements_Library 


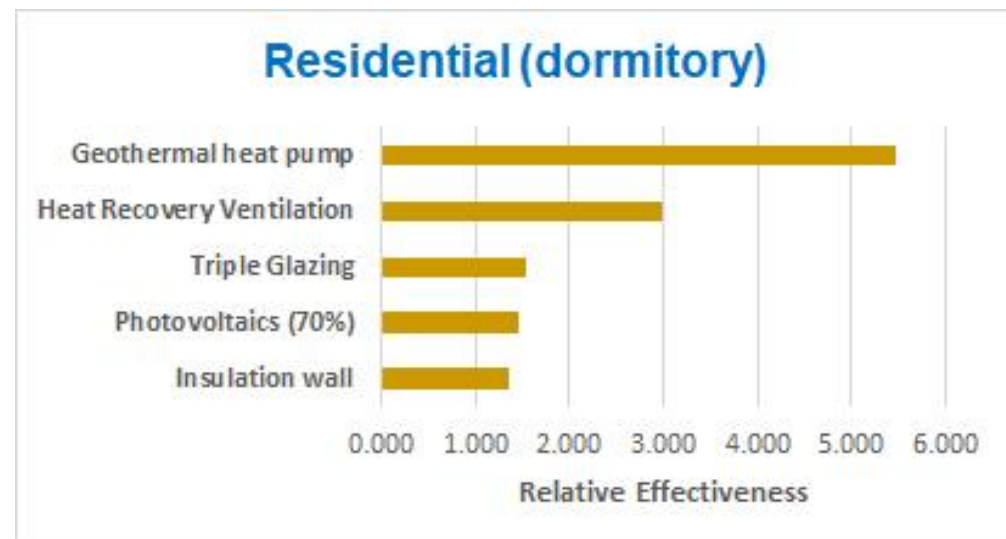

Figure 08_Comparison Proposed Improvements_Residential Low Rise

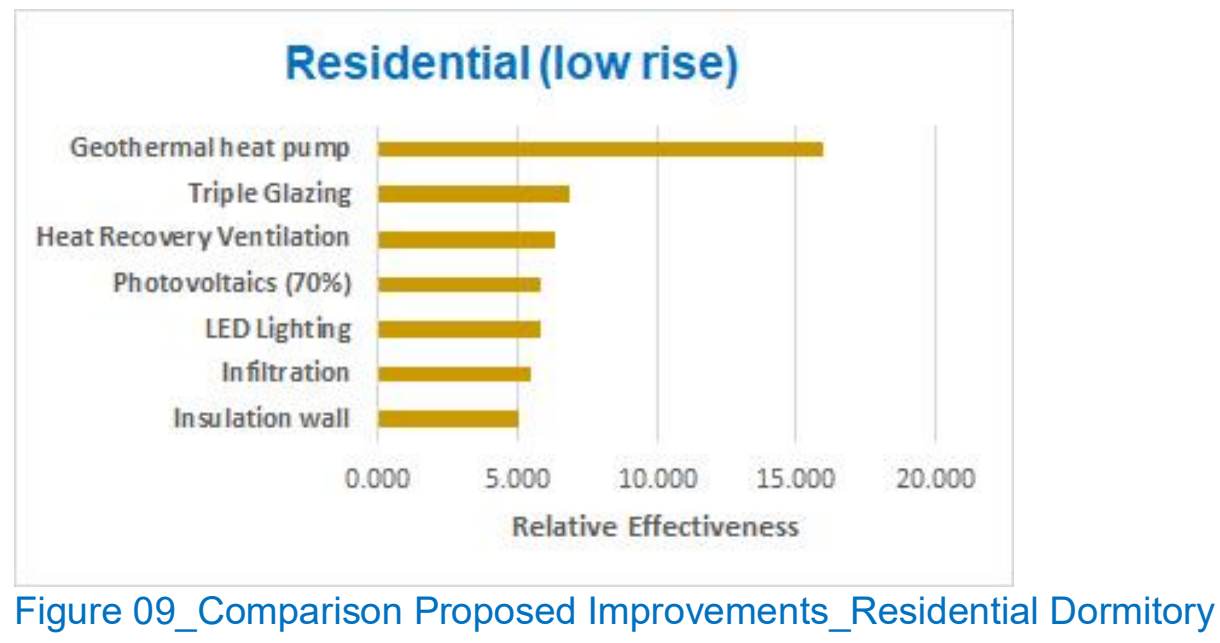

\section{Conclusion}

Overall, investments in building performance improvements provide an opportunity to significantly reduce operation costs and $\mathrm{CO}_{2} \mathrm{e}$ emissions. Improvements to technical systems, especially when integrated with the use of local renewable energy systems such as photovoltaics, offer additional opportunities to significantly reduce the emissions contributions of existing buildings. Specifically, we recommend further investigation into the viability of heat pump technologies to be implemented as a very important step toward a $\mathrm{CO}_{2} \mathrm{e}$ emissions neutral campus. The efficiencies (COP) of geothermal and groundwater source heat pump systems are extremely high and are cost competitive in the long term. Furthermore, the technical feasibility of groundwater well heat pumps needs further examination and geotechnical expertise. For residential buildings, we recommend a combined improvement to building envelopes coupled with the intensive use of ductless mini-split units and photovoltaics.

However, a net zero $\mathrm{CO}_{2} \mathrm{e}$ emissions campus cannot be achieved by revised building standards and aggressive building renovations alone. While building renovation improvements were found to be very effective, there are limitations to how far $\mathrm{CO}_{2} \mathrm{e}$ emissions can be reduced. Emissions offsets are necessary to achieve net zero emissions for existing buildings on all U-M campuses. The investigation into large scale renewable energy power generation is outside the scope of this analysis but is essential. Investments into research work that focuses on renewables and on 
optimized local electricity grid systems are needed to attain the vision of a net zero emissions university.

\section{Additional considerations: \\ $\mathrm{CO}_{2} \mathrm{e}$ Emissions Reductions through Changes to Occupancy Scheduling}

A comparison has been calculated with the operation costs and $\mathrm{CO}_{2} \mathrm{e}$ emissions of four educational buildings. The analysis compares buildings with a conventional use schedule and buildings with a shorter occupancy schedule as follows:

Conventional:

Weekday: $\quad 7 A M-10$ PM

Weekend: $\quad 9 A M-4$ PM

Reduced Schedule:

Weekday: $\quad 8 \mathrm{AM}-8 \mathrm{PM}$

Weekend: no operation

Reducing the daytime occupied hours of a building results in significant reductions in the overall $\mathrm{CO}_{2} \mathrm{e}$ emissions and costs for building operation. This improvement is an outcome of a reduced demand for conditioned air and dehumidification during summer months. Results demonstrate that reducing daily building operation hours effectively reduces $\mathrm{CO}_{2} \mathrm{e}$ emissions and building operation costs.

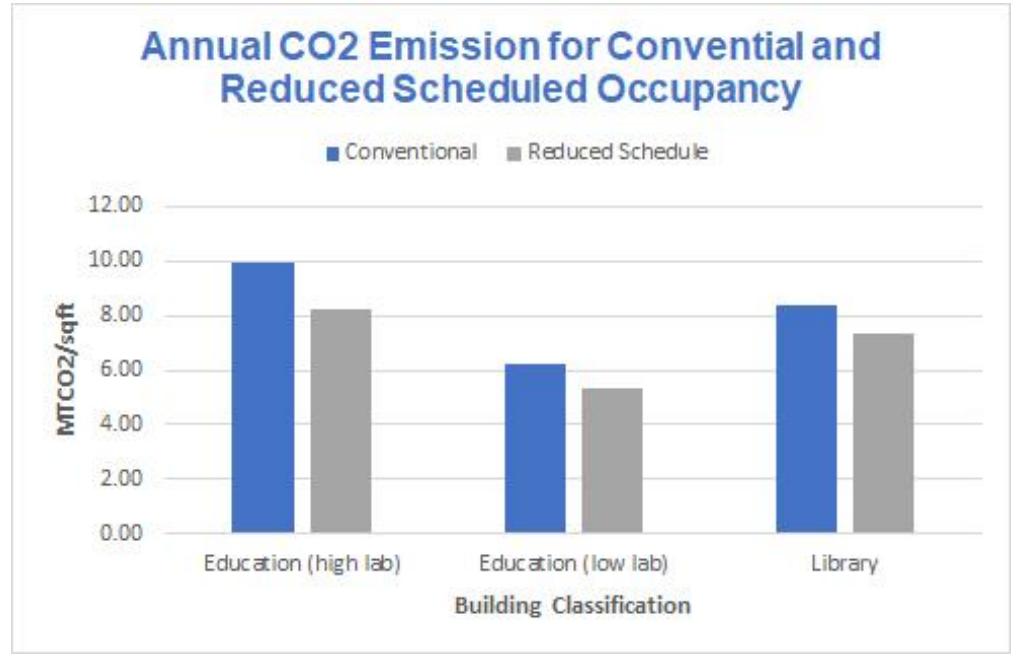

Figure 10_Existing Building Reduced Occupancy Potential

\section{Additional Considerations: Thermal Comfort and Occupant Behavior}

Beyond our emissions target recommendations, occupant behavior can be a significant influence on the actual energy performance of a new building. Designing for human comfort is therefore an important aspect of sustainability efforts. There are three categories of consideration to achieve high levels of comfort. These include thermal considerations, visual considerations, and acoustic considerations. Our simulations support the use of technologies and design strategies that will deliver a high degree of comfort while also reducing $\mathrm{CO}_{2} \mathrm{e}$ 
emissions. Thermal comfort is also defined in the internationally accepted building code ASHRAE 55 [55]. It includes requirements for the:

1. Air temperature

2. Radiant temperature

3. Relative humidity

4. Air velocity

In this study, all requirements of ASHRAE 55 for the thermal comfort will be fulfilled by the recommended solutions.

Building occupant behavior can reduce energy and economic savings potential even in high performance buildings by influencing operation and performance $[56,57,58]$. For example, the integration of smart sensors and user controls can have a positive impact on occupant comfort and energy savings. Integrated sensors and controls can help to identify when and where energy is used and when energy saving technology is underperforming or in need of maintenance [59]. Improved thermal comfort and air quality also have positive impacts on occupant health and well-being. In one example, employee sick days were found to have decreased by three days on average in an office setting designed with thermal comfort in mind [60].

The University of Michigan already has a range of educational activities underway that are aimed to support the reduction of energy use and greenhouse gas emissions. For example, the Office of Campus Sustainability website, urges occupants to disconnect lights and devices that are not in use as well as recommends a thermostat range of 68-76 degrees Fahrenheit, among other recommendations [61]. Researchers at the U-M Energy Institute have also been investigating the potential of embedding sensing and control devices as well as real-time energy monitoring and tracking. A 2012 article suggests that the U-M Energy Institute has/had at least one research project investigating "embedded sensing and control devices that respond to shifting exterior conditions and occupants' preferences" with respect to reducing building energy footprint [62]. Including these technologies that reduce occupant behavior caused discrepancies in projected energy savings in further "green" building code for the university is essential in achieving a carbon neutral goal.

Planet Blue also completed a 2019 research highlight on Erik Boyer and the Energy Management Program in which he states that the group is working on "a real-time energy monitoring and tracking tool for campus-wide utility data" [63]. Boyer notes that energy saving potential discrepancies can sometimes occur when just looking at campus utility bills. The Office of Campus Sustainability site for this research does have recommendations to turn off lights, to unplug devices while not in use, and to set a thermostat between 68 to 76 degrees Fahrenheit, but they lack building recommendations that go beyond these actions [64].

In conclusion, thermal comfort plays a significant role in occupant satisfaction in high performance buildings. Likewise, dissatisfaction can lead to occupant behaviors that are detrimental to the overall building performance as individuals act to correct their thermal discomfort by opening windows or adjusting thermostat temperatures [65]. The relationship between thermal comfort, occupant behavior and building performance is an active topic of research addressing questions including: 1) how to model and understand occupant behavior, 2) how to factor occupant behavior into design estimations of expected building energy consumption, and 3) which HVAC systems are best suited to provide thermal comfort and/or respond to occupant behavior to improve thermal comfort. This ongoing work is important and can be integrated or informed by work already underway at U-M to achieve the best possible performance outcome and provide excellent occupant satisfaction. 


\title{
APPENDIX E
}

Detailed Analysis: Priority \#3 Recommendation

New Construction: Water conservation and site design

\begin{abstract}
Water
Water management within urban contexts is undergoing a significant transformation toward approaches favoring integration and resource recovery. This paradigmatic shift has come to be recognized as the "One Water" approach. One Water promotes geographically contextual water management as a single resource to be managed holistically, viably, and sustainably. A One Water approach works from a watershed perspective to consider the inter-relationships between all waters running through it including drinking water, wastewater, stormwater, recycled water, aquifers, and rivers. One Water places a strong emphasis on recovering resources associated with water systems including water, energy, nutrients, and other materials as the most effective approach to integrated water management $[66,67]$. For a summary comparison of the shift from 19th- and early 20th-century urban water management approaches toward a One Water 21stcentury approach, see Daiger et al. 2019 [68].
\end{abstract}

This approach also makes a more explicit connection between energy and water. Energy can be recovered from flowing water, through thermal exchange and chemical processes (such as the use of organic matter). At the building scale, the recovery of thermal energy from discharged graywater is an underutilized opportunity. Sources of graywater tend to be heated water (showers, laundry) therefore temperatures typically range from $64^{\circ} \mathrm{F}$ to $100^{\circ} \mathrm{F}$ [69] which affords the opportunity for heat capture with heat exchange systems. Recovery potential varies yet has been demonstrated to reduce potable water heating energy consumption by up to $30 \%$ to $50 \%$ $[70,71,72,73]$. While beyond the scope of this report, additional energy recovery and generation opportunities exist if implemented at the scale of the campus or city. For a thorough review of emerging technologies identified as "enablers" of integrated One Water resource recovery systems, see Daiger et al. 2019 [74]. It should be noted that these systems are an active form of research and additional study of the system as well as on a case by case basis would be necessary to determine a more specific understanding of potential feasibility and opportunity.

High performance buildings typically focus on reducing a building's operational energy demand through improvements to a building's envelope and HVAC systems. Water delivery and treatment systems also consume energy and therefore contribute to a building's overall emissions footprint. Recent work at a national and local level have developed baseline estimates of water-related energy use in the United States [75] and Washtenaw County [76]. This work tracks the large amount of energy expended to supply, treat, and use water and links these energy expenditures to carbon dioxide emissions. For example, the River Network's research found that as of 2009, U.S. water-related energy use was at least 521 million MWh a year-equivalent to $13 \%$ of the nation's electricity consumption. They further linked energy consumption to emissions and estimated that the carbon footprint associated with distributing, treating, and heating water in the United States was at least 290 million metric tons a year at that time.

The Huron River Watershed's "The Carbon Footprint of Domestic Water Use in the Huron River Watershed" cites that $50 \%$ of the total energy consumed by the City of Ann Arbor goes to drinking water and wastewater treatment. This report offers additional data that situates the 
relationship between energy and water in the Huron River watershed including water delivery, water heating and wastewater treatment. For example, as of 2014, the overall energy intensity of drinking water in the Huron River watershed was calculated to be 2,580 kWh/MG [77]. Water consumed on the UM-Ann Arbor campus is provided through the City of Ann Arbor's water infrastructure. Using the general data available for the broader watershed offers a ballpark picture of the carbon dioxide emissions associated with water delivery. As of FY2019, U-M's Ann Arbor campus consumed 1,210,297,948 gallons of potable water which equates to 1,784 $\mathrm{MtCO}_{2} \mathrm{e}$ emissions.

The treatment of wastewater also consumes significant energy. Treatment levels vary across facilities which influences energy consumption metrics. Wastewater generated on the UM-Ann Arbor campus is treated by the City of Ann Arbor's wastewater treatment facility which utilizes advanced wastewater treatment processes that consume approximately 4,422 kWh/MG annually [78]. As of FY2019, U-M Ann Arbor's campus discharged 942,026,790 gallons of wastewater which equates to 2,380 $\mathrm{MtCO}_{2} \mathrm{e}$ emissions [79]. Currently, $\mathrm{CO}_{2} \mathrm{e}$ emissions driven by wastewater treatment are not included in U-M's annual calculations of total GHG emissions.

Given the energy demands driven by water systems, efforts to conserve water are both relevant from a scarcity perspective as well as an emissions reduction perspective. Water conservation measures include the use of low flow fixtures as well as reuse of graywater and rainwater. Graywater and rainwater recycling are quickly emerging as a viable pathway to promote the preservation of fresh water supplies, reduce energy consumption and reduce overall costs [80]. The following are recommendations of measures that can form the basis of updated building standards related to water conservation and reuse.

Recommendations for water conservation improvements

1. Revise water-efficient fixture specifications

Water efficiency technologies are generally designed to minimize the amount of water utilized to accomplish a task. Low flow devices are commonly implemented in new construction including fixtures for toilets, faucets, and showers.

U-M AEC Design guidelines currently specify water conservation compliance measures for all new construction as follows:

a. Incorporate water conservation measures that in aggregate use $20 \%$ less water than a baseline water use (not including irrigation) based on Energy Policy Act of 1992 fixture performance requirements (which are incorporated into the Michigan Plumbing Code).

b. Incorporate the following mandatory water conservation measures:

- Dual flush water closets;

- Waterless or 1/8 gallon per flush urinals; and

- 2 GPM shower heads.

c. Incorporate additional measures as required to meet the $20 \%$ water conservation target. (1/2 GPM aerators for lavatory faucets are required by the plumbing code and thus may not be used as a credit toward the $20 \%$ target.)

In comparison, the best performing university in our peer institution review regarding water use per person is The George Washington University. The design standards in place for 
new construction and major renovations specifies the following related to water conservation compliance measures [81]:

"When installed with accompanying aerators, flush valves and related components, target water consumption for new construction fixtures shall be as follows or as required by the local code, whichever is more stringent:

a. Toilets, residential/tank style: 1.28 gpf (Note that low flow water closets may not be reliable in buildings with older sanitary waste systems)

b. Toilets, commercial/wall-hung with flushometer: $1.28 \mathrm{gpf}$

c. Urinals: $0.125 \mathrm{gpf}$

d. Residential lavatory faucets: $0.5 \mathrm{gpm}$

e. Commercial lavatory faucets, metering: $0.5 \mathrm{gpm}$

f. Sink faucets: $1.5 \mathrm{gpm}$

g. Shower heads: $1.5 \mathrm{gpm} "$

2. Implement integrated rainwater collection and graywater reuse systems when feasible

Decentralized non-potable water (DNW) systems (on-site systems) can be implemented at a building or district scale. Several factors are driving increased demand for DNW systems including green building efforts, water conservation credits in LEED, reducing discharge demand to overburdened wastewater infrastructure, and the need to increase the reliability and resiliency of local water supplies. The integration of rainwater harvesting, and graywater reuse systems have been shown to offer water savings of $36 \%$ in houses and $42 \%$ in multistory residential buildings $[82,83]$. Residential buildings are typically understood to have greater water reuse potential due to the higher water rates associated with showers and domestic laundry. No national water quality or monitoring standards exist within the United States currently. Therefore, local jurisdictions are navigating the challenges of assessing risk and opportunities and often turn to regulations developed for centralized reuse systems that may not be scale appropriate.

Graywater systems typically reuse water for irrigation and/or toilet flushing. Accurately estimating and matching supply and demand is a key aspect of efficiently designed systems [84]. Collection systems require the separation of graywater sources (showers, lavatory sinks, laundry) from blackwater (toilets, kitchen water) and storage capacity. The 2015 International Plumbing Code (IPC) has been adopted by the State of Michigan and establishes requirements for on-site non-potable water reuse systems, section 1302 [85]. Allowable storage times and treatment requirements are associated with the intended end use. For a detailed look at treatment options and trade-offs for rainwater and graywater, see Leong et al. 2017 [86]. For the purposes of this report, additional materials (pipes, etc) necessary to implement these systems has not been analyzed in detail and would be a consideration to weigh during the schematic design and design development phases in order to evaluate total $\mathrm{CO}_{2} \mathrm{e}$ emissions reduction potential.

The cost implications of implementing integrated rainwater capture and graywater reuse systems are driven by the need to separate different water types, the selection of roofing materials and other surfaces that water interfaces with and by the addition of water storage tanks. An implementation project on the campus of Tecnológico de Monterrey, Mexico found that more than half of the total investment for a rainwater harvesting and graywater reuse system was associated with the water storage tanks [87]. Roof runoff typically provides the 
highest quality water for reuse; however, some roofing materials can significantly degrade the quality of stormwater. For a detailed analysis of concentrations of zinc, copper, and lead in roof runoff based on roof material type, see Committee on the Beneficial Use of Graywater and Stormwater 2016, Table 4-1-1 [88]. For a summary of costs associated with treatment strategies used in typical graywater systems, see Boyjoo et al. 2013 [89].

Currently, the State of Michigan does not have formal graywater regulations and treats graywater as septic. Other states provide models for permitting or regulating the reuse of graywater for irrigation and/or non-potable indoor reuse as either a tiered approach (Arizona, California, New Mexico, Oregon, Washington) or without a tiered approach (Florida, Georgia, Montana, Massachusetts, North Carolina, South Dakota, Texas, Utah, Virginia, Wisconsin, Wyoming) [90]. Regulations for graywater reuse vary by jurisdiction but treatment targets are a focus of ongoing research and established targets can be used to model practices that could be adopted at U-M [91]. Targets are influenced by water quality criteria established at a national level. In the United States, the National Science Foundation and the Environmental Protection Agency establish regulations governing criteria for domestic water standards [92].

Considerations from recent research regarding the consideration of the implementation of graywater systems that pertain to the potential integration of these systems at U-M includes further study on how graywater quality may be impacted by university specific occupancy and use characteristics in educational buildings.

3. Implement green roofs when feasible (and not in conflict with photovoltaics)

The integration of green roofs represents an alternate strategy to reduce stormwater discharge. In addition to water absorption, green roofs present other advantages to traditional roofing materials including:

- Mitigating urban heat island effect, via evapotranspiration

- Reducing sensible heat flux and decreasing the building's heating and cooling demands

- Enhancing biodiversity in urban areas

- Purifying air and water runoff

- Visually signifying commitment to and implementation of sustainability measures

Green roof water performance is influenced by the vegetation and design of the green roof, including differences between intensive and extensive systems [93]. Green roof design considerations such as vegetation root structure, roof slope, substrate depth, and building roof structural elements are key components of assessment analyses for performance modeling $[94,95]$. The moisture content of the soil substrate has been found to be a more significant influence on heat flux than evapotranspiration rates. Water-limited irrigation treatment was found to increase thermal insulation capacity and to reduce the total transferred heat energy by $25 \%$ to $71 \%$ depending on the season [96]. In this regard, substrate design can play a particularly important role from both water and energy perspectives. 


\section{APPENDIX F}

\section{Detailed Analysis: Priority \#4 Recommendation}

Potential partnership with City of Ann Arbor regarding net zero affordable housing

\section{Sustainable and Affordable Housing}

A study has been conducted to find sustainable and affordable solutions for residential building designs within U-M's cold climate region.

A zero net emissions residential building is very energy efficient and fully powered from renewable energy sources, resulting in an annual net total of zero $\mathrm{CO}_{2} \mathrm{e}$ emissions for building operations. Zero net emissions buildings require a high-performance building envelope, efficient HVAC technologies, and on-site renewable energy systems. The high-performance building envelope includes well-insulated triple glazing systems, increased R-values, and continuous airtight construction layers. The HVAC technologies include a mechanical ventilation system with heat recovery and an efficient heat pump. The renewable energy source is a photovoltaic system that collects solar radiation for electricity generation.

Designing an affordable zero net emissions building is not without its challenges. Several problem areas must be addressed for successful construction and operation of a zero net emissions building:

1. The high-performance building technology necessary for zero net emissions buildings is expensive. Insulation, triple glazing, and mechanical ventilation with heat recovery are examples of costly materials and technologies. Triple glazing with a well-insulated frame is currently only available in Europe, adding to monetary and $\mathrm{CO}_{2} \mathrm{e}$ emissions costs with the required overseas shipping.

2. The relationship between operation costs and $\mathrm{CO}_{2} \mathrm{e}$ emissions for building operation can be an issue. In most cases, the $\mathrm{CO}_{2} \mathrm{e}$ looking to reduce emissions and cost at the same time.

3. Currently, the relatively low energy cost in the United States (compared to other countries) reduces the economic feasibility for investments into sustainable technology.

4. A large burden for low-income households is the relatively high investment cost for improvements in the building envelope, installation of efficient systems, and use of renewable energy sources. The U.S. Department of Energy provides an economically feasible framework that outlines a maximal payback period of seven years. Even with the comparatively short payback period of seven years, the high investment cost is still a burden for low-income households.

This initial study found that affordable zero net emissions buildings are possible with today's technology. However, interdisciplinary research work is essential in achieving this important goal. A well-balanced solution is necessary for an ideal assessment of the building envelope, the technical system (HVAC), and the renewable energy system. The optimal solution should be applicable for sustainable and affordable new buildings and renovation projects. It should also be scalable and transferable to buildings outside of the U-M campus, including buildings in other climate zones. Future research in building technology should focus on the question of how to make zero net emissions building affordable for low-income and middle-class families.

The author of this study proposes the following strategies: 
1. Investigation of how expensive technologies for zero net emissions buildings can be substituted with cost-effective or affordable technologies. This strategy includes the development of glazing systems that can be produced locally (on-site) in place of importing expensive European glazing systems.

2. Development of a cost-effective localized ventilation control technology at the building envelope that replaces an expensive mechanical ventilation system with heat recovery. This form of technology has been successfully applied in office buildings by the author. The investment cost is reduced by approximately $30 \%$ compared to conventional highperformance building technologies.

3. Investigation into increasing internal thermal mass in buildings that conventionally do not have it (timber constructions). Internal thermal mass can reduce the energy demand for heating and cooling up to $30 \%$.

4. Introduction of cost-effective building automation systems (BAS) that predict occupancy levels, renewable energy availabilities, and capacities of thermal storage systems. The investment cost of these control systems is very low while the potential to reduce operational energy demand is high.

5. Use of innovative mini split units for heating in combination with photovoltaic systems. The combination of these technical systems is paving a pathway to fully electric buildings.

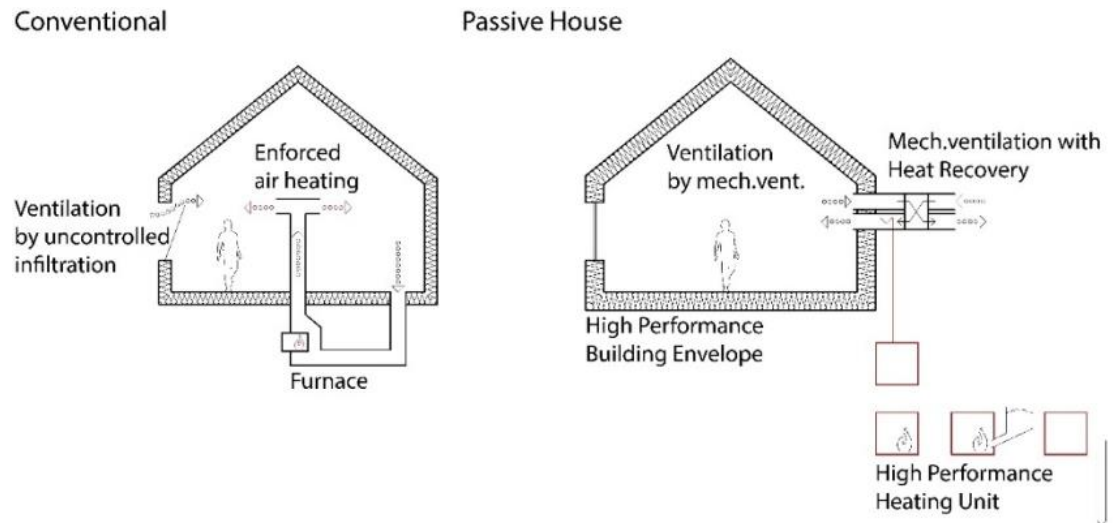

Proposed Technology

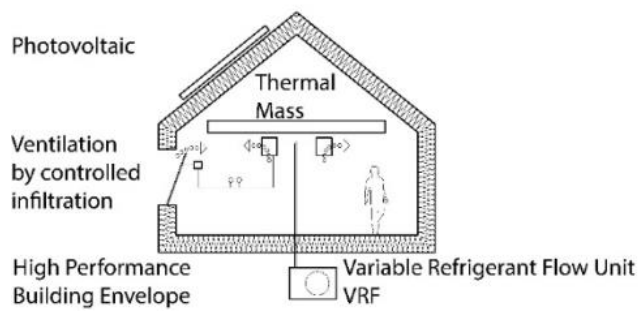

Figure 11_Proposed Technology Affordable Housing 


\section{APPENDIX G \\ Emerging Zero Codes Benchmarking}

\section{Overview}

Across North American building codes and metrics, there is broad support in adopting "zero codes." Some codes prioritize Net Zero Energy targets while others target Net Zero Carbon Dioxide Emissions including the consideration of embodied carbon metrics and carbon-free renewable energy sources. Given that buildings and building systems consume most of the energy on college campuses, an important step toward transitioning to a Net Zero Emissions strategy is to minimize the energy demand of buildings. This drastically reduces overall campus energy demand and enables the integration of emissions offsets, including renewable energy resources, to be less burdensome and more cost-effective. Therefore, minimizing U-M's $\mathrm{CO}_{2} \mathrm{e}$ emissions requires a focus on both energy efficient building design and transitioning to carbonfree renewable energy sources.

Reducing energy consumption is a very important contributor to reductions in GHG emissions, however, net zero energy buildings do not equate to net zero emissions buildings. Net Zero Energy buildings reach net zero consumption by using on-site renewables that equal the energy used by the building annually. In this equation, buildings consume a reduced amount of non-renewable energy and produce GHG emissions that are impacted by the energy mix consumed. To balance the equation, a building must produce or purchase an equal amount of energy using renewables. While the annual net calculation of energy consumption is balanced through these means, GHG emissions may not be. In contrast, Net Zero Emissions buildings require that the balancing equation center around the metrics of carbon dioxide emissions. In this case, the source mix of any energy consumed must be balanced by offsets. High performance building envelopes and systems are important contributors to net zero emissions solutions in addition to a broader consideration of their relationship to the energy infrastructures that serve them.

There are many emerging net zero energy and net zero emissions codes representing a range of metrics, targets and timeframes to reach "zero." For example, Clean Energy DC, Minnesota Sustainable Building Guidelines, and the ASHRAE 90.1 Standard are using Energy Use Intensity (EUI) targets to reach net zero energy goals by 2030 or later. Other examples include the AIA 2030 Zero Code, Net Zero Cambridge, the Zero Carbon Building Standard (Canada Green Building Council), and the City of Toronto Zero Emissions Buildings Framework. These are using a mix of EUI and carbon dioxide emissions targets. The Canadian codes are implementing zero carbon building techniques now, whereas Net Zero Cambridge outlines a plan stretching to 2040 for city-wide carbon reductions. The 2030 Challenge, widely incorporated into many of these codes, asks for fossil fuel reductions in all new buildings and major renovations of $70 \%$ in $2015,80 \%$ in $2020,90 \%$ in 2025 , and $100 \%$ (carbon neutral) in 2030. Designs must meet a fossil fuel, GHG-emitting, energy consumption performance standard of $60 \%$ below the building type's regional average through implementing innovative sustainable design strategies, generating on-site renewable power, or purchasing renewable energy ( $20 \%$ maximum). The zero codes are discussed in greater detail below. 

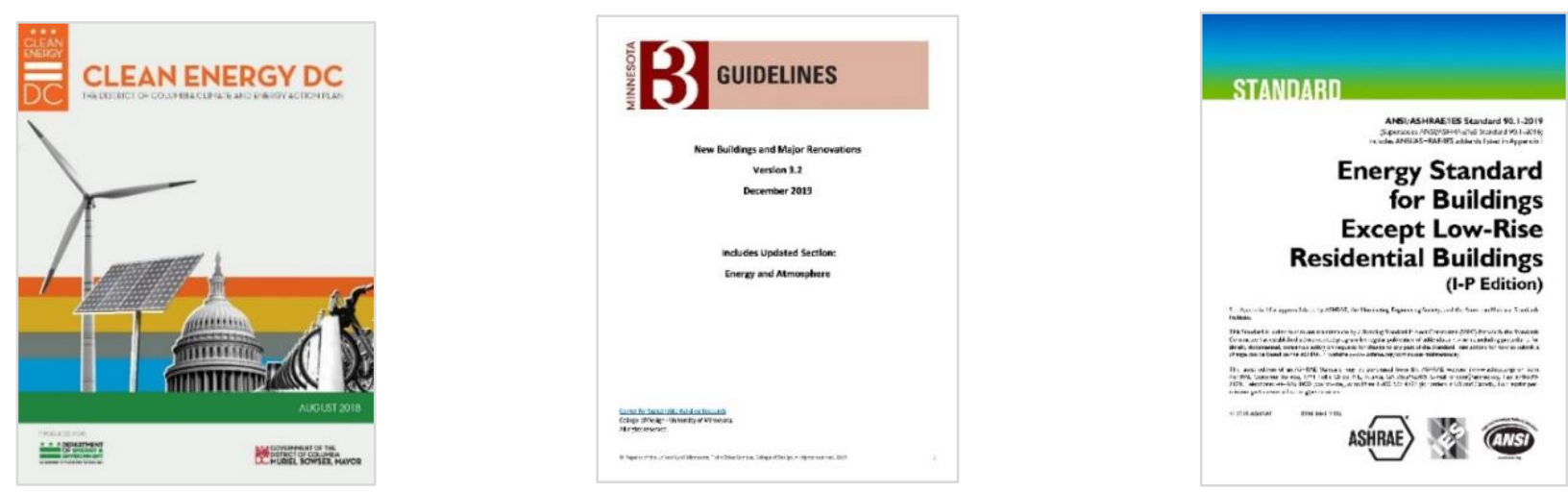

Clean Energy DC, adopted in 2018, merges ASHRAE Standard 90.1-2013 and Standard 189.1 codes for greater efficiency. The goal is to meet or exceed $50 \%$ reductions in GHG emissions by 2032 based on 2006 levels in the District of Columbia. Three major GHG sources that the plan targets are buildings, energy supply, and transportation. To address the building sector, the Clean Energy DC plan outlines Appendix Z. This is a voluntary, performance-based code compliance pathway that outlines energy efficient building with on-site and/or off-site renewable energy sources. The District Government must use EUI metrics to define compliance requirements and to track progress. A plan will be developed in 2020 that lays out actions to meet carbon neutrality goals by 2050 [97]. Additional codes include a Net Zero Code for Residential in 2020 and a Net Zero Code for Commercial in 2026.

The Minnesota Sustainable Building Guidelines (MSBG) work to increase overall energy efficiency and sustainability of buildings through using the Sustainable Buildings 2030 (SB 2030) energy standard (comparable to the Architecture 2030 Challenge). Adopted in 2001 and continuously updated, the MSBG code has evolved to incorporate an online tool that calculates EUI goals based on building type and occupancy among other factors. This tool allows for consistent application of energy reduction targets. SB 2030 is being applied to state funded buildings as a model for the move toward net zero carbon buildings by 2030 . They are more aggressive in their approach than the 2030 Challenge because they do not currently allow for off-site renewables to offset excess energy demand. In 2020, an updated Energy and Atmosphere guidelines will go into effect along with the increased SB 2030 energy goal of $80 \%$ reduction compared to the average 2003 baseline building [98]. New buildings should meet energy consumption reductions of $90 \%$ by 2025 .

ASHRAE Standard 90.1 is used to set minimum energy performance standards and energy codes. The ASHRAE Standards offer details and metrics for minimum energy efficiency requirements of most new and existing building types, except for low-rise residential buildings. Since its first adoption in 1989, ASHRAE Standard 90.1 has undergone seven revisions, each improving upon the last with more stringent energy efficiency requirements (Figure 01_ASHRAE Driving Towards Net Zero Graphic). The most recent version is Std. 90.1-2019, but many states are still operating on Std. 90.1-2007 or a less energy efficient code. U-M is already requiring $30 \%$ better than the statewide ASHRAE Standard 90.1-2013. If 90.1-2016 were to be adopted, the improvements in comparison with 90.1-2013 alone would not equal the standards already in place. Compared to 90.1-2013, new commercial buildings meeting 90.1-2016 requirements exhibit $8.3 \%$ energy cost savings, $7.9 \%$ source energy savings, and $6.8 \%$ site energy savings $[99,100]$. Furthermore, the categories of building type most prevalent on the U-M campus, such as office and hospital, show the smallest percentage improvements. Over the 90.1-2013, 90.1- 
2016, and 90.1-2019 versions of the ASHRAE standard, there have been minimal improvements to prescriptive path requirements with changes seen only in door and fenestration target metrics. To achieve the university's carbon neutrality goals, any new building standards to be adopted must exceed available ASHRAE standards.

Net Zero Carbon Dioxide Emissions
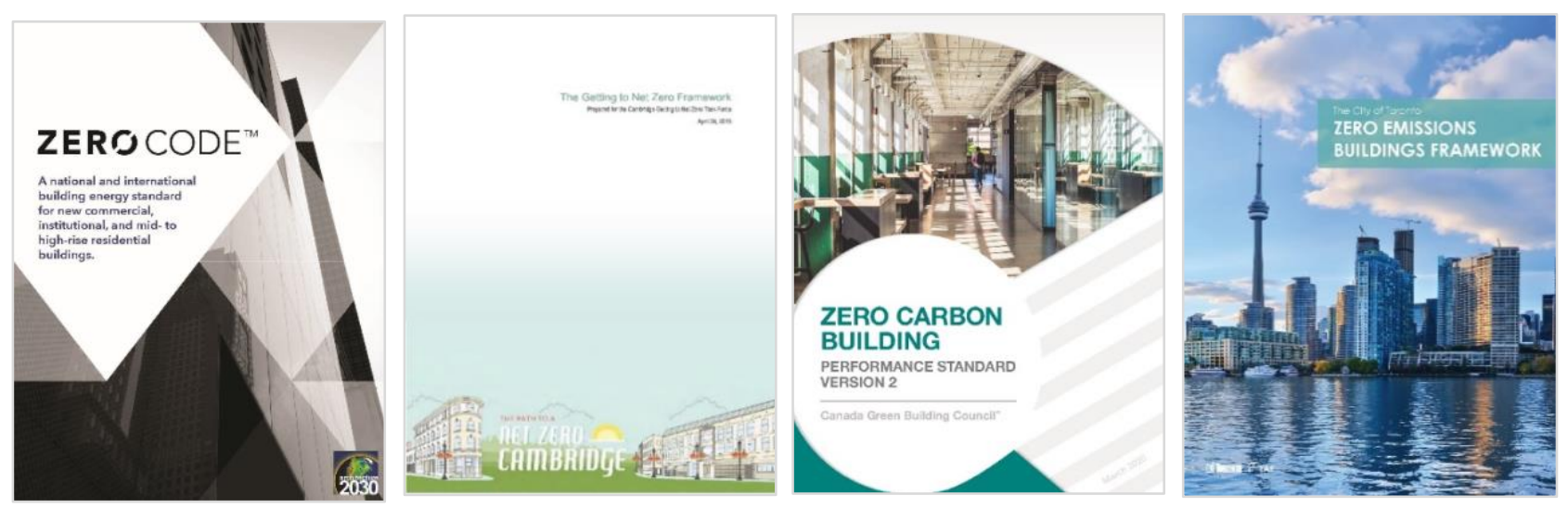

The AIA 2030 Zero Code, issued in 2018, targets Zero-Net-Carbon (ZNC) buildings through the integration of energy efficiency standards with on-site and/or off-site renewable energy. The AIA 2030 Zero Code is an appendix to the 2021 IECC that requires renewable energy sources (onsite if possible, with off-site also allowed) to meet annual net zero carbon building performance goals. Several different EUI metrics are used in the evaluation process. The code employs a prescriptive path to ensure minimum requirements as outlined in ASHRAE Standard 90.1-2016 are met for building energy efficiency with building envelope, HVAC, lighting, and equipment categories; and uses a performance path to model energy efficiency and determine if it meets or exceeds these minimum requirements. Then, on-site and off-site renewable energy needs are calculated to reach ZNC. The AIA 2030 Zero Code supports upgrades every three years along with changing the ASHRAE 90.1 compliance path as new versions are released.

Adopted in 2015, Net Zero Cambridge is one of the pioneering plans moving toward zero emissions. Because $80 \%$ of $\mathrm{GHG}$ emissions in Cambridge result from building operations, the city is targeting all GHG emissions produced through building operations to be offset by carbonfree energy production. The plan is centered around five actionable targets: energy efficiency in existing buildings, net zero standards for new construction, renewable energy supply, the establishment of a local carbon fund, and robust engagement and capacity building.

Renewables (on-site and off-site), offsets, and renewable energy credits (RECs, as a temporary measure) are allowed with this standard. The timeline reaches from 2015 to 2040, with a projected emissions reduction of $70 \%$ by that time. Cambridge will be positioned to achieve their goal of $80 \%$ community $\mathrm{GHG}$ reduction in 2050 , just by addressing the building sector $\mathrm{GHG}$ emissions.

The Zero Carbon Building Standard (Canadian Green Building Council) supports Canada's climate change commitments through assessing carbon use in new and existing buildings. This performance-focused standard uses carbon reductions as the key metric for evaluating building performance. The 2017 Zero Carbon Standard V1 required a zero carbon operational balance, and the 2020 Zero Carbon Standard V2 went a step further by incorporating life-cycle analysis of a building's embodied carbon. Standard V2 allows for carbon offset purchasing, raises energy 
efficiency requirements, and requires offsets for construction material embodied carbon. The Zero Carbon Building Standard offers a high level of flexibility with three pathway options provided to project teams. Option 1 provides the most flexibility by requiring thermal energy demand intensity (TEDI) of $30-40 \mathrm{kWh} / \mathrm{m}^{2} / \mathrm{yr}\left(10-13 \mathrm{kBtu} / \mathrm{ft}^{2} / \mathrm{yr}\right)$ and a site EUI of $25 \%$ better than the 2017 national code. Option 2 incorporates more passive design strategies and thus targets a TEDI of $20-30 \mathrm{kWh} / \mathrm{m}^{2} / \mathrm{yr}\left(6-10 \mathrm{kBtu} / \mathrm{ft}^{2} / \mathrm{yr}\right)$. Option 3 targets zero carbon without relying on purchased carbon offsets or RECs, requiring a TEDI of 30-40 kWh/m²/yr (10-13 $\mathrm{kBtu} / \mathrm{ft}^{2} / \mathrm{yr}$ ), renewable energy from owned assets, and significant energy-use reductions [101]. These options allow for working between different metrics (EUI, TEDI, embodied carbon, etc.) to make zero carbon building more feasible for many project teams.

The City of Toronto Zero Emissions Buildings Framework was instituted in 2017. This Zero Emissions plan builds upon the existing Toronto Green Standard (TGS) performance measures. Essentially, TGS has two versions of code. Version 1.0 was developed in 2010 and included Tier 1 (required) and Tier 2 (more stringent, voluntary). Version 2.0 came out in 2014 which raised standards higher for Tier 1 and Tier 2, and included Tiers 3 and 4 . Tier 4 targets are closest to zero-emissions level and promote shifting to electricity/renewable energy sources. Through these tiers, the framework establishes clear, stepped GHG and energy targets to meet the city's zero emissions goal by 2030 . Three primary metrics are used: Total Energy Use Intensity (EUI), Thermal Energy Demand Intensity (TEDI), and GHG Intensity (GHGI). EUI targets ensure higher efficiency buildings and lower utility costs; TEDI targets focus on better building envelopes, improved occupant comfort, and enhanced resilience; and GHGI targets guarantee low-carbon fuel choices and reduced building emissions [102]. These metrics are outlined for different building types, including Low-Rise Multi-Unit Residential Buildings, Office Buildings, and Mixed-Use buildings, which can all be found on U-M's campuses. 


\section{APPENDIX H \\ Peer Benchmarking}

Peer benchmarking provides an overview of how institutions across North America are undertaking efforts to improve building efficiency metrics on their campuses and, in some cases, implementing customized building standards toward these aims. Our initial peer benchmarking efforts examined information published on each institution's website. Data was collected from 43 universities defined as "peer" institutions for several reasons including Big Ten status, academic excellence as a private or public university or for known exemplary efforts in sustainable building standards.

\section{Sustainability Tracking Assessment and Rating System (STARS)}

After analyzing the peer institutions (selected as active, rated as gold or platinum and indicating hospital or medical facilities as part of their campus) participating in the Sustainability Tracking, Assessment and Rating System (STARS) from AASHE, it was found that the University of Michigan consists of more ground square footage (gsf) than any of the peer schools analyzed as of 2017 (with the exception of the conglomerate SUNY campuses). For energy consumption from buildings, the University of Michigan Ann Arbor consuming more total energy than any other peer institution analyzed. When adjusting for gross building square footage and considering the $\mathrm{CO}_{2}$ e emissions rates for the institutions compared, U-M places 9th out of 22 (Appendix M, Table 9 Peer Institutions Energy Comparisons STARS). An average EUI reduction per year column was added to identify schools either increasing or decreasing EUI at significant rates. Here, U-M performs better but it is still closer to the average of all schools analyzed.

Comparisons in water metrics reveal that of the 21 institutions with reported potable water use, the five institutions with the lowest potable water intensity per gross building square footage are 1) the University of Missouri (18.3 Gal/GSF), 2) University of Louisville (21.2 Gal/GSF), 3) Cornell University (22.6 Gal/GSF), 4) Princeton University (23.5 Gal/GSF), and 5) Indiana University- Purdue University Indianapolis (23.9 Gal/GSF) (Appendix M, Table 10 Peer Institutions Water Comparisons STARS). These institutions employ a variety of water and stormwater conservation strategies, including special emphasis on the reduction of potable water use in utility plants, grey water recycling, and the discontinuation of exterior power washing of buildings. The University of Michigan ranks 16th of the 21 peer institutions, with a potable water intensity of $34.74 \mathrm{Gal} / \mathrm{GSF}$.

\section{Life Cycle Costing}

Of the 42 peer institutions evaluated, 26 employ life cycle costing metrics rather than simple payback period when assessing the relative contributions of various building design strategies relative to the overall project cost [103]. Additionally, Duke University requires LCCA for water, energy and systems evaluations but does not require this as a university-wide policy and the University of Illinois Urbana-Champaign has an active proposal for LCCA requirements that is pending approval as of March 9, 2020. Furthermore, of the 26 institutions, Stanford University has employed life cycle metrics for the longest period (since at least 2011) as outlined in their Guidelines for Life Cycle Cost Analysis [104]. 
To facilitate this process, several institutions have developed calculators intended to facilitate decision making informed by the consideration of all present and future costs related to new construction, renovation, equipment replacement, or other up-front and ongoing expenditures. Two such examples include Harvard University's Life Cycle Costing policy and Calculator (which corresponds to ASTM Life Cycle Cost Analysis standards) [105] and the University of Virginia's Life Cycle Cost (LCC) Calculator [106] (based on Harvard's open source calculator). 


\section{APPENDIX I}

\section{Certifications Benchmarking}

\section{Leadership in Energy and Environmental Design (LEED)}

Leadership in Energy and Environmental Design (LEED) is the most extensively used green building rating system in North America. Developed by the U.S. Green Building Council (USGBC) in 1998, it has become a widely adopted certification program for new construction and major renovation projects, including at the University of Michigan which currently requires all new buildings and additions over $\$ 10$ million construction cost "to determine project-specific LEED certification requirements" [107]. (For a summary of recent U-M LEED projects and how their current energy performance and emissions compares to our recommended targets for new construction see Appendix M, Table $11 \mathrm{U}$ of M LEED Certified Buildings.) Although LEED is a nationally and internationally sought-after sustainability benchmark for the design, construction and operation of high-performance buildings, there is not a research-based consensus to validate this popularity [108].

Since its inception, LEED has undergone many revisions and has been regularly updated as versions including LEED-NC v2.0 in 2000, v2.1 in 2002, v2.2 in 2005, v3(v2009) in 2009, v4 in 2013, and v4.1 in 2019 [109]. Changes across versions make direct comparisons of the effectiveness of LEED certification challenging, yet the basic reference system is currently based on credit allocation across nine categories, including: Integrative Process; Location and Transportation; Sustainable Site; Water Efficiency; Energy and Atmosphere; Materials and Resources; Indoor Environmental Quality; Innovation and Regional Priority. Buildings gain certification through an evaluation process that awards points if requirements are met. The relative distribution of points per category also varies with building type. Strategies for "point chasing" easily achieved credits have emerged which can lead to an imbalance of emphasis across categories. In particular, the energy and atmosphere and material resources categories have a significantly lower credit achievement degree when compared with the others [110].

There is also a growing consensus indicating persistent and ongoing gaps between the predicted level of energy efficiency and the actual energy performance of LEED buildings $[111,112,113,114,115,116,117,118,119,120]$. A building's Energy Use Intensity (EUI) is the most common metric of operational energy performance used in these studies. The EUI $\left(\mathrm{kBtu} / \mathrm{ft}^{2}\right)$ is calculated by dividing a building's total annual energy usage (for all energy types) by the building's gross square footage. While there is value in establishing a comparative metric, there are also limitations inherent to the EUI as the choice metric. Limitations identified in the literature include not distinguishing between buildings with differing occupant density, usage patterns or process loads [121].

Furthermore, the majority of published studies evaluating LEED building performance focus on buildings' site EUI, as a result of more readily available data from utilities bills tracking the energy consumed by each building, rather than accounting for source energy which also includes accounting for off-site production, transmission and associated off-site losses $[122,123,124]$. Focusing on site EUI data yields a more specific understanding of an individual building's operational energy consumption and can be a meaningful basis of comparison if understanding operational energy is the intended goal. In contrast, source EUI expands the context of energy dynamics and allows for a greater understanding of greenhouse gas emissions as related to building operational energy consumption [125]. 
As it currently stands, the LEED v.4.1 Building Design and Construction framework devotes a maximum of 14 points out of 110 possible points to efforts that can be attributed to directly reducing carbon dioxide emissions reductions. Of these, only one is a required pathway that rewards between 1 and 5 points. Given this, it is both clear and imperative that the University of Michigan enact new building standards that more directly and impactfully target reductions in emissions.

Despite the need for standards that exceed what LEED certification delivers in terms of emissions reductions, the certification program may continue to play an important role at U-M for other reasons including national visibility and in accounting measures used by rating programs such as STARS.

\section{Living Building Challenge}

The Living Building Challenge (LBC) is a relatively new and strict certification system for green building with its top certification designating very high performance, regenerative buildings. Established in 2006 by the International Living Future Institute (ILFI), its scope and specifications differ greatly from LEED certification. As of 2019, there were 105 projects with some level of certification and over 500 registered as in progress. Of the campuses investigated as a comparison to University of Michigan standards, only one (Harvard University) documents that it uses LBC for university-wide benchmarks, but even in this case LEED-gold is also an acceptable certification, and Harvard currently has no projects registered with ILFI.

Since its beginning, there have been 4 versions of the LBC with v1.0 in 2006, v2.0 in 2009, v3.0 in 2014 , and v.4.0 in 2019. There are five levels of certification within LBC across four typologies of building scope. New buildings, existing buildings, interior projects and landscape or infrastructure projects can achieve Zero Carbon, Zero Energy, Core Green Building, Petal, or Living Certification, depending on which requirements are completed. LBC requirements do not specify best practices but rather actual performance-based goals which fall under the following seven categories, or "Petals": place, water, energy, health and happiness, materials, equity, and beauty. Within each Petal are "Imperatives," of which there are 20 that specify requirements that must be documented as reaching specific performance goals after the building has been in operation for at least 12 months. Some Imperatives detail performance-based goals, such as a certain percentage in energy use reduction compared to a baseline for a comparable project. Others, such as the Beauty and Biophilia Imperative, specify only that the project must document how it plans to achieve "deliberately incorporating nature's patterns," for example. The highest certification, Living Certification, requires documentation of all 20 Imperatives. The Petals contain unequal volumes of Imperatives, with the Materials Petal containing the highest at 5 total Imperatives. Twelve of the Imperatives are designated as Core Imperatives, and a project can reach Core Green Building certification if it achieves 10 Core Imperatives, with no more than two under each Petal. Projects are registered with a fee and certified by an ILFI auditor at the completion of the projects' 12 months of operation, suggesting that LBC represents little gap between predicted and performed EUI and other metrics.

Less than thirty buildings have received Living certification, one of which is a single-family residential home in Ann Arbor. There are eight total registered projects in the state of Michigan. Four of the Living certified buildings and three Petal certified buildings are attributed to American Universities. Smith College (Northampton, MA) and Hampshire College (Amherst, MA) have one and two Living certified projects, respectively, and Washington University in St. Louis (St. Louis, MO) has one Living certified field station. The University of Chicago (Chicago, 
IL), Williams College (Williamson, MA), and Berea College (Berea, KY). Cal State University Monterey Bay (Monterey Bay, CA), San Francisco State University (San Francisco, CA), and Williams College are all currently registered with the Living Community Challenge, which involves a larger scale project of infrastructure sharing between multiple buildings to hit all imperatives of the Living Building Challenge. The Georgia Institute of Technology (Atlanta, Georgia) and Vanderbilt University (Nashville, TN) have a project currently pursuing Living and Petal certification, respectively. Though not yet officially registered, Yale University (New Haven, $\mathrm{CT}$ ) has announced that it plans to build the largest academic LBC project and possibly a Living Community Challenge-certified campus through its Divinity School [126].

For the scope of the PCCN, the most pertinent parts of the LBC are the Zero Carbon certification as well as the Existing Buildings (renovation) construction/design typology. Zero Carbon requires $100 \%$ of the operational energy of the project to be offset by renewable energy, either on- or off-site along with a target reduction in embodied carbon and target level of energy efficiency. Carbon emissions related to project construction and materials must also be offset in addition to the operational carbon emissions. The specific goals for each of these metrics differ by typology, meaning that renovations are held to a different standard than completely new construction. This flexibility would help the challenge to be more applicable to U-M building standards, since the Flint and Dearborn campuses especially will be doing a lot of renovation of existing buildings in the coming years.

The main limitations of the LBC itself are, as the updated versions themselves mention, the standards can only require what the market can provide at the time of the standards' induction and therefore leaves less room for developing technology. The standards themselves are adaptable with feedback from projects, as the ILFI has a Dialogue function in which they take feedback from project partners to make smaller updates to the current versions. Though projects conform to the version they register for, building standards would need to be under annual review to agree with the most current LBC version.

The rigor of the LBC is what makes it a growing green building certification system but offers a sort of limitation in that aiming for true Living certification could be impractical for an institution such as the University of Michigan. However, the adaptability of different goals for different building typologies as well as the option of the less stringent Zero Carbon certification, for example, might provide more attainable implementation at the university's institutional level.

LBC standards indicate that the University of Michigan building standards must be much more holistic and based on actual performance. They also emphasize the importance of offset and acquisition of renewable energy.

(source to be formatted later-all of this is from the ILFI website though some is specifically from the publication of LBC v4.0 rather than the website itself)

\author{
Living Certified \\ Hampshire College (Amherst, MA)-has 2 \\ Smith College (Northampton, MA) \\ Washington University in St. Louis-Tyson Living Learning Center (field station)
}

\title{
Petal Certified
}

University of Chicago

Williams College (Williamson, MA)

Berea College (KY) 
Pursuing Living Community

Cal State University Monterey Bay is registered to be a living community (Vision Plan

Compliant)

SFSU

Williams College

\section{Pursuing Living}

Georgia Tech

\section{Pursuing Petal}

Vanderbilt

\section{Law Limitation}

Found a statement that some of the local laws can prohibit implementation of mandatory aspects of the LBC such as treating a building's own wastewater [127]. Did note that it was a very rural community, but the LBC says it should be able to be done anywhere.

\section{Material Limitation}

There is a "red list" of materials that cannot be used to build a project, but some of these are almost impossible to go without in certain markets, and so there is flexibility that they can be used as a last resort (and not an endorsement) with special documentation which makes certification more difficult [128].

\section{Strengths:}

- Stringent is good because we are in a state of climate emergency and this seems to be the way to a sustainable future of building

- Performance-based goals rather than a rating system close the gap between projected and actual EUI and carbon reductions, as we have seen is a growing problem, especially with human occupancy factors, etc. [129]

- Appears to be cheaper than LEED, which is good economically as well as for the issue we discussed of having the name brand of LEED without high performing buildings. (LBC I LEED)

- No optional credits prevent cutting corners

\section{Limitations:}

- Performance-based metrics rather than best practice checkboxes require a more creative design team

- Stringent can be bad because some of the certifications might just be beyond the scope of what is physically and economically feasible at some institutions (probably including U-M) no optional credits means no cutting corners means can be expensive and difficult

- Smaller/newer program means fewer examples and people to consult with? 


\section{APPENDIX J Emerging Building Materials and Technologies}

Several new and ongoing research efforts at the University of Michigan are contributing to the building sector. Innovative research by U-M faculty, staff, and students is essential to the improvement of sustainable buildings and overall campus emissions reductions. The following examples of work within the topics of High-Performance Building, Material Science, and Smart Grids have the potential for future involvement within U-M's built environment.

\section{High Performance Building and Building Automation}

\section{High Performance Building Science}

Associate Professor Lars Junghans

The research group of Lars Junghans is focused on the development of new types of net zero emissions high-performance buildings. Passive design strategies (envelope), efficient active systems (HVAC), innovative building automation systems, and renewable energy systems combine to form a holistic, optimized building concept. The goal is to provide technologies that are simultaneously sustainable, affordable, and applicable within all climate zones. A primary focus of the research is the integration of predictive control systems into buildings. Several buildings with these concepts have been realized and tested successfully. The building "22/26" in Austria (architect D.Eberle) is an award winning project that is perceived to be the building of the future by European experts [130]. https://taubmancollege.umich.edu/news/2015/03/06/junghans-presents-energy-optimizationaward-winning-2226

\section{Cyber-Physical Systems}

Professor Jerome P. Lynch

The research group of Prof. Lynch develops controllers and control algorithms that can be used for building automation systems. The controllers need a very small amount of energy and can be used as grid independent operating systems. Prof. Lynch's model predictive control algorithms hold great potential in contributing to highly efficient, "smart" buildings. Prof. Lynch also worked on Smart City technologies and can help to develop a local smart grid technology for the University of Michigan campus.

\section{Material Science and Engineering}

\section{Carbon Dioxide Sequestering Durable Concrete Thermal Adaptive Bendable Concrete for Thermal Mass Enhancement} Professor Victor C. Li

Prof. Li's research focuses on the development of concrete that has significantly less $\mathrm{CO}_{2} \mathrm{e}$ emissions through rethinking the most $\mathrm{CO}_{2} \mathrm{e}$-intensive conventional concrete ingredient: cement. His interdisciplinary team at the University of Michigan developed a way to mitigate the material's negative effects on the environment by using $\mathrm{CO}_{2} \mathrm{e}$ as a resource-capturing it, mineralizing it, and incorporating it into the composition and structural use of new smart fiber reinforced cementitious composites. Sequestering carbon, from cement or from a coal-based power generation plant, during the production of Engineered Cementitious Concrete (ECC) creates environmental advantages and increases long-term durability of structural applications. 
Prof. Li's research group is developing a range of products that are based on the new type of concrete, including a thermal adaptive bendable concrete and a brick system. These materials innovatively reduce the embodied energy of construction materials through their composition and through providing internal thermal mass, helping the industry to reach net zero carbon emissions buildings.

https://lowcarbonfuture.umich.edu, https://acemrl.engin.umich.edu

\section{High Efficiency Semi-Transparent Organic Photovoltaic Cells}

Professor Stephen Forrest

Prof. Forrest's research group worked on the development of highly-transparent, highly conductive photovoltaic elements that can be integrated onto glazing systems. As the window and glazing areas of contemporary buildings are relatively large, transparent photovoltaic elements can help increase the amount of renewable energy that is produced on-site without using additional space on the roof. This emerging technology is an incredible opportunity to incorporate on-site renewables into a net zero carbon emissions building design. Prof. Forrest's other research projects of note include Organic Light Emitting Diodes, Organic Energy and Charge Transport, and Organic and Inorganic Photovoltaic Cells. http://umich.edu/ ocm/

\section{Artificial Photosynthesis: $\mathrm{CO}_{2} \mathrm{e}$ Conversion}

Professor Zetian Mi

Prof. Mi's research group investigates semiconductor nanostructures within electronic, photonic, and solar energy systems. The team developed a new artificial photosynthesis approach that uses sunlight to turn $\mathrm{CO}_{2} \mathrm{e}$ into methane. With the capability of recycling smokestack $\mathrm{CO}_{2} \mathrm{e}$ into clean-burning fuel, even natural-gas-powered devices could be carbon neutral within the next decade. Prof. Mi's research on solar fuels will have the greatest impact on the transportation sector. This scalable carbon management solution will play an essential role in the future of climate mitigation policies. https://www.pnas.org/content/117/3/1330 https://news.umich.edu/green-methane-from-artificial-photosynthesis-could-recycle-co2/

\section{Smart Grid and Future Planning (University scale, local scale)}

\section{Downtime on the Microgrid: Architecture, Electricity, and Smart City Islands} Professor Malcolm McCullough

Prof. McCullough's book, Downtime on the Microgrid, takes a look at local resilience, the cultural role of urban infrastructure, and electrification of smart cities. His research draws the conclusion that island microgrids should be clustered together to provide intermittent connectivity for future resilience. https://mitpress.mit.edu/books/downtime-microgrid

\section{Solar Microgrid Feasibility Study for the City of Ann Arbor (2017) Multidisciplinary Team of U-M Students This team assessed the feasibility of solar microgrid installations at Ann Arbor city sites. The study results encouraged Ann Arbor to work with others in exploring community solar programs, landfill solar systems, and microgrid integration. \\ https://energy.umich.edu/research/publications/publication/solar-microgrid-feasibility-study-for- city-of-ann-arbor-2017/}


Scenario Planning for Cities and Regions: Managing and Envisioning Uncertain Futures Assistant Professor Rob Goodspeed

Asst. Prof. Goodspeed explains the effectiveness of scenario planning in preparing for multiple plausible futures. His book includes an overview of planning methods, simulation tools, case studies, and interconnected theories to promote community resilience in a time of uncertainty. https://www.lincolninst.edu/publications/books/scenario-planning-cities-regions

Other Initiatives:

Fastest Path to Zero

The Fastest Path to Zero is a team of interdisciplinary experts creating technology-neutral tools to help communities transform energy systems.

https://energy.umich.edu/research/fastest-path-to-zero/

\section{Global $\mathrm{CO}_{2} \mathrm{e}$ Initiative}

Director: Professor Volker Sick

The Global $\mathrm{CO}_{2} \mathrm{e}$ Initiative research aims to transform $\mathrm{CO}_{2} \mathrm{e}$ into commercially successful products through technology development and commercialization systems.

https://www.globalco2initiative.org/ 


\section{APPENDIX K}

\section{Dark Skies Initiative}

\section{Dark Skies Initiative as model for bridging culture, aesthetics, and metrics}

Just like air, water, and land pollution, light pollution is also an issue worldwide. Light pollution is the inappropriate and unnecessary use of artificial light that consequently creates negative effects for both the environment and human health. Research shows the impact of artificial light at night on plant and animal species can be extremely harmful and even deadly, while the adverse impact on human health includes increased risk of sleep disorders, obesity, depression, diabetes, and breast cancer. Additionally, studies show up to $50 \%$ of outdoor lighting is wasted, needlessly increasing GHG emissions. Both the University of Michigan Central Student Government and the Faculty Senate Assembly encourage U-M to comply with recommended best practices to minimize light pollution and associated negative effects.

The Dark Skies Initiative objectives are to promote energy efficiency, protect the natural environment from nighttime manmade light, and minimize light trespass, glare, and skyglow. This initiative would support larger university energy reduction efforts through preventing unnecessary nighttime light use. The goals of net zero carbon emissions building, and light pollution reduction align closely: they both seek to improve human health and well-being while eliminating excess GHG emissions. The summaries and excerpts from the Assembly Resolution 9-069 and Senate Assembly Resolution on Dark Skies documents below emphasize how the Dark Skies Initiative and proposed improved building standards can work in support of one another to reduce energy inefficiencies.

\section{Assembly Resolution 9-069: A Declarative and Directive Resolution Calling for the Reduction of Light Pollution by the University of Michigan \\ The University of Michigan Central Student Government}

The AR 9-069 document requests U-M to reduce their contribution to light pollution, pointing toward the 3,379 streetlights owned by U-M within Ann Arbor. The authors note that the globeshaped light fixtures emit light directly upwards into the sky, that blue-rich LEDs suppress production of melatonin and are thus harmful to human and wildlife circadian rhythms, and that poorly shielded LED lights can visually impair drivers. They recommend reducing on-campus light pollution through the following methods:

- "In future installations, use light fixtures with full cut-off shielding.

- Retrofit or replace existing lighting, especially globe lights, with full cut-off shielding.

- When replacing and installing light bulbs, use eco-friendly lighting with a correlated color temperature (CCT) of less than $3,000 \mathrm{~K}$ and a minimum color rendering index (CRI) of greater than 70 .

- Adhere to any future Ann Arbor Outdoor Lighting Ordinance that would apply to all exterior lighting, to minimize the adverse impacts of light pollution.

- Revise the existing Design Guidelines to adhere to lighting best practices as laid out by the International Dark Sky Association, with illumination levels no greater than recommended by The Lighting Handbook published by the Illumination Engineering Society of North America (IESNA)." 


\section{Senate Assembly Resolution on Dark Skies}

Faculty Senate Assembly

"Whereas some forms of night-time lighting impede public safety and are a serious environmental concern, corresponding to forms of lighting that are a nuisance and serve no useful purpose, and are therefore defined as light pollution;

Whereas, in particular, glare impedes visibility on roads and pedestrian walkways, creating a threat to roadway users, especially cyclists and pedestrians; and light trespass and skyglow disrupt human sleep cycles and are linked to multiple medical conditions;

Whereas artificial light at night is also a major threat to the environment because it disrupts the natural ecosystem and generates energy inefficiencies that contribute to climate change;

Whereas artificial light at night is also necessary to help ensure the safe performance of outdoor activities;

Therefore, in order to:

1. Minimize adverse impacts of light pollution in the form of light trespass, glare and skyglow;

2. Protect the natural environment from artificial light at night;

3. Promote energy efficiency;

4. Foster an environment that supports and/or enhances nighttime activities serving the University's missions in research, teaching, and service;

Be it resolved that the Faculty Senate Assembly encourages the University to comply with best practices for minimizing light pollution that are recommended by the International Dark Sky Association and the Illuminating Engineering Society, by revising the U-M Design Guidelines and mitigating existing sources of light pollution as soon as is feasible." 


\section{APPENDIX L}

Public Comments (as of 02/18/2020)

- $\quad$ Adopt stringent building standards (e.g., Passive House, Living Building, Architecture 2020)

- Source low carbon materials for construction/renovations

- Add living roofs, green roofs, or garden roofs to building design, especially new buildings

- Design all buildings to facilitate the inevitable switch to hot-water heating

- Stop building new buildings, use space more efficiently and consider how buildings can be repurposed

- Use carbon-neutral concrete

- More permeable surfaces

- Convert to all-electric grounds equipment

- Create an inventory of building space and scheduled construction

- Consider what a steady-state would look like in terms of U-M's footprint

- Work quickly to determine new building standards

- Build new buildings with sustainability measures in place so they don't have to be retrofitted down the line

- Regulate and limit light pollution

- U-M needs to create a 'model' project once the new standards are in place to show the community what a carbon-neutral building could look like, perhaps the new building in Detroit

- Ensure that donor influence does not stand in the way of sustainability standards

- Plant more trees and/or create a tree adoption program

- Build the new Clinical Inpatient Tower (CIT) to ensure its heating can be run by clean, sustainable energy 


\section{APPENDIX M Report Tables}

Table 00: Summary Matrix

\begin{tabular}{|c|c|c|c|c|c|c|}
\hline Priority & New/ Major Renovation (MR) & $\begin{array}{c}\mathrm{CO}_{2} \\
\text { (Reduction \%) }\end{array}$ & $\begin{array}{c}\mathrm{CO}_{2} \\
\left(\mathrm{MTCO}_{2} / \mathrm{yr}\right)\end{array}$ & $\begin{array}{c}\text { Financial Cost } \\
\text { (Relative \$) }\end{array}$ & Metrics & $\begin{array}{l}\text { Timeline } \\
\text { Factors }\end{array}$ \\
\hline 1 & NEW & $32.5 \%$ (average) & VARIABLE & $\begin{array}{c}\text { \$S - \$S\$S } \\
\text { (low admin - high clinical) }\end{array}$ & Dynamic modeling & $\begin{array}{l}\text { Time to develop and } \\
\text { implement }\end{array}$ \\
\hline 2 & MR & $55.5 \%$ (average) & 324,000 (total) & $\begin{array}{c}\text { \$S - \$\$\$\$ } \\
\text { (low library - high clinical) }\end{array}$ & Advanced metering & $\begin{array}{l}\text { Funding capacity, } \\
\text { implementation logistics }\end{array}$ \\
\hline 3 & NEW & $25 \%$ (average) & $446-1,041$ & $\begin{array}{c}\text { \$-\$S } \\
\text { (fixtures - rainwater harvest) }\end{array}$ & Advanced metering & $\begin{array}{l}\text { Funding capacity, } \\
\text { implementation logistics }\end{array}$ \\
\hline 4 & NEW & $100 \%$ & VARIABLE & $\begin{array}{c}\text { \$\$ } \\
\text { (long term savings in } \\
\text { operations) }\end{array}$ & Smart metering & $\begin{array}{l}5 \text { years from research to } \\
\text { implementation }\end{array}$ \\
\hline
\end{tabular}


Table 1: Existing Buildings Potential $\mathrm{CO}_{2}$ Reductions

Educational (no lab)

\begin{tabular}{lc}
\hline \hline $\begin{array}{l}\text { Initial } \\
\text { Envelope }\end{array}$ & $\begin{array}{c}\text { Potential Reduction \% } \\
\text { CO2 Emissions }\end{array}$ \\
\hline LOW & 48 \\
\hline MEDUUM & 44 \\
\hline HIGH & 35 \\
\hline
\end{tabular}

Educational (low load lab)

\begin{tabular}{lc}
\hline \hline $\begin{array}{l}\text { Inital } \\
\text { Envelope }\end{array}$ & $\begin{array}{c}\text { Potential Reduction \% } \\
\text { CO2 Emissions }\end{array}$ \\
\hline LOW & 35 \\
\hline MEDIUM & 11 \\
\hline HIGH & 4 \\
\hline
\end{tabular}

Educational (high load lab)

Initial Potental Reduction ?

Envelope Pot Emissions

LOW 25

\begin{tabular}{lc}
\hline MEN & 25 \\
\hline MIGH & 9 \\
\hline
\end{tabular}

Residential (low rise, duplex, single family)

\begin{tabular}{cc}
\hline $\begin{array}{c}\text { Initial } \\
\text { Envelope }\end{array}$ & $\begin{array}{c}\text { Potential Reduction \% } \\
\text { CO2 Emissions }\end{array}$ \\
\hline LOW & 85 \\
\hline MEDUM & 78 \\
\hline HIGH & 70 \\
\hline
\end{tabular}

Residential (dormitory)

Initial Potentlal Reduction \%

LOW 44

MEDUM 43

Library

Initial Potential Reduction \%

Envelope CO2 Emissions

\begin{tabular}{ll}
\hline LOW & 58 \\
\hline MEDUM & 55
\end{tabular}

\begin{tabular}{ll}
$\mathrm{HIGH}$ & 42 \\
\hline
\end{tabular}

Athletic

\begin{tabular}{lc}
\hline $\begin{array}{c}\text { Initial } \\
\text { Envelope }\end{array}$ & $\begin{array}{c}\text { Potential Reduction \% } \\
\text { CO2 Emissions }\end{array}$ \\
\hline LOW & 55 \\
\hline MEDUUM & 51 \\
\hline HIGH & 41
\end{tabular}

HIGH

Administrative

Initial Potential Reduction \%

Envelope CO2 Emissions:

LOW 60

\begin{tabular}{ll}
\hline MEDUM & 50 \\
\hline HIGH & 57 \\
\hline
\end{tabular}

Clinical

\begin{tabular}{lc}
\hline \hline $\begin{array}{c}\text { Initial } \\
\text { Envelope }\end{array}$ & $\begin{array}{c}\text { Potential Reduction \% } \\
\text { CO2 Emissions }\end{array}$ \\
\hline LOW & 56 \\
\hline MEDUUM & 55 \\
\hline HIGH & 44 \\
\hline
\end{tabular}


Table 02: Definition of Building Types

\begin{tabular}{|c|c|c|c|c|}
\hline & & & & $\begin{array}{c}\text { Table 403.3.1.1 } \\
2015 \text { MI Mechanical Code }\end{array}$ \\
\hline $\begin{array}{l}\text { Building Standards IAT } \\
\text { Proposed Building Types }\end{array}$ & $\begin{array}{l}2015 \text { MI Building Code, Section } 302 \\
\text { Use and Occupancy Classification }\end{array}$ & LEED v4.1 & Living Building Challenge & $\begin{array}{l}\text { Area outdoor airflow rate in breathing zone, } \\
\text { CFMsf }\end{array}$ \\
\hline $\begin{array}{l}\text { Athletic } \\
\text { Library }\end{array}$ & Assembly & & & Range: $0.06-0.48$ \\
\hline \multirow{4}{*}{$\begin{array}{c}\text { Administrative } \\
\text { Educational (no lab) } \\
\text { Educational (low load lab) * } \\
\text { Educational (high load lab) * }\end{array}$} & Business & Data Centers & Commercial & Range: 0.06 \\
\hline & Educational & Schools & & Range: $0.06-0.18$ \\
\hline & $\begin{array}{l}\text { Factory } \\
\text { Industrial }\end{array}$ & & & \\
\hline & High Hazard & & & \\
\hline \multirow[t]{2}{*}{ Clinical } & Institutional & Healthcare & $\begin{array}{c}\text { Institutional } \\
\text { Medical + Laboratory }\end{array}$ & \\
\hline & Mercantile & Retail & & \\
\hline \multirow[t]{3}{*}{$\begin{array}{l}\text { Residential (low rise, duplex, single family) } \\
\text { Residential (dormitory) }\end{array}$} & Residential & $\begin{array}{l}\text { Single Family Homes } \\
\text { Multifamily Homes }\end{array}$ & $\begin{array}{l}\text { Single Family Homes } \\
\text { Multifamily Homes }\end{array}$ & Range: 0.06 \\
\hline & Storage & $\begin{array}{l}\text { Warehouses } \\
\text { Distribution Centers }\end{array}$ & & Range: 0.06 \\
\hline & $\begin{array}{l}\text { Utility } \\
\text { Miscellaneous }\end{array}$ & $\begin{array}{l}\text { New Construction } \\
\text { Major Renovation }\end{array}$ & & \\
\hline
\end{tabular}

- Educational occupancy is defined by the Michigan building code to include grades K-12 only. Higher education is classified under business occupancy. 
Table 03: New Construction Recommended Emissions Targets

Based on University of Michigan Ann Arbor Campus

Recommended Maximum Emissions Targets by Building Type

\begin{tabular}{|c|c|c|c|c|c|c|c|c|c|c|}
\hline \multicolumn{11}{|l|}{ U-M Buildings } \\
\hline Classification & & $\begin{array}{l}\text { Educational Building } \\
\text { (no lab) }\end{array}$ & $\begin{array}{l}\text { Educational Building } \\
\text { (low load lab) }\end{array}$ & $\begin{array}{l}\text { Educational Building } \\
\text { (high load lab) }\end{array}$ & Library & Clinical & $\begin{array}{l}\text { Residential } \\
\text { (dormitory) }\end{array}$ & $\begin{array}{c}\text { Residential } \\
\text { (low rise, duplex, } \\
\text { single family) }\end{array}$ & Administrative & $\begin{array}{c}\text { Athletic } \\
\text { (excluding } \\
\text { natatoria) }\end{array}$ \\
\hline \multicolumn{11}{|l|}{ ASHRAE 90.12013} \\
\hline Carbon Dioxide Emission & $\mathrm{kg}$ CO2/sqfit & 14.0 & 21.0 & 28.0 & 7.5 & 19.0 & 7.9 & 4.5 & 15.0 & 7.0 \\
\hline \multicolumn{11}{|l|}{ Recommended Goal } \\
\hline Carbon Dioxide Emission & $\mathrm{kg}$ CO2/sqft & 10.0 & 16.0 & 21.0 & 6.0 & 15.0 & 5.2 & 1.0 & 10.0 & 5.0 \\
\hline $\begin{array}{l}\text { \% reduction from } \\
\text { ASHRAE } 90.12013\end{array}$ & & $28.6 \%$ & $23.8 \%$ & $25.0 \%$ & $20.0 \%$ & $21.1 \%$ & $34.2 \%$ & $77.8 \%$ & $33.3 \%$ & $28.6 \%$ \\
\hline
\end{tabular}


Table 04: Existing Building Emissions by Funding Category

\section{Building Energy Consumption and Emission Contributions by Funding Category FY19}

\begin{tabular}{|c|c|c|c|c|c|c|c|}
\hline Funding Category & $\begin{array}{c}\text { Total Gross } \\
\text { SF }\end{array}$ & $\begin{array}{l}\text { Average EUI } \\
\text { (kBtu/sf/yr) }\end{array}$ & $\begin{array}{c}\text { Max EUI } \\
\text { (kBtu/sf/yr) }\end{array}$ & Total MTCO2 & $\mathrm{kgCO}_{2} / \mathrm{sf}$ & $\begin{array}{l}\% \text { of Total } \\
\text { Gross SF }\end{array}$ & $\begin{array}{c}\% \text { of Total } \\
\text { M TCO2 } \\
\text { contribution }\end{array}$ \\
\hline Athletics & $1,908,895$ & 111 & 482 & 17,868 & 9.4 & $5 \%$ & $3 \%$ \\
\hline Auxiliary & 981,701 & 423 & 4,729 & 14,396 & 14.7 & $3 \%$ & $2 \%$ \\
\hline General Fund & $15,546,902$ & 160 & 691 & 273,726 & 17.6 & $41 \%$ & $47 \%$ \\
\hline Leased Property & 261,126 & 59 & 103 & 2,186 & 8.4 & $1 \%$ & $0 \%$ \\
\hline MI Medicine & $7,316,223$ & 163 & 1,194 & 170,108 & 23.3 & $20 \%$ & $29 \%$ \\
\hline Other & $2,280,700$ & 174 & 367 & 62,741 & 27.5 & $6 \%$ & $11 \%$ \\
\hline Parking & $3,840,812$ & 9 & 34 & 4,159 & 1.1 & $10 \%$ & $1 \%$ \\
\hline Student Life & $5,371,792$ & 90 & 201 & 38,242 & 7.1 & $14 \%$ & $7 \%$ \\
\hline Total & $37,508,151$ & 148 & 4,729 & 583,426 & 15.6 & $100 \%$ & $100 \%$ \\
\hline
\end{tabular}


Table 05: Estimated Initial Cost per $\mathrm{MTCO}_{2}$ Emissions Reductions

\section{$\left(\$ / \mathrm{MTCO}_{2}\right)$}

\begin{tabular}{ccc}
\hline \multirow{2}{*}{ Payback Years } & \multicolumn{2}{c}{ Initial Cost } \\
\cline { 2 - 3 } & Low & High \\
\hline 5 & $4,433.81$ & $15,206.73$ \\
\hline 10 & $2,216.90$ & $7,603.37$ \\
\hline 15 & $1,477.94$ & $5,068.91$ \\
\hline 20 & $1,108.45$ & $3,801.68$ \\
\hline 25 & 886.76 & $3,041.35$ \\
\hline 30 & 738.97 & $2,534.46$ \\
\hline 35 & 633.40 & $2,172.39$ \\
\hline 40 & 554.23 & $1,900.84$ \\
\hline 45 & 492.65 & $1,689.64$ \\
\hline 50 & 443.38 & $1,520.67$ \\
\hline & & \\
\hline
\end{tabular}


Table 6: Estimated Costs to Achieve Net Zero Emission in an Educational Building Estimates by Technology Options (excluding building envelope)

\begin{tabular}{|c|c|c|c|c|c|}
\hline HVAC Options & & Baseline & Geothermal & Groundwater Well & $\begin{array}{c}\text { Variable Refrigerant } \\
\text { Flow (VRF) }\end{array}$ \\
\hline Coefficient of Performance (COP) & - & 0.92 & 5.3 & 5.3 & 2.4 \\
\hline \multicolumn{6}{|l|}{ Heating } \\
\hline Intial Cost & $\$ / s f$ & 0.00 & 18.19 & 11.45 & 11.90 \\
\hline \multicolumn{6}{|l|}{ Cooling } \\
\hline Initial Cost & $\$ / s f$ & 0.00 & 4.07 & 4.07 & 0.00 \\
\hline \multicolumn{6}{|l|}{ CO2 Emission } \\
\hline Carbon Dioxide Emission & $\mathrm{kg} \mathrm{CO} 2 / \mathrm{sf}$ & 14.04 & 4.10 & 4.10 & 8.04 \\
\hline \multicolumn{6}{|l|}{ Photovoltaic (PV) } \\
\hline required to offset $\mathrm{CO}_{2}$ & $\$ / s f$ & $1,225.83$ & 357.97 & 357.97 & 701.97 \\
\hline \multicolumn{6}{|l|}{ Heating + Cooling + PV } \\
\hline Total Initial Cost & $\$ / s f$ & $1,239.87$ & 384.33 & 377.59 & 721.91 \\
\hline
\end{tabular}


Table 07: Itemized Estimated Costs for $\mathrm{CO}_{2}$ Emissions Reductions Cost per $\mathrm{MTCO}_{2}$ Emission Reduction $\left(\$ / \mathrm{MTCO}_{2}\right)$

\begin{tabular}{|c|c|c|c|c|c|c|c|c|c|c|c|}
\hline Payback Period & 1 & 5 & 10 & 15 & 20 & 25 & 30 & 35 & 40 & 45 & 50 \\
\hline \multicolumn{12}{|l|}{ Improvements } \\
\hline DOAS 1 (Heat Recovery) & 70,838 & 14,092 & 6,998 & 4,634 & 3,452 & 2,742 & 2,269 & 1,932 & 1,678 & 1,481 & 1,324 \\
\hline DOAS 2 (Heat Recovery + radiant) & 47,293 & 9,386 & 4,647 & 3,068 & 2,278 & 1,804 & 1,488 & 1,262 & 1,093 & 962 & 856 \\
\hline VRF (air) & 47,045 & 9,405 & 4,700 & 3,132 & 2,348 & 1,877 & 1,564 & 1,339 & 1,171 & 1,041 & 936 \\
\hline Heat Pump (geothermal loop) & 28,986 & 5,779 & 2,878 & 1,912 & 1,428 & 1,138 & 945 & 806 & 703 & 622 & 558 \\
\hline Heat Pump (geothermal well) & 28,309 & 5,644 & 2,811 & 1,866 & 1,394 & 1,111 & 922 & 787 & 686 & 607 & 544 \\
\hline Triple glazing & 94,097 & 18,723 & 9,303 & 6,163 & 4,593 & 3,651 & 3,023 & 2,575 & 2,239 & 1,977 & 1,768 \\
\hline Photovoltaic & 18,422 & 3,569 & 1,712 & 1,093 & 784 & 598 & 474 & 386 & 320 & 268 & 227 \\
\hline LED & 140,869 & 28,049 & 13,946 & 9,245 & 6,895 & 5,484 & 4,544 & 3,873 & 3,369 & 2,977 & 2,664 \\
\hline
\end{tabular}


Table 08: Renovation Project Cost Ranges

Cost Ranges provided by $U$ of $M A E C$

\begin{tabular}{lccc}
\hline \multirow{2}{*}{ Building Classification } & \multicolumn{3}{c}{ Renovation } \\
\cline { 2 - 4 } & Low (\$/sf) & Ave $(\$ / s f)$ & High $(\$ /$ sf) \\
\hline Educational (no lab) & 255.00 & 517.00 & 778.00 \\
\hline Educational (wet laboratory) & 354.00 & 670.00 & 986.00 \\
\hline Educational (dry laboratory) & 226.00 & 526.00 & 825.00 \\
\hline Residential & 225.00 & 433.00 & 623.00 \\
\hline Administrative & 255.00 & 517.00 & 778.00 \\
\hline
\end{tabular}


Table 9: Peer Institutions Energy Comparisons STARS

North American Peer Institutions Current and Target Energy and Emissions

\begin{tabular}{|c|c|c|c|c|c|c|c|c|c|}
\hline & & & & & $\begin{array}{c}\text { Energy } \\
\text { Eulding Enerpy } \\
\text { Consumpscoin }\end{array}$ & & $\begin{array}{l}\text { Bulidings } \\
\text { Bulloting Destond and } \\
\text { Construction }\end{array}$ & & \\
\hline & & & & & STAPS & & STARS & & \\
\hline Peor institution & state & BA Clumate Zone & $\begin{array}{l}\text { IECC chimate } \\
\text { Zone }\end{array}$ & $\begin{array}{l}\text { IECC Moisture } \\
\text { Regime }\end{array}$ & $\begin{array}{l}\text { Total Buildings Cross } \\
\text { SF }\end{array}$ & $\begin{array}{l}\text { N growth over } 5 \\
\text { years }\end{array}$ & $\begin{array}{l}\text { Nof nowiy } \\
\text { constructed space } \\
\text { achieving } \\
\text { cerrufication }\end{array}$ & $\begin{array}{l}\text { S. Builaing Space } \\
\text { Dosignated as } \\
\text { Energy Intensive }\end{array}$ & $\begin{array}{c}\begin{array}{c}\text { EUI } \\
\text { (Btugsf) }\end{array}\end{array}$ \\
\hline Wake Forest University & NC & Mixed-Humid & 4 & A & $4,993.280$ & $13 \%$ & $53 \%$ & $1 \%$ & 10970 \\
\hline Univessive of Texas at Austin & Tx & Hot-Humia & 2 & A & $27,581,956$ & $6 \%$ & $98 \%$ & $6 \%$ & 73.54 \\
\hline Unverativ at connecticut & ст & coild & 5 & A & $10,873,545$ & $9 \%$ & $87 \%$ & $5 \%$ & 168.05 \\
\hline Pennsyvania State University & $P A$ & cold & 5 & A & $20,886,526$ & $4 \%$ & $100 \%$ & $7 \%$ & 136.02 \\
\hline Universic or Mami & FL & Hot-Humia & 1 & A & 9.936 .736 & $6 \%$ & $76 \%$ & $6 \%$ & 81.35 \\
\hline University of Lovisville & $\mathrm{kr}$ & Mixed-Humid & 4 & A & 9,963,269 & $8 \%$ & $100 \%$ & $9 \%$ & 76.29 \\
\hline George Wastinoton Universty & $D C$ & Mixed-Humid & 4 & A & $8,614,351$ & $30 \%$ & $67 \%$ & $10 \%$ & 118.73 \\
\hline Yase Unversity & ст & cold & 5 & A & $16,075,327$ & $24 \%$ & $10 \%$ & $6 \%$ & 230.58 \\
\hline Universicu of Michioan & Mi & cold & 5 & A & $36,946,998$ & $8 \%$ & $36 \%$ & $13 \%$ & 189.84 \\
\hline comell Unversing & NY & cold & 6 & A & $15,873,205$ & $6 \%$ & $100 \%$ & $12 \%$ & 209.04 \\
\hline Unversity of Atzona & $A Z$ & Hot-Dry & 2 & в & $14,721,402$ & $12 \%$ & $58 \%$ & $14 \%$ & 203.10 \\
\hline 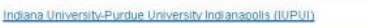 & IN & cold & 5 & A & $12,121,613$ & $5 \%$ & $100 \%$ & $9 \%$ & 15561 \\
\hline Universily of Nath Carchna at Chapei itill & NC & Mixed-Humid & 4 & A & $18,943,498$ & $4 \%$ & $55 \%$ & $16 \%$ & 18684 \\
\hline Unversic of penos weania & $P A$ & Mixed-Humia & 4 & A & $15,864,661$ & $14 \%$ & $100 \%$ & $24 \%$ & 169.52 \\
\hline Unversity of Missoun & мо & Mixed-Hunid & 4 & A & $14,415,671$ & $2 \%$ & $71 \%$ & $22 \%$ & 196.51 \\
\hline Colorado State University & $\infty$ & cold & 5 & B & $12,359,438$ & $13 \%$ & $96 \%$ & $20 \%$ & 137.52 \\
\hline Unversitv of calltomia San oleag & $C A$ & Marine & 3 & c & $20,956,546$ & $18 \%$ & $100 \%$ & $34 \%$ & 150.38 \\
\hline Eman vaniverain & GA & Mixed-Hunid & 3 & A & $10,641,529$ & $15 \%$ & $57 \%$ & $34 \%$ & 17588 \\
\hline The onio state Unversitiv & $\mathrm{OH}$ & cold & 5 & A & $24,895,053$ & $10 \%$ & $90 \%$ & $38 \%$ & 194.70 \\
\hline Universily of Viminia & VA & Mixed-Humid & 4 & A & $17,078,000$ & $13 \%$ & $100 \%$ & $36 \%$ & 25051 \\
\hline erencetan Universin & NJ & cold & 5 & A & $9,232,747$ & $15 \%$ & $0 \%$ & अ\% & 168.95 \\
\hline virima Tech & VA & Mixed-Humid & 4 & A & $10,140,464$ & $10 \%$ & $100 \%$ & $16 \%$ & 20219 \\
\hline
\end{tabular}




\begin{tabular}{|c|c|c|}
\hline $\begin{array}{l}\text { S Increase or } \\
\text { Decrease } \\
\text { (Performance } \\
\text { compared to } \\
\text { Easetine) }\end{array}$ & $\mathrm{MrCO}_{2}$ & MTCO $/ \mathrm{st}$ \\
\hline$-15 \%$ & 52,062 & 0.0104 \\
\hline 565 & 300,700 & 0.0109 \\
\hline -195 & 124,342 & 0.0114 \\
\hline $.22 x$ & 241,427 & 0.0116 \\
\hline -115 & 116,777 & 0.0118 \\
\hline $47 \%$ & 119.622 & 0.0120 \\
\hline $8 \%$ & 109,340 & 0.0120 \\
\hline 214 & 198,322 & 0.0123 \\
\hline $21 \%$ & 470,207 & 0.0127 \\
\hline $11 \%$ & 202,240 & 0.0127 \\
\hline $43 \%$ & 188,614 & 0.0128 \\
\hline 78 & 166,716 & 0.0138 \\
\hline $24 \mathrm{k}$ & 263.662 & 0.0139 \\
\hline os & 236.519 & 0.0148 \\
\hline$-17 \%$ & 217.966 & 0.0151 \\
\hline-185 & 192,690 & 0.0156 \\
\hline 59. & 357,629 & 0.0171 \\
\hline $25 \mathrm{~K}$ & 181.868 & 0.0171 \\
\hline $.17 \%$ & 437,998 & 0.0176 \\
\hline $14 \mathrm{~s}$ & ${ }^{303,027}$ & 0.0177 \\
\hline$-19 \%$ & 172,159 & 0.0186 \\
\hline os & 286,458 & 0.0282 \\
\hline
\end{tabular}


Table 10: Peer Institutions Water Comparisons STARS

North American Peer Institutions Current and Target Energy and Emissions

\begin{tabular}{|c|c|c|c|c|c|c|c|c|}
\hline & & & & & $\begin{array}{c}\text { Energy } \\
\text { Buldong Energy } \\
\text { Consumpotan } \\
\end{array}$ & & $\begin{array}{l}\text { Buidings } \\
\text { Buliang Design and } \\
\text { Constructoon } \\
\end{array}$ & $\begin{array}{l}\text { Water } \\
\text { Wuster Use }\end{array}$ \\
\hline & & & & & STARS & & STARA & STARS \\
\hline Peer institution & State & BA Clim ato Zone & $\begin{array}{l}\text { IECC Climate } \\
\text { Zons }\end{array}$ & $\begin{array}{l}\text { IECC Moisture } \\
\text { Regime }\end{array}$ & $\begin{array}{l}\text { Total Buildings Gross } \\
\text { SF }\end{array}$ & $\begin{array}{l}\text { \% growth over } 5 \\
\text { years }\end{array}$ & $\begin{array}{l}\text { Yof of newly } \\
\text { constructed space } \\
\text { achieving } \\
\text { certification }\end{array}$ & $\begin{array}{l}\text { Potable Water Use } \\
\text { Perform ance Year } \\
\text { (gallons) }\end{array}$ \\
\hline University of Missoun & Mo & Moced-Humid & 4 & A & $14,415,671$ & $2 \%$ & $71 \%$ & $263,767,439$ \\
\hline Universitv af Louisville & $\kappa \gamma$ & Moced-Humid & 4 & A & 9,983,269 & $8 \%$ & $100 \%$ & 211164000 \\
\hline Comell University & NY & Cold & 6 & A & $15,873,205$ & $6 \%$ & $100 \%$ & $359,271,880$ \\
\hline PincetennUniversity & Nu & Cold & 5 & A & $9,232,747$ & $15 \%$ & $0 \%$ & $216,762,000$ \\
\hline Indiana Universw-Purdve Univers: indiananodis IUPUII & $\mathbb{N}$ & cold & 5 & A & $12,121,613$ & $5 \%$ & $100 \%$ & $290,096,611$ \\
\hline Universisv of Narth Carolina a: Chapel Hill & NC & Moxed-Humid & 4 & A & $18,943,498$ & $4 \%$ & $55 \%$ & $453,535,000$ \\
\hline Wake Forest Universin & NC & Moxed-Humid & 4 & A & $4,993,280$ & $13 \%$ & $53 \%$ & $147,692,894$ \\
\hline Emar unversidy & GA & Moced-Humid & 3 & A & $10.641,529$ & $15 \%$ & $57 \%$ & $304,735,000$ \\
\hline Celecado State Unversity & $c 0$ & Cold & 5 & 8 & $12,359,438$ & $13 \%$ & $96 \%$ & 361.285 .019 \\
\hline Universive of Calfomia San Divean & $C A$ & Marine & 3 & c & $20,956,546$ & $18 \%$ & $100 \%$ & $617,011,736$ \\
\hline Geape Washinaton University & DC & Moced-Humid & 4 & A & $8,614,351$ & $30 \%$ & $67 \%$ & $254,394,478$ \\
\hline Universinc at Connectiour & CT & cold & 5 & A & $10,873,545$ & $9 \%$ & $87 \%$ & $324,854,000$ \\
\hline Universitv of Virainia & VA & Mbred-Humid & 4 & A & $17.078,000$ & $13 \%$ & $100 \%$ & 514.519 .000 \\
\hline University of Anizona & $A Z$ & Hot-Dy & 2 & 8 & $14,721,402$ & $12 \%$ & $58 \%$ & $447,496,000$ \\
\hline Pernsivania State University & PA & cold & 5 & A & $20,886,526$ & $4 \%$ & $100 \%$ & $698,976,160$ \\
\hline Unversiv of Michian & MI & Cold & 5 & A & $36,946,938$ & $8 \%$ & $36 \%$ & $1,283,544,917.0$ \\
\hline Unversitiv of Miami & FL & Hot-Humid & 1 & A & $9,936,736$ & $6 \%$ & $76 \%$ & $412,935,166$ \\
\hline Virania Tech & VA & Moced-Humid & 4 & A & $10,140,484$ & $10 \%$ & $100 \%$ & $467,801,000$ \\
\hline The ohio State Univeraty & $\mathrm{OH}$ & cold & 5 & A & $24,895.053$ & $10 \%$ & $90 \%$ & $1,235,880,008$ \\
\hline Universive of Pennswivania & PA & Moced-Humid & 4 & A & $15,864,661$ & $14 \%$ & $100 \%$ & 976.771 .800 \\
\hline Unversiv of Teas ar Austin & $T X$ & Hot-Humid & 2 & A & 27.581 .856 & $6 \%$ & 98\% & $540,714,494,000$ \\
\hline
\end{tabular}




\begin{tabular}{|c|c|c|}
\hline & $\begin{array}{c}\text { Water } \\
\text { Water Use }\end{array}$ & $\begin{array}{c}\text { Water } \\
\text { Water Use }\end{array}$ \\
\hline & STARS & STARS \\
\hline $\begin{array}{l}\text { \% Increase or } \\
\text { Decrease } \\
\text { (Performance } \\
\text { compared to } \\
\text { Baseline) } 3\end{array}$ & $\begin{array}{l}\text { Potable Water Use } \\
\text { per weighted campus } \\
\text { user, Performance } \\
\text { Year (gallons) }\end{array}$ & $\begin{array}{l}\text { Potable Water use } \\
\text { Per unit of floor area, } \\
\text { Performance Year } \\
\text { (gallons/GSF) }\end{array}$ \\
\hline$-25 \%$ & 8.925 .65 & 18.3 \\
\hline$-19 \%$ & $10,425.66$ & 21.2 \\
\hline$-24 \%$ & 13.251 .03 & 22.6 \\
\hline$-11 \%$ & $16,308.32$ & 23.5 \\
\hline $38 \%$ & 12.082 .58 & 23.9 \\
\hline$-40 \%$ & $14,864.19$ & 23.9 \\
\hline$-16 \%$ & $19,079,43$ & 28.1 \\
\hline $11 \%$ & $12,865.07$ & 28.6 \\
\hline$-23 \%$ & 13,285 & 29.2 \\
\hline$-13 \%$ & $16,504.81$ & 29.4 \\
\hline$-11 \%$ & $11,904.28$ & 29.5 \\
\hline$-40 \%$ & 13.657 .43 & 29.9 \\
\hline $0 \%$ & $16,746.89$ & 30.1 \\
\hline $2 \%$ & 10.662 .73 & 30.4 \\
\hline$-22 \%$ & $14,126.08$ & 33.5 \\
\hline$-2 \%$ & 19,232 & 34.74 \\
\hline $21 \%$ & 20.711 .48 & 41.6 \\
\hline$-7 \%$ & $14,493.32$ & 46.1 \\
\hline$-19 \%$ & $18,164,33$ & 49.0 \\
\hline $29 \%$ & $31,825.48$ & 61.6 \\
\hline$-39 \%$ & $11,589,574,48$ & $19,604,0$ \\
\hline
\end{tabular}


Table 11: $U$ of $M$ LEED Certified Buildings

Energy and emissions performance

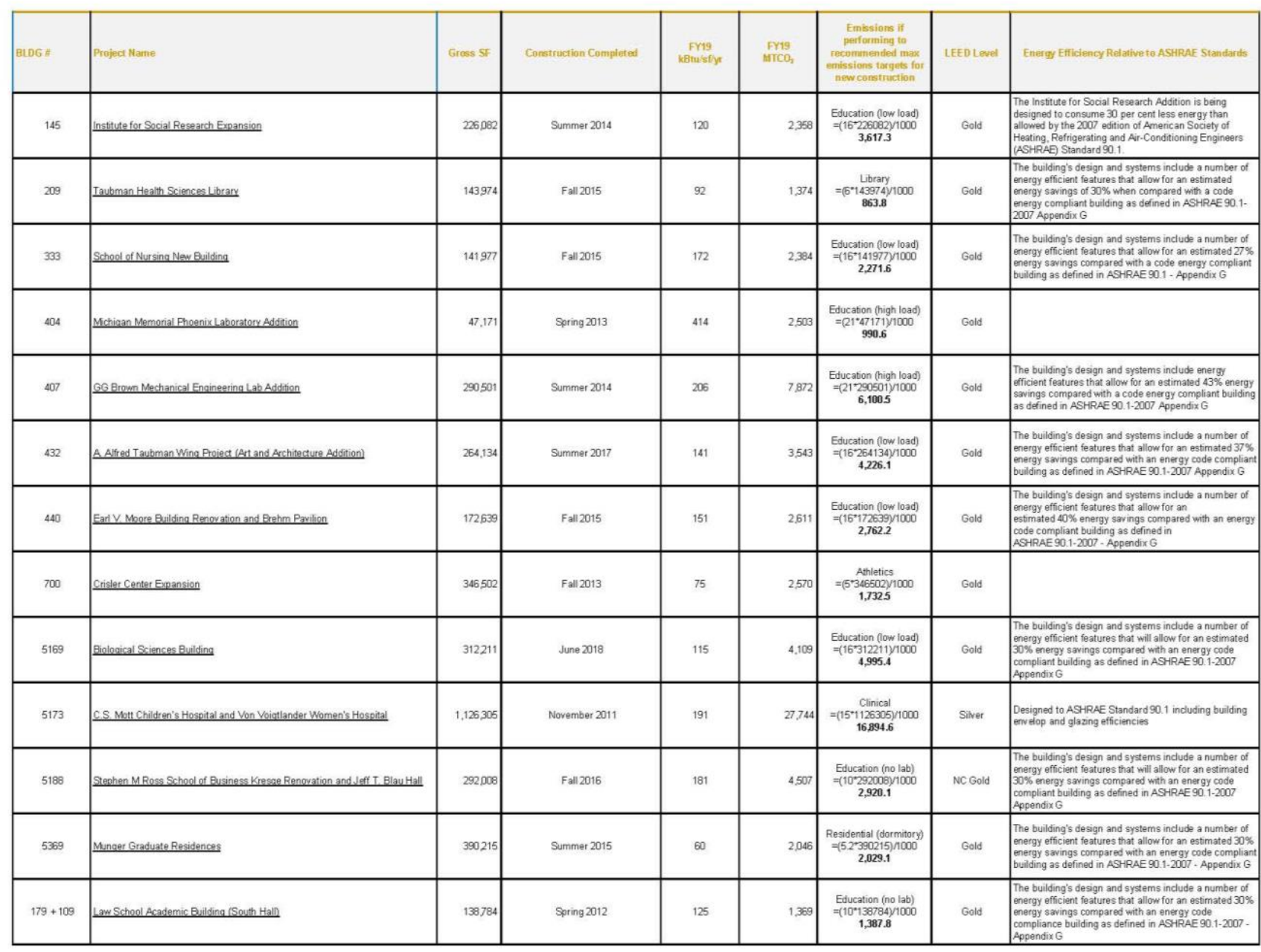




\section{APPENDIX N Team Biographies}

\section{Faculty Co-leads}

Lars Junghans is an Associate Professor of Architecture at the University of Michigan, Taubman College of Architecture and Urban Planning. His research is focused on the development and optimization of net zero emissions high-performance buildings with a comprehensive view of all aspects of the building's thermal behavior, including passive and active strategies. His goal is to find holistic optimal solutions that are simultaneously sustainable, affordable, and applicable within all climate zones. A primary focus of the research is the integration of predictive control systems into buildings, as seen in Junghans's building "22/26" in Austria (architect D. Eberle).

Jen Maigret is an Associate Professor of Architecture at the University of Michigan, Taubman College of Architecture and Urban Planning, where she teaches design studios and courses in sustainability and representation. She is a principal of PLY+ architecture, urbanism \&amp; design, a collaborative practice in partnership with Professor Craig Borum and William Carpenter. Her educational and professional experience within the fields of biology and architecture inform her design expertise and approach to architecture as a component of broader environmental systems. Maigret was previously a partner in the trans-disciplinary, collaborative practice MAde Studio, where she contributed to projects ranging from regional green infrastructure analyses and oversaw the design and fabrication of architectural elements within public spaces.

\section{Team Members}

McHugh Carroll is a Master of Architecture candidate at U-M's Taubman College. Since elementary school, he has understood the importance in reducing carbon emissions and worked to contribute through Solar Decathlon Competitions, participation in environmental clubs, and a personal interest in bikes. He recognizes the importance that the built environment plays in our daily lives and hopes to enhance our normal experiences with it through increased air quality, daylighting, water reuse, and other sustainable concepts.

Hannah Irish is graduating this year with a Bachelor of Science in the Environment as well as in Ecology, Evolution, and Biodiversity. She specializes in Climate Change and Biodiversity. She has worked in building energy as a team member contributing to EUI assessments to advance the work of the Ann Arbor 2030 district. She hopes one day to attend graduate school for Environmental Management and subsequently work to make corporate America more sustainable through improved policy and better business practices.

Mitchell Mead is an undergraduate student pursuing a dual degree in Architecture and Economics. He is a LEED Accredited Professional for Building Design and Construction. He has worked as an operational and energy consultant, economist, and construction innovator. Mitch is the founder of the Impact Design Collaborative, an evidence-based design think tank focused on identifying solutions for society's social and environmental problems. He plans on pursuing an entrepreneurial career that develops new built solutions for promoting human health and environmental stewardship. 
Shuhaib Nawawi is graduating this spring with an MEng in Energy Systems Engineering. This summer, he will be joining the Tenderloin Neighborhood Development Corporation's Sustainability Team in San Francisco, California, as a 2020 Environmental Defense Fund (EDF) Climate Corps Fellow. Particularly, he will analyze healthy building materials and recommend sustainable procurement decisions. In the long term, he plans to contribute to the global deep decarbonization efforts through renewable energy.

Nicole Rusk is a Master of Architecture candidate at U-M's Taubman College. She is a Certified Passive House Consultant who believes in bringing a higher level of consciousness to what architecture can become in service to the community and the environment through sustainable building principles. Nicole's goal is to become a licensed architect, with the intention of creating equitable, socially responsible designs that address our collective and individual spatial experiences.

Kay Wright is graduating this year with a Bachelor of Science in Architecture from the University of Michigan's Taubman College of Architecture and Urban Planning. She is interested in closely studying the relationship between moving materials and the built environment-to find interdependencies between climate and architecture as a strategy to inform the design of sites and shelters. She plans to attend graduate school for architecture in the future and hopes to one day support both pedagogy and practice. 


\section{Endnotes}

${ }^{1}$ University of Michigan Office of Campus Sustainability. "University of Michigan-FY2019 Annual Environmental Metrics Report: Raw Data Overview." https://ocs.umich.edu/wpcontent/uploads/2020/04/FY2019-Env-metrics.pdf

${ }^{2}$ Boake, Terri Meyer. 2008. "The Leap to Zero Carbon and Zero Emissions: Understanding How to Go Beyond Existing Sustainable Design Protocols." Journal of Green Building 3, no. 4 (Fall): 64-77.

3 Tufts, Robb. 2016. "LEED by the Numbers: 16 Years of Steady Growth." USGBC. https://www.usgbc.org/articles/leed-numbers-16-years-steady-growth

${ }^{4}$ University of Michigan Facilities \& Operations Architecture, Engineering and Construction. 2019. "Design Guideline 3.1: Sustainable Design and LEED Requirements." September, 3.

${ }^{5}$ Da Silva, Lucas, and Janaka Y. Ruwanpura. 2009. "Review of the LEED Points Obtained by Canadian Building Projects." Journal of Architecture Engineering 15, no. 2: 38-54.

${ }^{6}$ UNEP (United Nations Environment Programme). 2017. “Global Status Report 2017: Towards a Zero-Emission, Efficient, and Resilient Buildings and Construction Sector." https://www.worldgbc.org/sites/default/files/UNEP\%20188 GABC en\%20\%28web\%29.pdf

${ }^{7}$ University of Michigan Office of Campus Sustainability. "University of Michigan-FY2019 Annual Environmental Metrics Report: Raw Data Overview." https://ocs.umich.edu/wpcontent/uploads/2020/04/FY2019-Env-metrics.pdf

8 University of Michigan Office of Campus Sustainability. "University of Michigan-FY2019 Annual Environmental Metrics Report: Raw Data Overview." https://ocs.umich.edu/wpcontent/uploads/2020/04/FY2019-Env-metrics.pdf

${ }^{9}$ Raymer, Marjory. 2018. “UM-Flint's New Science Building Ranks as Downtown Flint's LargestEver Development." Flint Side, October 24.

https://www.flintside.com/inthenews/umflintnewmurchiesciencebuildingranksaslargestever.aspx

10 Gold, Robert. 2018. "New Additions and Upgrades at UM-Flint." M-Flint Now, News and Happenings, September 4. https://news.umflint.edu/2018/09/04/new-additions-and-upgrades-atum-flint/

11 Gold, Robert. 2019. "Campus Plugs into Energy Savings." M-Flint Now, News and Happenings, August 23. https://news.umflint.edu/2019/08/23/campus-plugs-into-energysavings/

12 EPRI (Electric Power Research Institute). 2001. Advanced Lighting Guidelines. Section 8.

${ }^{13}$ For data for $\mathrm{CO}_{2}$ emission of specific fuel, see https://www.epa.gov/sites/production/files/2015-07/documents/emission-factors 2014.pdf. 
${ }^{14}$ DTE Energy. N.d. "Fuel Mix." https://newlook.dteenergy.com/wps/wcm/connect/dteweb/home/community-and-news/common/environment/fuel-mix

${ }^{15}$ EPRI (Electric Power Research Institute). 2001. Advanced Lighting Guidelines. Section 8.

${ }^{16}$ DTE Energy. N.d. "Fuel Mix." https://newlook.dteenergy.com/wps/wcm/connect/dteweb/home/community-and-news/common/environment/fuel-mix

17 ASHRAE (American Society of Heating and Refrigerating and Air Conditioning Engineers). 2010. Thermal Environmental Conditions for Human Occupancy. ANSI/ASHRAE Standard 552010. Atlanta: ASHRAE.

18 "U-M Central Power Plant Expansion Expected to Reduce Emissions." 2017. Michigan News, March 16. https://news.umich.edu/u-m-central-power-plant-expansion-expected-to-reduceemissions/

19 United States Environmental Protection Agency. 2014. "Emission Factors for Greenhouse Gas Inventories." https://www.epa.gov/sites/production/files/2015-07/documents/emissionfactors 2014.pdf

${ }^{20}$ Integral Group. 2019. "Zero Energy Buildings in Massachusetts: Saving Money from the Start." USGBC Massachusetts.

${ }^{21}$ Leach, Matt, Shanti Pless, and Paul Torcellini. 2014. "Cost Control Best Practices for Net Zero Energy Building Projects." NREL. iiSBE Net Zero Built Environment 2014 Symposium. https://www.nrel.gov/docs/fy14osti/61365.pdf

${ }^{22}$ Ascione, F., N. Bianco, C. De Stasio, G. M. Mauro, and G. P. Vanoli. 2016. "Multi-Stage and Multi-Objective Optimization for Energy Retrofitting a Developed Hospital Reference Building: A New Approach to Assess Cost-Optimality." Applied Energy 174 (July): 37-68.

${ }^{23}$ Deb, Kalyanmoy, Associate Member, IEEE, Amrit Pratap, Sameer Agarwal, and T. Meyarivan. 2002. "A Fast and Elitist Multi-objective Genetic Algorithm: NSGA-II." IEEE Transactions on Evolutionary Computation 6, no. 2 (April).

24 Deb, Kalyanmoy, Associate Member, IEEE, Amrit Pratap, Sameer Agarwal, and T. Meyarivan. 2002. "A Fast and Elitist Multi-objective Genetic Algorithm: NSGA-II." IEEE Transactions on Evolutionary Computation 6, no. 2 (April).

${ }^{25}$ DIN (Deutsche Institut für Normung). 2018. Energy Efficiency of Buildings-Calculation of The Net, Final and Primary Energy Demand for Heating, Cooling, Ventilation, Domestic Hot Water and Lighting. DIN V 18599-1:2018-09.

${ }^{26}$ ISO (International Organization for Standardization). 2012. Thermal Performance of Buildings_Calculation of Internal Temperatures of A Room in Summer without Mechanical Cooling-General Criteria and Validation Procedures. EN ISO 13791:2012. Paris: ISO.

${ }^{27}$ ASHRAE (American Society of Heating and Refrigerating and Air Conditioning Engineers). 2011. Standard Method of Test for the Evaluation of Building Energy Analysis Computer Programs. ANSI/ASHRAE Standard 140-2011. Atlanta: ASHRAE. 
${ }^{28}$ Burmeister, Harald, and Bruno Keller. 1998. "Climate Surfaces: A Quantitative BuildingSpecific Representation of Climates." Energy and Buildings 28, no. 2 (October): 167-177.

29 Turconi, Roberto, Alessio Boldrin, and Thomas Fruergaard Astrup. 2013. "Life Cycle Assessment (LCA) of Electricity Generation Technologies: Overview, Comparability and Limitations." Renewable and Sustainable Energy Reviews 28 (December): 555-565.

30 Valancius, Kestutis, Tatjana Vilutiene, and Artur Rogoza. 2018. "Analysis of the Payback of Primary Energy and CO2 Emissions in Relation to the Increase of Thermal Resistance of a Building." Energy and Buildings 179 (November): 39-48.

31 Circular Ecology. 2019. "Embodied Energy and Carbon-The Ice Database." https://www.circularecology.com/embodied-energy-and-carbon-footprintdatabase.html\#.XodVoS2ZPGJ

32 DTE Energy. 2019. "Net Zero Carbon Emissions Goal Announced by DTE Energy Electric Company." Press release, September 26. https://ir.dteenergy.com/news/press-releasedetails/2019/Net-Zero-Carbon-emissions-goal-announced-by-DTE-Energy-ElectricCompany/default.aspx

${ }^{33}$ Koubogiannis, D., and C. Nouhou. 2016. "How Much Energy Is Embodied in Your Central Heating Boiler." PROCEEDINGS IOP Conference, Material Science and Engineering. https://iopscience.iop.org/article/10.1088/1757-899X/161/1/012094/pdf

${ }^{34}$ Hernandez, Patxi, and Paul Kenny. 2010. "From Net Energy to Zero Energy Buildings: Defining Life Cycle Zero Energy Buildings (LC-ZEB)." Energy and Buildings 42 (October): 815821.

${ }^{35}$ Koubogiannis D. G., A. Daskalaki, and C. A. Balaras. 2013. "A Contribution to Building Lifecycle Analysis: Embodied Energy Analysis of Mechanical Installations for a Typical Urban Greek Dwelling." PROCEEDINGS: 3rd International Exergy Life Cycle Assessment, and Sustainability Workshop \& Symposium (ELCAS3), Nisyros-Greece, July 7-9.

${ }^{36}$ Rodriguez, B., L. Amany, and K. Simonen. 2019. "Embodied and Operational Carbon of Typical Heating, Ventilation and Air Conditioning (HVAC) Systems in Office Buildings in Washington State: A Study of Buildings Registered under LEED v3 2009." Proceedings IOP Conference, Earth and Environmental Science.

${ }^{37}$ Seo, S., A. Passer, J. Zelezna, H. Birgisdottir, T. Lutzendorf, M. Mistretta, T. Oka, C. U. Chae, A. H. Wiberg, T. Malmqvist, R. Fritschknecht, and A. Moncaster. 2016. "Evaluation of Embodied Energy and CO2eq for Building Construction (Annex 57)." International Energy Agency.

38 Sadineni, Suresh B., Srikanth Madala, and Robert F. Boehm. 2011. "Passive Building Energy Savings: A Review of Building Envelope Components." Renewable and Sustainable Energy Reviews 15 (January): 3617-3631.

${ }^{39}$ Cullin, J. R., L. Xing, E. Lee, J. D. Spitler, and D. E. Fisher. 2012. "Feasibility of Foundation Heat Exchangers for Residential Ground Source Heat Pump Systems in the United States." ASHRAE Transactions 118 (1): 1039-1048. 
40 Dubois, Marie-Claude., and Ake Blomsterberg. 2011. "Energy Saving Potential and Strategies for Electric Lighting in Future North European, Low Energy Office Buildings: A Literature Review." Energy and Buildings 43 (April): 2572-2582.

${ }^{41}$ Bakker, Christel de, Myriam Aries, Helianthe Kort, and Alexander Rosemann. 2017. "Occupancy-Based Lighting Control in Open-Plan Office Spaces: A State-Of-The-Art Review." Building and Environment 119 (July): 308-321.

42 United States Environmental Protection Agency. 2007. "Biomass CHP Catalog of Technologies." https://www.epa.gov/chp/biomass-chp-catalog-technologies

43 Partnership for Policy Integrity. 2011. "Air Pollution from Biomass Energy." http://www.pfpi.net/air-pollution-2

44 United States Department of Energy. N.d. "Geothermal Heat Pumps." https://www.energy.gov/energysaver/heat-and-cool/heat-pump-systems/geothermal-heat-pumps

${ }^{45}$ Ciapała, Bartłomiej, Jakub Jurasz, and Alexander Kies. 2019. "The Potential of Wind PowerSupported Geothermal District Heating Systems-Model Results for a Location in Warsaw (Poland)." Energies 12 (October).

46 Yavuzturk, C., and J. D. Spitler. 1999. "A Short Time Step Response Factor Model for Vertical Ground Loop Heat Exchangers.” ASHRAE Transactions 105 (2): 475-485.

47 Junghans, Lars. 2015. "Evaluation of the Economic and Environmental Feasibility of Heat Pump Systems in Residential Buildings, with Varying Qualities of the Building Envelope." Renewable Energy 76 (April): 699-705.

${ }^{48}$ Lohrenz E., S. Almeida, and P. Eng. 2013. "Ground-Coupled Heat Pump and Energy Storage." ASHRAE Journal (April): 14-22.

${ }^{49}$ Cullin, J. R., L. Xing, E. Lee, J. D. Spitler, and D. E. Fisher. 2012. "Feasibility of Foundation Heat Exchangers for Residential Ground Source Heat Pump Systems in the United States." ASHRAE Transactions 118 (1): 1039-1048.

50 Lohrenz E., S. Almeida, and P. Eng. 2013. "Ground-Coupled Heat Pump and Energy Storage." ASHRAE Journal (April): 14-22.

${ }^{51}$ E. Dinkel, B. Braun, M. Muhrbeck, W. Reul, A. Meeder, U. Szewzyk, and T. Scheytt. 2018. "Groundwater Circulation Wells for Geothermal Use: Preliminary Results of the Project Integralsonde Type II." PROCEEDINGS: 43rd Workshop on Geothermal Reservoir Engineering Stanford University, Stanford, California, February 12-14, SGP-TR-213.

52 Lo Russo, Stefano, Glenda Taddia, and Vittorio Verda. 2012. "Development of the Thermally Affected Zone (TAZ) Around a Groundwater Heat Pump (GWHP) System. A Sensitivity Analysis." Geothermics 43 (July): 66-74. 
${ }^{53}$ Rode, Alexander, Tanja Liesch, and Nico Goldscheider. 2015. "Open-Loop Geothermal Heating by Combined Extraction-Injection One-Well Systems: A Feasibility Study." Geothermics 56 (July): 110-118.

${ }^{54}$ Rees, S. J., C. D. Orio, J. D. Spitler, C. N. Johnson, and Z. Deng. 2004. "A Study of Geothermal Heat Pump and Standing Column Well Performance." ASHRAE Transactions 109.

${ }^{55}$ ASHRAE (American Society of Heating and Refrigerating and Air Conditioning Engineers). 2010. Thermal Environmental Conditions for Human Occupancy. ANSI/ASHRAE Standard 552010. Atlanta: ASHRAE.

${ }^{56}$ Jazizadeh, Farrokh, Ali Ghahramani, Burcin Becerik-Gerber, Tatiana Kichkaylo, and Michael Orosz. 2014. "User-Led Decentralized Thermal Comfort Driven HVAC Operations for Improved Efficiency in Office Buildings." Energy and Buildings 70 (February): 398-410. https://www.sciencedirect.com/science/article/abs/pii/S0378778813007731

${ }^{57}$ Klein, Laura, Geoffrey Kavulya, Farrokh Jazizadeh, Jun-young Kwak, Burcin Becerik-Gerber, Pradeep Varakantham, and Milind Tambe. 2011. "Towards Optimization of Building Energy and Occupant Comfort Using Multi-Agent Simulation." The International Association for Automation and Robotics in Construction.

http://www.iaarc.org/publications/proceedings of the 28th isarc/towards optimization of build ing energy and occupant comfort using multiagent simulation.html

${ }^{58}$ Kim, Joyce, Fred Bauman, Paul Raftery, Edward Arens, Hui Zhang, Gabe Fierro, Michael Andersen, David Culler. 2019. "Occupant Comfort and Behavior: High-Resolution Data from a 6-Month Field Study of Personal Comfort Systems with 37 Real Office Workers." Building and Environment 148 (January): 348-360.

https://www.sciencedirect.com/science/article/pii/S0360132318307078

59 Bean, Frances, Maarten De Groote, and Jonathan Volt. 2017. "Opening the Door to Smart Buildings." The Buildings Performance Institute Europe. http://bpie.eu/wpcontent/uploads/2017/06/PAPER-Policy-recommendations Final.pdf

${ }^{60}$ Ambrose, Beth. 2016. "Building the Business Case: Health, Wellbeing and Productivity in Green Offices." World Green Building Council. https://www.worldgbc.org/sites/default/files/WGBC BtBC Dec2016 Digital Low-MAY24 0.pdf

61 University of Michigan, Office of Campus Sustainability. N.d. "Sustainability Tips." https://ocs.umich.edu/resources/sustainability-tips/

62 Gargaro, Paul. 2012. "U-M Researchers Look to Smart Building Exteriors for Reduced Energy Costs and a Cleaner Environment." University of Michigan Planet Blue. http://sustainability.umich.edu/news/u-m-researchers-look-smart-building-exteriors-reducedenergy-costs-and-cleaner-environment

${ }^{63}$ Weil, Ari. 2019. "PBA Spotlight: Erik Boyer and the Energy Management Program." University of Michigan Planet Blue. http://sustainability.umich.edu/news/pba-spotlight-erik-boyer-andenergy-management-program 
64 "Greenhouse Gas Reduction." University of Michigan Office of Campus Sustainability. https://ocs.umich.edu/sustainability-goals/greenhouse-gas-reduction/

65 Delzendeh, Elham, Song Wu, Angela Lee, and Ying Zhou. 2017. "The Impact of Occupants' Behaviours on Building Energy Analysis: A Research Review." Renewable and Sustainable Energy Reviews 80 (December): 1061-1071. https://www-sciencedirectcom.proxy.lib.umich.edu/science/article/pii/S1364032117309061\#bib26

${ }^{66}$ Zodrow, Katherine R., Qilin Li, Regina M. Buono, Wei Chen, Glen Daigger, Leonardo Dueñas-Osoria, Menachem Elimelech, Xia Huang, Guibin Jiang, Jae-Hong Kim, Bruce E. Logan, David Sedlak, Paul Westerhoff, and Pedro J. J. Alvarez. 2017. "Technologies, and Complex Systems Analyses: Emerging Opportunities to Enhance Urban Water Security." Environmental Science \& Technology 51, no. 18: 10274-10281.

${ }^{67}$ Larsen, Tove A., Sabine Hoffmann, Christoph Lüthi, Bernhard Truffer, and Max Mauer. 2016. "Emerging Solutions to the Water Challenges of an Urbanizing World." Science 352, no. 6288: 928-933.

68 Daigger, Glen T., Sybil Sharvelle, Mazdak Arabi, and Nancy G. Love. 2019. "Progress and Promise Transitioning to the One Water/ Resource Recovery Integrated Urban Water Management Systems." Journal of Environmental Engineering 145, no. 10. https://doiorg.proxy.lib.umich.edu/10.1061/(ASCE)EE.1943-7870.0001552

${ }^{69}$ Eriksson, Eva, Karina Auffarth, Mogens Henze, and Anna Ledin. 2002. "Characteristics of Grey Wastewater." Urban Water 4, no. 1: 85-104.

${ }^{70}$ McNabola, Aonghus, and Killian Shields. 2013. "Efficient Drain Water Heat Recovery in Horizontal Domestic Shower Drains." Energy and Buildings 59:44-49.

${ }^{71}$ Meggers, Forrest, and Hansjurg Leibundgut. 2011. "The Potential of Wastewater Heat and Exergy: Decentralized High-Temperature Recovery with a Heat Pump." Energy and Buildings 43, no. 4: 879-886.

72 Proskiw, G. 1998. "Technology Profile: Residential Greywater Heat Recovery Systems.” http://www.gfxtechnology.com/Proskiw-NRCan.pdf

73 Smith, I. E. 1975. "Recovery and Utilisation of Heat from Domestic Waste Water." Journal of Applied Energy 1, no. 3: 205-214.

${ }^{74}$ Daigger, Glen T., Sybil Sharvelle, Mazdak Arabi, and Nancy G. Love. 2019. "Progress and Promise Transitioning to the One Water/ Resource Recovery Integrated Urban Water Management Systems." Journal of Environmental Engineering 145, no. 10. https://doiorg.proxy.lib.umich.edu/10.1061/(ASCE)EE.1943-7870.0001552

75 Griffiths-Sattenspiel, Bevan, and Wendy Wilson. 2009. "The Carbon Footprint of Water." River Network Report. www.rivernetwork.org

${ }^{76}$ Esselman, Rebecca. 2014. "The Carbon Footprint of Domestic Water Use in the Huron River Watershed." Huron River Watershed Council Report. 
77 Esselman, Rebecca. 2014. "The Carbon Footprint of Domestic Water Use in the Huron River Watershed." Huron River Watershed Council Report.

${ }^{78}$ Esselman, Rebecca. 2014. "The Carbon Footprint of Domestic Water Use in the Huron River Watershed." Huron River Watershed Council Report.

${ }^{79}$ EPRI (Electric Power Research Institute). 2001. Advanced Lighting Guidelines. Section 8.

80 Jefferson, B., A. Laine, S. Parsons, T. Stephenson, and S. Judd. 1999. "Technologies for Domestic Wastewater Recycling." Urban Water 1, no. 4: 285-292.

81 The George Washington University. 2019. "Design Standards for New Construction and Major Renovation." Facilities and Resource Planning.

${ }^{82}$ Ghisi, Enedir, and Sulayre Mengotti de Oliveira. 2007. "Potential for Potable Water Savings by Combining the Use of Rainwater and Greywater in Houses in Southern Brazil." Building and Environment 42, no. 4: 1731-1742.

${ }^{83}$ Ghisi, Enedir, and Daniel F. Ferreira. 2007. "Potential for Potable Water Savings by Using Rainwater and Greywater in a Multi-Storey Residential Building in Southern Brazil." Building and Environment 42, no. 7: 2512-2522.

${ }^{84}$ Bergdolt, J., S. Sharvelle, and L. A. Roesner. 2011. "Guidance Manual for Separation of Graywater from Blackwater for Graywater Reuse." WERF Project INFR4SG09a. Alexandria, VA: Water Environment Research Foundation.

85 ICC (International Code Council). 2015. Nonpotable Water Systems. International Plumbing Code Section 1302. Washington: ICC.

${ }^{86}$ Leong, Janet Yip Cheng, Kai Siang Oh, Phaik Eong Poh, and Meng Nan Chong. 2017. "Prospects of Hybrid Rainwater-Greywater Decentralized System for Water Recycling and Reuse: A Review." Journal of Cleaner Production 142:3014-3027.

87 Zavala, Miguel Ángel López, Ricardo Castillo Vega, and Rebeca Andrea López Miranda. 2016. "Potential of Rainwater Harvesting and Greywater Reuse for Water Consumption Reduction and Wastewater Minimization." Water 8, no. 264.

${ }^{88}$ Committee on the Beneficial Use of Graywater and Stormwater. 2016. Using Graywater and Stormwater to Enhance Local Water Supplies: An Assessment of Risks, Costs, and Benefits. Washington, DC: National Academies Press.

${ }^{89}$ Boyjoo, Yash, Vishnu K. Pareek, and Ming Ang. 2013. "A Review of Greywater Characteristics and Treatment Processes." Water Science \& Technology 67, no. 7: 1403-1424.

90 Sharvelle, Sybil. 2013. "Treatment, Public Health, and Regulatory Issues Associated with Greywater Reuse." Guidance Document.

91 Thompson, Kyle A. 2018. "Evaluating Treatment Approaches for Sustainable Reuse of Greywater, Wastewater and Stormwater." Dissertation DAI-B 79/10(E), University of Colorado Boulder. 
92 Jefferson, B., A. Laine, S. Parsons, T. Stephenson, and S. Judd. 1999. "Technologies for Domestic Wastewater Recycling." Urban Water 1:285-292.

${ }^{93}$ Berndtsson, Justyna Czemiel, Lars Bengtsson, and Kenji Jinno. 2009. "Runoff Water Quality from Intensive and Extensive Vegetated Roofs." Ecological Engineering 35, no. 3: 369-380. https://doi.org/10.1016/j.ecoleng.2008.09.020

${ }^{94}$ Nagase, Ayako, and Nigel Dunnett. 2012. "Amount of Water Runoff from Different Vegetation Types on Extensive Green Roofs: Effects of Plant Species, Diversity and Plant Structure." Landscape and Urban Planning 104, no. 3: 356-363.

${ }^{95}$ Akther, Musa, Jianxun He, Angus Chu, Jian Huang, and Bert van Duin. 2018. "A Review of Green Roof Applications for Managing Urban Stormwater in Different Climatic Zones." Sustainability 10 (8): 2864.

${ }^{96}$ Azeñas, V., J. Cuxart, R. Picos, H. Medrano, G. Simó, A. López-Grifol, and J. Gulías. 2018. "Thermal Regulation Capacity of a Green Roof System in the Mediterranean Region:

The Effects of Vegetation and Irrigation Level." Energy and Buildings 164 (April): 226-238.

${ }^{97}$ Bowser, Muriel. 2018. "Clean Energy DC: The District of Columbia Climate and Energy Action Plan." Department of Energy and Environment.

98 Graves, Richard, and Patrick Smith. 2018. "Minnesota Sustainable Building Guidelines: History, Effectiveness and Path for the Future." Journal of Green Building 13, no. 2: 163-180.

${ }^{99}$ Athalye, Rahul, Mark Halverson, Michael Rosenberg, Bing Liu, Jian Zhang, Reid Hart, Vrushali Mendon, Surpriya Goel, Yan Chen, YuLong Xie, and Mingjie Zhao. 2017. "Energy Savings Analysis: ANSI/ASHRAE/IES Standard 90.1-2016." U.S. Department of Energy, Office of Energy Efficiency \& Renewable Energy.

100 Bocra, Gina, and Emily Hoffman. 2019. "New York City Buildings Future Changes to the NYC Energy Code." NYCECC.

101 Webber, Douglas, et al. 2020. "Zero Carbon Building Design Standard Version 2." Canada Green Building Council.

102 Provident, Morrison Hershfield, Integral Group (prepared by). 2017. "The City of Toronto Zero Emissions Buildings Framework.” City Planning Division, City of Toronto.

${ }^{103}$ See Table 15.01 for the LCCA status of these institutions.

${ }^{104}$ As cited in University of Michigan Campus Sustainability Integrated Assessment, Buildings Analysis- Phase II Report, February 25, 2011.

${ }^{105}$ Harvard University. N.d. "Life Cycle Costing." https://green.harvard.edu/topics/greenbuildings/life-cycle-costing

106 University of Virginia. N.d. "UVA Life Cycle Cost Calculator." https://sustainability.virginia.edu/resources/uva-life-cycle-cost-calculator-0 
107 University of Michigan Facilities \& Operations Architecture, Engineering and Construction. 2019. "Design Guideline 3.1: Sustainable Design and LEED Requirements." (September): 3.

108 Da Silva, Lucas, and Janaka Y. Ruwanpura. 2009. "Review of the LEED Points Obtained by Canadian Building Projects." Journal of Architecture Engineering 15, no. 2: 38-54.

109 Tufts, Robb. 2016. "LEED by the Numbers: 16 Years of Steady Growth." USGBC. https://www.usgbc.org/articles/leed-numbers-16-years-steady-growth

${ }^{110}$ Wu, Peng, Chao Mao, Jun Wang, Yongze Song, and Xiangyu Wang. 2016. "A Decade Review of The Credits Obtained by LEED V2.2 Certified Green Building Projects." Building and Environment 102:167-178.

111 Turner, Cathy, and Mark Frankel. 2008. "Energy Performance of LEED for New Construction Buildings." New Buildings Institute report, March 4.

https://newbuildings.org/sites/default/files/Energy Performance of LEED-NC BuildingsFinal 3-4-08b.pdf

112 Cheng Li, Tianzhen Hong, and Da Yan. 2014. "An Insight into Actual Energy Use and Its Drivers in High-Performance Buildings." Applied Energy 131 (October): 394-410.

113 Scofield, John H., and Jakob Cornell. 2019. "A Critical Look at "Energy Savings, Emissions Reductions, and Health Co-Benefits of the Green Building Movement." Journal of Exposure Science \& Environmental Epidemiology 29, no. 4 (July): 584-593.

114 Qian Chen, Lauren Kleinman, and Aparna Dial. 2015. "Energy Performance of Campus LEED Buildings: Implications for Green Building and Energy Policy." Journal of Green Building 10 (March): 137-160.

${ }^{115}$ Menassa, Carol, Seth Mangasarian, Mounir El Asmar, S.M.ASCE, and Carl Kirar. 2012. "Energy Consumption Evaluation of U.S. Navy LEED-Certified Buildings." Journal of Performance of Constructed Facilities 26, no. 1: 46-53.

${ }^{116}$ Fowler, Kim, Emily Rauch, Jordan Henderson, and Angela Kora. 2011. "Assessing Green Building Performance: A Post Occupancy Evaluation of 12 GSA Buildings." Pacific Northwest National Laboratory.

117 Diamond, Rick. 2011. "Evaluating the Energy Performance of the First Generation of LEEDCertified Commercial Buildings." Lawrence Berkeley National Laboratory. https://escholarshiporg.proxy.lib.umich.edu/uc/item/498009ks

118 Turner, Cathy, and Mark Frankel. 2008. "Energy Performance of LEED for New Construction Buildings." New Buildings Institute report, March 4.

https://newbuildings.org/sites/default/files/Energy Performance of LEED-NC Buildings-

Final 3-4-08b.pdf

119 Newsham, Guy R., Sandra Mancini, and Benjamin J. Birt. 2009. "Do LEED-Certified

Buildings Save Energy? Yes, but...” Energy and Buildings 41, no. 8: 897-905. 
120 Scofield, John H. 2009. "Do LEED-Certified Buildings Save Energy? Not Really..." Energy and Buildings 41:1386-1390.

121 Stoppel, Christopher M., and Fernada Leite. 2013. "Evaluating Building Energy Model Performance of LEED Buildings: Identifying Potential Sources of Error through Aggregate Analysis." Energy and Buildings 65:185-196.

122 Fowler, Kim, Emily Rauch, Jordan Henderson, and Angela Kora. 2011. "Assessing Green Building Performance: A Post Occupancy Evaluation of 12 GSA Buildings." Pacific Northwest National Laboratory.

123 Diamond, Rick. 2011. "Evaluating the Energy Performance of the First Generation of LEEDCertified Commercial Buildings." Lawrence Berkeley National Laboratory. https://escholarshiporg.proxy.lib.umich.edu/uc/item/498009ks

124 Turner, Cathy, and Mark Frankel. 2008. "Energy Performance of LEED for New Construction Buildings." New Buildings Institute report, March 4.

https://newbuildings.org/sites/default/files/Energy Performance of LEED-NC BuildingsFinal 3-4-08b.pdf

125 Scofield, John H. 2009. "Do LEED-Certified Buildings Save Energy? Not Really..." Energy and Buildings 41:1386-1390.

126 Yale Divinity School. "The Living Village: Building Communities of the Future at Yale Divinity School." https://divinity.yale.edu/livingvillage

127 Straka, Vera, and Lilia Sousedova. 2010. "LEED v Living Building Challenge: Critical Evaluation." Proceedings SB10 Euregion: Towards 0-Impact buildings and environments Conference. Maastricht, Liege, and Aachen.

128 Weinstein, Nathalie. 2009. "Red List Challenges Living Building Architects in Oregon." Daily Journal of Commerce. Portland, Oregon.

129 Pires, Samantha. 2019. "Living Building Challenge: Understanding Green vs. Greenwashed Architecture." Architecture 41, no. 84: 41.

130 Junghans, Lars, and Peter Widerin. 2017. "Thermal Comfort and Indoor Air Quality of the 'Concept 22/26,' A New High Performance Building Standard.” Energy and Buildings 149 (August): 114-122. 